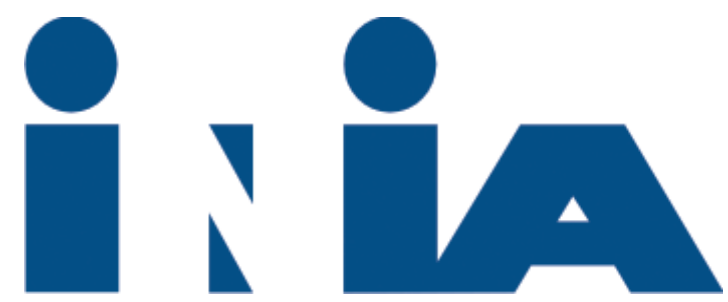

INSTITUTO NACIONAL DE INVESTIGACIÓN AGROPECUARIA

URUGUAY

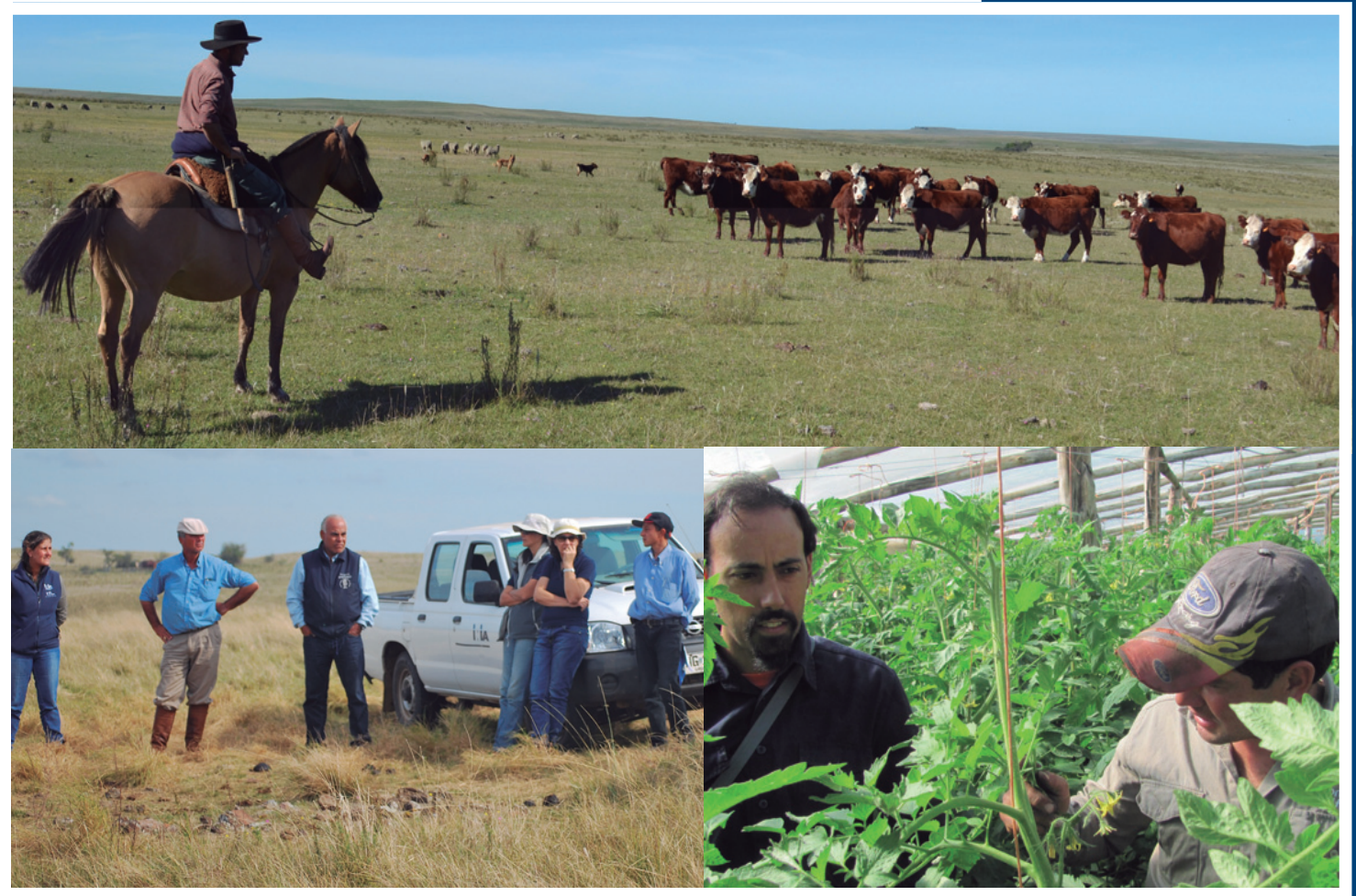

LACO-INNOVACIÓN

COMO ESTRATEGIA

PARA PROMOVER

SISTEMAS DE

PRODUCCIÓN MÁS

SUSTENTABLES.

Estudios de caso en

predios familiares del norte

Setiembre, 2018

SERIE TÉCNICA

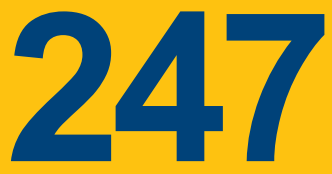

INIA 


\section{LACO-INNOVACIÓN COMO ESTRATEGIA PARA PROMOVER SISTEMAS DE PRODUCCIÓN MÁS SUSTENTABLES. Estudios de caso en predios familiares del norte}

Editor: Gómez Miller, Raúl* 
Título: LA CO-INNOVACIÓN COMO ESTRATEGIA PARA PROMOVER SISTEMAS DE PRODUCCIÓN MÁS SUSTENTABLES.

Estudios de caso en predios familiares del norte.

\section{Editor: Raúl Gómez Miller}

Serie Técnica $N^{\circ} 247$

(C) 2018, INIA

ISBN 978-9974-38-408-8

Editado por la Unidad de Comunicación y Transferencia de Tecnología del INIA Andes 1365, Piso 12. Montevideo - Uruguay

http://www.inia.uy

Quedan reservados todos los derechos de la presente edición. Esta publicación no se podrá reproducir total o parcialmente sin expreso consentimiento del INIA. 


\section{Instituto Nacional de Investigación Agropecuaria}

\section{Integración de la Junta Directiva}

D.M.T.V., Ph.D. José Luis Repetto - Presidente

Ing. Agr., Mag. Mariana Hill - Vicepresidenta

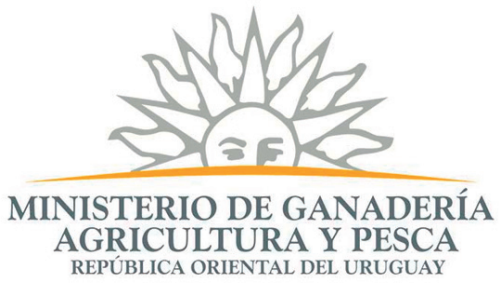

Ing. Agr. Jaime Gomes de Freitas

Ing. Agr. Jorge Peñagaricano
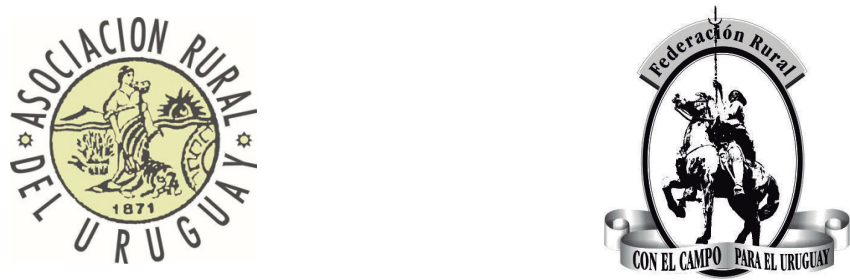

Ing. Agr. Pablo Gorriti

Ing. Agr. Alberto Bozzo
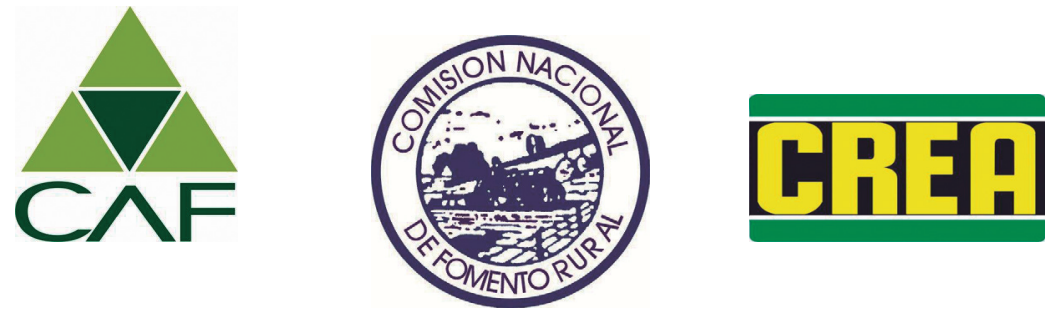


\section{CONTENIDO}

I. INTRODUCCIÓN ................................................................................................. 1

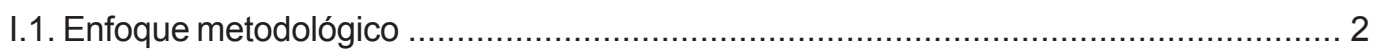

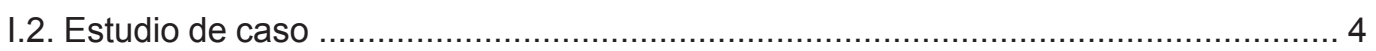

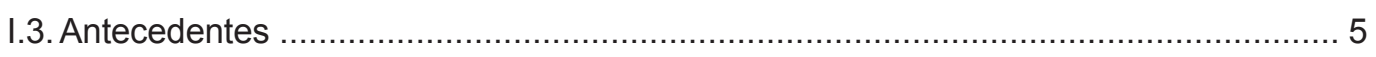

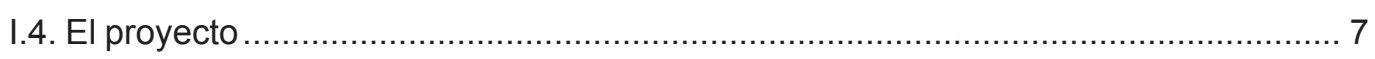

I.4.1. Predios piloto re-diseñados ........................................................................ 7

I.4.2. Metodología de trabajo adaptada para abordar el re-diseño de sistemas de

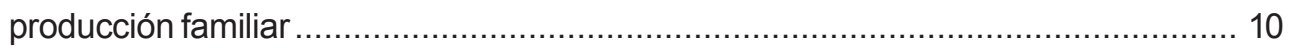

I.4.3. Propuesta de indicadores para el monitoreo y evaluación de la sustentabilidad ..... 10

I.4.4. Generación de pautas para contribuir al desarrollo de la zona ............................. 10

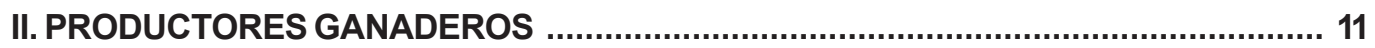

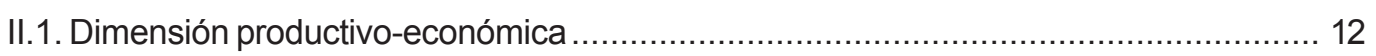

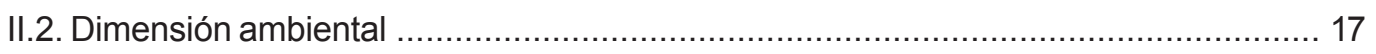

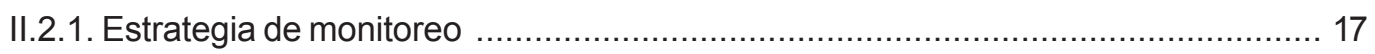

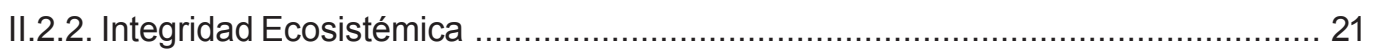

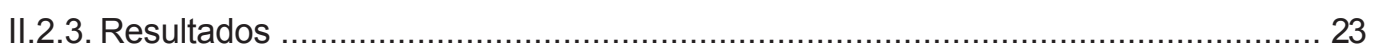

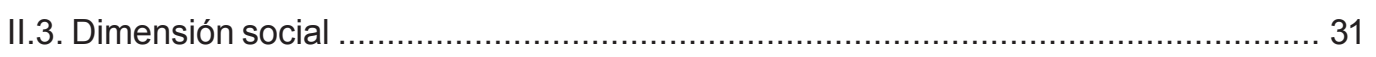

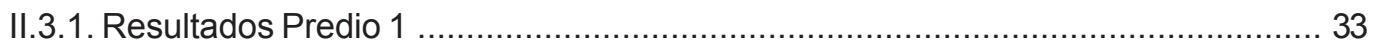

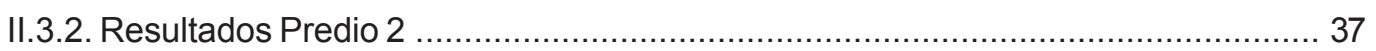

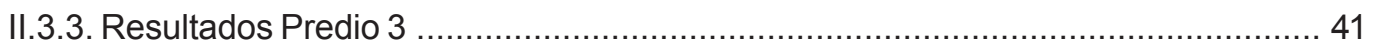

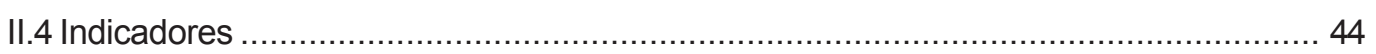

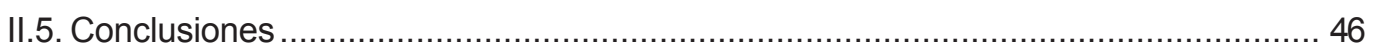

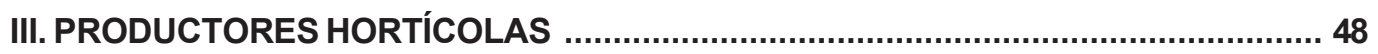

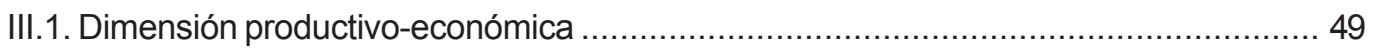

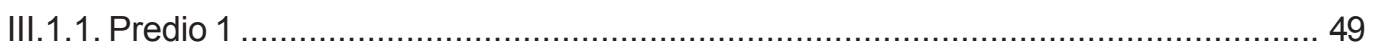

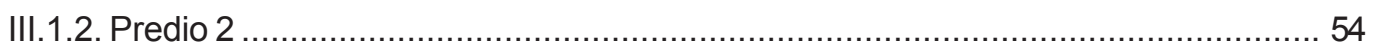

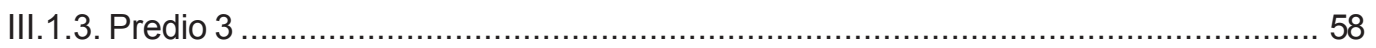

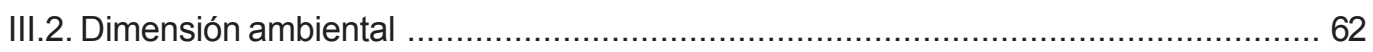

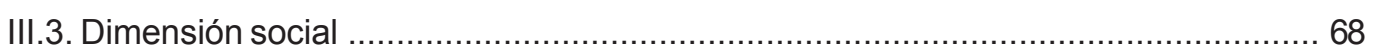

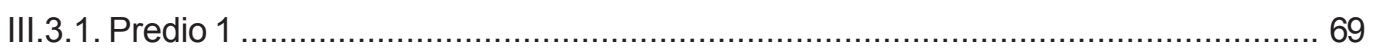

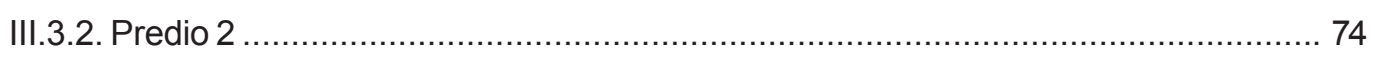

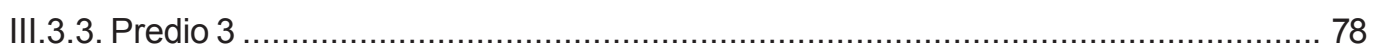

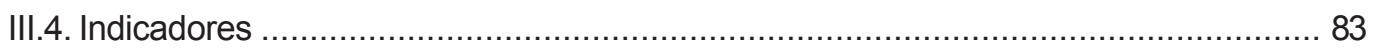

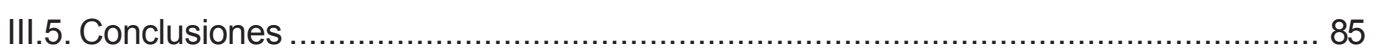

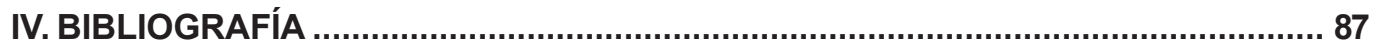




\section{ÍNDICE DE FIGURAS}

II.2.

Página

Figura 1. Contenido de carbono orgánico del suelo ............................................... 23

Figura 2. Análisis de componentes principales según grupos productivos .................. 25

Figura 3. Comparación de medias de la cobertura de Paspalum dilatatum ................. 26

Figura 4. Comparación de medias de la cobertura de Sporobolus indicus . ................ 26

Figura 5. Comparación de medias de la cobertura de Mnesithea selloana. ................. 27

Figura 6. Rarefacción por cobertura y extrapolación .................................................. 29

Figura 7. Índices de integridad ecosistémica ......................................................... 29

II.4.

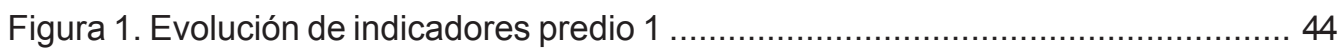

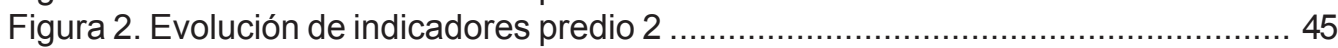

Figura 3. Evolución de indicadores predio 3 .................................................... 45

III.2

Figura 1. Porcentaje de individuos según gremio alimenticio para el establecimiento 1 .... 66

Figura 2. Porcentaje de individuos según gremio alimenticio para el establecimiento $2 \ldots 66$

Figura 3. Porcentaje de individuos según gremio alimenticio para el establecimiento 3 .... 66

III.4.

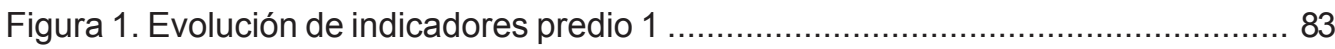

Figura 2. Evolución de indicadores predio 2 ................................................. 84

Figura 3. Evolución de indicadores predio 3 ..................................................... 84 


\section{ÍNDICE DE CUADROS}

II.1.

Página

Cuadro 1. Referencia de indicadores productivo-económicos ....................................... 14

Cuadro 2. Uso del conjunto de tecnologías de producción ........................................ 15

Cuadro 3. Resultados productivo-económicos en los tres predios ................................ 16

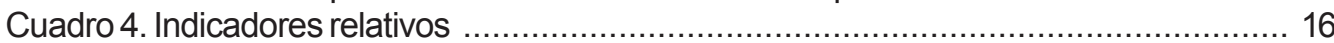

II.2.

Cuadro 1. Resumen de indicadores ambientales ..................................................... 22

Cuadro 2. Contenido de carbono orgánico en las diferentes fracciones

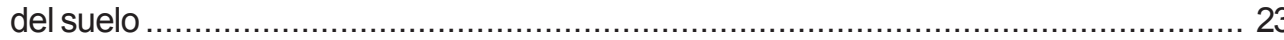

Cuadro 3. Índice de calidad de agua en los tres predios ........................................... 24

Cuadro 4. Número de especies registradas .......................................................... 24

Cuadro 5. Análisis de similitud de la composición florística de los manejos ganaderos

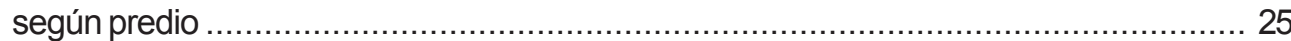

Cuadro 6. Tasas de crecimiento promedio de la comunidad vegetal según manejo

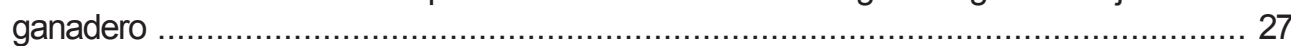

Cuadro 7. Coeficientes EUR según predio y manejo ganadero .................................. 28

Cuadro 8. Especies prioritarias para la conservación registradas en el proyecto .............. 28

Cuadro 9. IIE por predio y su evolución ................................................................. 30

Cuadro 10. Riqueza de aves por predio y su evolución ............................................. 30

Cuadro 11. Carbono activo del suelo por predio y su evolución ..................................... 30

II.3.1.

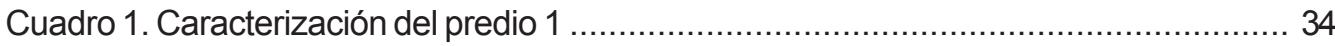

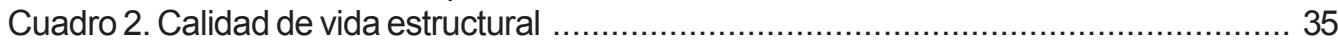

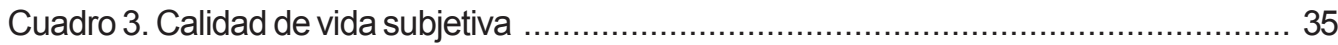

Cuadro 4. Valoración del estado de la sucesión ......................................................... 35

Cuadro 5. Grado en que el productor valora y usa la planificación .................................. 36

Cuadro 6. Aprendizajes y cambios más relevantes .................................................... 36

II.3.2.

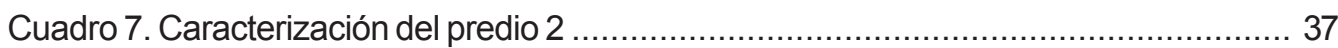

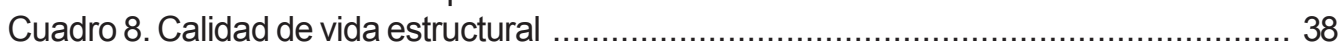

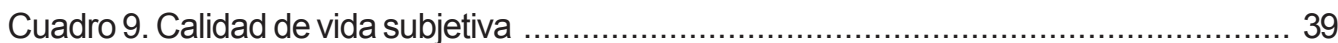

Cuadro 10. Valoración del estado de la sucesión ........................................................ 39

Cuadro 11. Grado en que el productor valora y usa la planificación ............................... 39

Cuadro 12. Aprendizajes y cambios más relevantes ................................................. 40

II.3.3.

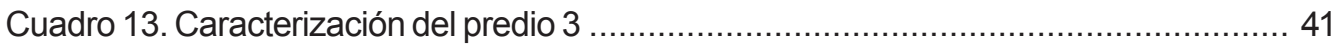

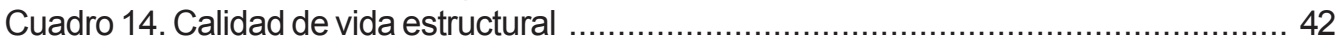

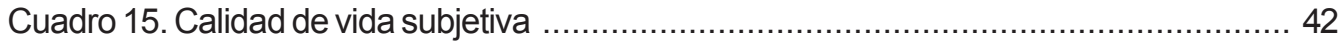

Cuadro 16. Valoración del estado de la sucesión .......................................................... 43

Cuadro 17. Grado en que el productor valora y usa la planificación ............................... 43

Cuadro 18. Aprendizajes y cambios más relevantes .............................................. 44 
III.1.1

Página

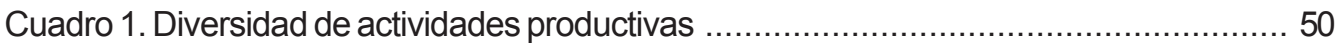

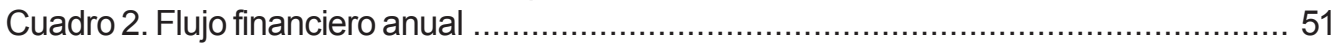

Cuadro 3. Conformidad con la comercialización de productos .................................... 51

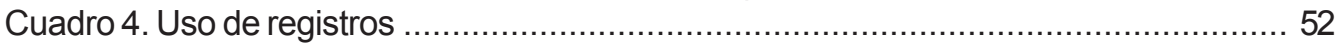

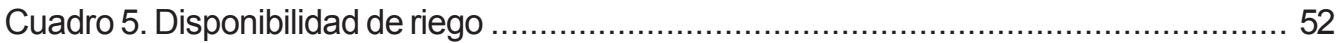

Cuadro 6. Estrategias para desinfección de suelos ................................................... 53

III.1.2.

Cuadro 7. Diversidad de actividades productivas ................................................... 55

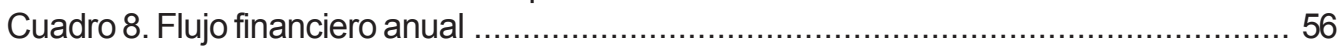

Cuadro 9. Conformidad con la comercialización de productos .................................... 56

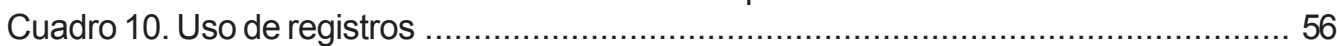

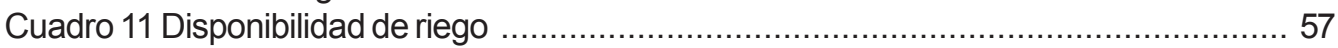

Cuadro 12. Estrategias para desinfección de suelos ............................................. 57

III.1.3

Cuadro 13. Diversidad de actividades productivas ...................................................... 59

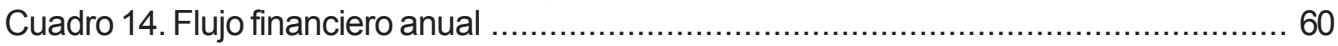

Cuadro 15. Conformidad con la comercialización de productos ................................... 60

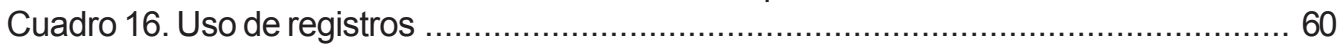

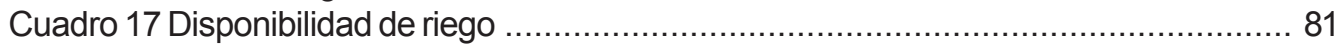

Cuadro 18. Estrategias para desinfección de suelos ............................................... 61

III. 2 .

Cuadro 1. Contenido de C orgánico en suelo en cada predio ......................................6 63

Cuadro 2. Contenidos de fósforo y nitrógeno para aguas superficiales y subterráneas

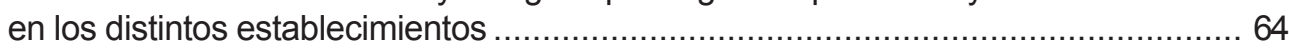

Cuadro 3. Especies de aves (total y por tipo de sitio) en cada uno de los predios ............6 65

Cuadro 4. Especies prioritarias para la conservación y su presencia en los predios .........65 65

III.3.1.

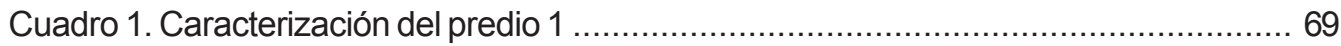

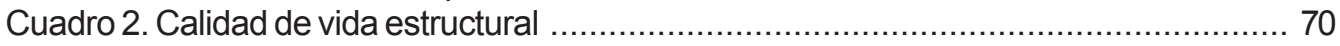

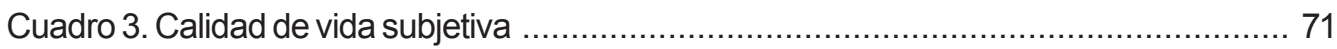

Cuadro 4. Uso del conjunto de tecnologías de producción propuestas .......................... 71

Cuadro 5. Grado en que el productor valora y usa la planificación ................................. 72

Cuadro 6. Aprendizajes y cambios más relevantes ................................................ 73

III.3.2.

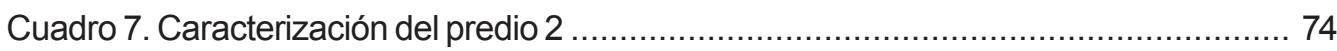

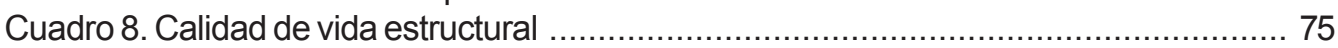

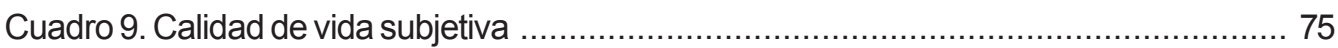

Cuadro 10. Uso del conjunto de tecnologías de producción propuestas ......................... 76

Cuadro 11. Grado en que el productor valora y usa la planificación ................................ 76

Cuadro 12. Aprendizajes y cambios más relevantes ............................................. 77

III.3.3.

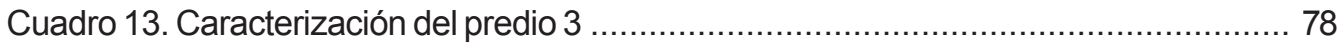

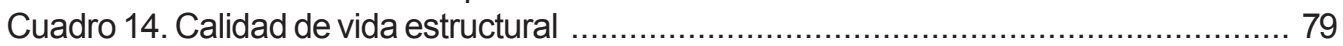

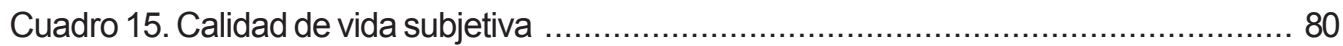

Cuadro 16. Uso del conjunto de tecnologías de producción propuestas ......................... 80

Cuadro 17. Grado en que el productor valora y usa la planificación ................................ 80

Cuadro 18. Aprendizajes y cambios más relevantes .............................................. 81 


\section{PRÓLOGO}

Desde el 2006, INIA a través del Programa Nacional de Investigación en Producción Familiar (PPF) ha ido integrando la dimensión social, en conjunto con la ambiental y la económica, a través de la inclusión de nuevos enfoques y metodologías de investigación y a fin de generar productos que contribuyan a la sostenibilidad de los productores familiares del Uruguay. Más específicamente, el abordaje de problemas complejos, como lo es la ganadería y la horticultura familiar, obligó a incorporar y a ampliar las metodologías de investigación y los trabajos multidisciplinarios, como fueron los proyectos de co-innovación desarrollados en el norte y este de nuestro país (Salto, Tacuarembó y Rocha).

Durante este periodo el PPF, en conjunto con otros Programas Nacionales de Investigación de INIA, como los de Carne y Lana, Horticultura y Pasturas y Forrajes, ha venido incorporando diferentes temáticas, a la vez de haber ampliado la vinculación con diversos actores nacionales e internacionales, diversificando así la estrategia de trabajo.

Específicamente en este caso, se articuló con la Comisión Nacional de Fomento Rural (CNFR), en conjunto con las Sociedades de Fomento Rural de Basalto Ruta 31, Mataojo Grande, Vera y Cañas, Colonia Gestido y la Mesa Hortícola de Salto. A esto se sumó la articulación y participación con el proyecto UFFIP (Uruguay Family Farm Improvement Project) ejecutado en conjunto con el instituto de investigación AgResearch de Nueva Zelanda, el Instituto Plan Agropecuario (IPA), la Dirección de Desarrollo Rural del Ministerio de Ganadería, Agricultura y Pesca (DGDR-MGAP) y el Secretariado Uruguayo de la Lana (SUL).

Esta publicación presenta los resultados del trabajo de investigación científica y desarrollo tecnológico del proyecto «Co-innovación para la promoción de sistemas productivos sustentables». El mismo asumió un compromiso de integración institucional que se planteó como objetivo abordar la problemática de los productores familiares y generar alternativas que contribuyeran a mejorar su viabilidad, en los sistemas de producción más importantes y teniendo en cuenta aspectos socio-económicos y ambientales. Para ello se innovó en la combinación de diferentes enfoques, metodologías y estrategias; el enfoque territorial, el de sistemas, la co-innovación y el involucramiento directo de las familias productoras, participando del proceso de generación de conocimiento.

Finalmente, queremos agradecer muy especialmente a las familias productoras que participaron activamente del proyecto, ya que sin ellos no hubiera sido posible realizar la investigación y presentar estos resultados.

También un particular agradecimiento a todos los técnicos que participaron desde la CNFR, las SFR involucradas, el IPA, la DGDR, el Instituto Nacional de Colonización, la UdelaR y la Intendencia de Salto.

Por último, un profundo reconocimiento al numeroso equipo científico y técnico-operativo de INIA (permanentes y aquellos que fueron contratados para el proyecto) que, con gran profesionalismo y dedicación, construyeron una red importante de actores vinculados y preocupados por la sustentabilidad de los productores familiares del país.

Ing. Agr. PhD. Alfredo Albín

Director Programa Nacional de Investigación en Producción Familiar 


\title{
INTRODUCCIÓN
}

\author{
Raúl Gómez Miller ${ }^{1}$
}

Entre las causas que han determinado la disminución del número de productores familiares en nuestro país se encuentran la baja productividad y problemas en el diseño de sus sistemas de producción -debido a una inadecuada selección y orientación de actividades productivas-, a la falta de conocimiento de opciones disponibles y a la falta de propuestas tecnológicas adecuadas ( $\mathrm{Pa}$ reja et al., 2011). Este concepto determina la necesidad de implementar propuestas de investigación/acción adecuadas, para conocer y atender desde INIA a ese público de productores.

La definición del término productor familiar se ha venido manejando en nuestro país desde hace bastante tiempo. Una primera caracterización, que aparece desarrollada por Piñeiro (1999) es que la agricultura familiar se puede definir como aquella en la que «la familia, además de tener los medios de producción, asume el trabajo en el establecimiento productivo». La agricultura familiar tiene objetivos vinculados a la actividad económica y está inserta en la sociedad de una manera global, pero la lógica de un productor familiar es distinta de la de un empresario agropecuario. Mientras para este el principal objetivo es lograr el mayor retorno sobre el capital invertido, para el productor familiar la prioridad es lograr los mayores ingresos monetarios a partir del manejo de los recursos de los cuales dispone para asegurar la reproducción familiar. En este caso, no existe una lógica de rentabilidad concebida como lucro sobre el capital manejado.

Una de las características distintivas del funcionamiento de las unidades familiares de producción que resalta la mayoría de los autores, y que tiene una importancia decisiva a la hora de analizar y evaluar aspectos tales como su viabilidad o eficiencia, es la integración prácticamente total de las actividades productivas y domésticas, además de su vínculo de tenencia (bajo diversas formas) del recurso tierra.

De acuerdo con la definición de productor familiar adoptada por el MGAP se concluye que un $77 \%$ de los establecimientos agropecuarios son de tipo familiar (DIEA, 2008), cuantificando la enorme importancia que tanto del punto de vista económico como social tiene este grupo de productores dentro del sector rural.

Todo productor familiar tiene un proyecto que es el que guía sus decisiones, entendiendo por tal «un conjunto complejo de objetivos más o menos jerarquizados, no desprovistos de contradicciones internas y susceptibles de evolucionar» (Brossier y Chia, 1986). Por lo tanto, las decisiones finales que un productor familiar toma en cuanto a la organización del trabajo y de la producción se establece en base a acuerdos básicos en la familia, que definen el rol de los miembros, los objetivos a alcanzar y los caminos a seguir para lograrlos, en un marco de información imperfecta, y tratando de mantener un equilibrio armónico entre la unidad productiva y la unidad doméstica. El entendimiento de estas lógicas es clave para evaluar las posibilidades de incorporación de tecnología y la promoción de cambios en las formas de producción y organización, para lo cual es necesario implementar estrategias de trabajo específicas que permitan alcanzar un efectivo compromiso.

A través del proyecto «Co-innovación para la promoción del desarrollo de sistemas productivos sustentables» se buscó contribuir a levantar las restricciones que limitan la capacidad de desarrollo sostenible de los sistemas de producción familiar de la región norte y litoral norte del país, a través del aná- 
lisis integral de esos sistemas, caracterizándolos en base a indicadores cuanti y cualitativos e incorporando una modalidad de trabajo innovadora en la institución.

Las características distintivas de esta forma de trabajo fueron, entre otras: i) trabajar con una lógica de sistema y no exclusivamente desde el rubro productivo, ii) proponer el modelo de co-innovación, trabajando en acuerdo con el sistema de decisión predial a partir del conocimiento de sus expectativas y mediante planes de desarrollo acordados y el aporte a la construcción de una plataforma interinstitucional con una visión acordada entre las organizaciones que operan en la región, contribuyendo a la propuesta desde sus capacidades y aprendiendo en la consolidación de una nueva estrategia de trabajo.

Mediante esta modalidad se buscó lograr un mejor entendimiento de los sistemas de producción familiar para evaluar las posibilidades de adopción de tecnología y la promoción de cambios en las formas de producción y organización, que permitan mejoras en la productividad e ingreso, disminución del impacto ambiental de las actividades productivas y un mejor desarrollo social del productor y su familia.

El trabajo se centró en el estudio de sistemas de producción reales, trabajando en forma directa con los productores y sus familias, empleando sus predios como estudios de caso. En paralelo se articuló con actores locales que desarrollan acciones en el territorio para lograr un abordaje regional y contribuir al desarrollo de la producción familiar mediante una propuesta de trabajo articulada, más ajustada a las características de los sistemas de producción familiar, tanto en el contenido como en la forma. El enfoque general de trabajo en el proyecto fue el de co-innovación, ya que implica procesos de aprendizaje colectivo (aprendizaje social), en un contexto intencionalmente diseñado (dinámicas de monitoreo y evaluación) basados en una visión de sistemas adaptativos complejos.

\section{I.1. ENFOQUE METODOLÓGICO ¿QUÉ SE ENTIENDE POR CO- INNOVACIÓN?}

Klerkx et al. (2012) definen innovación agrícola como un proceso de co-evolución que combina cambios tecnológicos, económicos y sociales. Se habla de innovación cuando un conocimiento, producto o proceso, luego de pasar a través de investigación y desarrollo, se incorpora en la producción. Se trata de la aplicación del conocimiento para lograr ciertos resultados.

Leeuwis (1999) propone abandonar la visión lineal de investigador, extensionista y productor adoptante de nuevas prácticas al momento de promover cambios efectivos en los sistemas productivos; en lugar de pensar en un proceso de «transferencia de tecnología» debe pensarse en mejorar la capacidad de aprender y experimentar de los agricultores. Por su parte, Van der Ploeg (1990) comenta que la innovación requiere de una visión que reconozca a los agricultores como agentes capaces de observar y de descubrir nuevas formas de hacer a través de la experimentación y del aprendizaje.

Gibbons et al. (1997) y Leeuwis (1999) manifiestan que las innovaciones no pueden concebirse como externas, sino que se desarrollan y diseñan en su contexto de aplicación y con la participación de quienes manejan los sistemas y toman decisiones. En este nuevo paradigma, los sistemas agropecuarios resultan sistemas adaptativos complejos en donde las innovaciones son el resultado de un proceso de selección por aprendizaje (Douthwaite et al., 2002).

De acuerdo con Engel y Salomon (1997) las tecnologías por sí solas no parecen ser la única respuesta, sino que se necesitan nuevas maneras de entender y facilitar las interacciones que se dan entre los actores para encontrar respuesta a las complejas situaciones a las que se enfrentan. En ese sentido, desde hace varios años se ha venido propiciando la participación de los productores en el desarrollo tecnológico para procurar tecnología más apropiada a sus necesidades. 
Por su parte, Masera et al. (2000) sugieren trabajar en propuestas que mejoren la sostenibilidad de los predios en su totalidad, utilizando metodologías que puedan medirla de manera integral, en todas sus dimensiones, a lo largo del tiempo. El enfoque prevé que los productores sean parte del proceso de generar, probar y evaluar las tecnologías, para resolver sus limitantes de producción, aumentar la productividad y los ingresos.

La co-innovación es un concepto que ha avanzado en los últimos años en diferentes sectores como forma de generación de conocimiento y su aplicación entre varios actores (Rossing et al., 2010; Dogliotti et al., 2012; Coutts et al., 2014, Aguerre y Albicette, 2018). La propuesta es incorporar a los agricultores como activos co-desarrolladores de nueva tecnología y no tanto como observadores pasivos que proveen información para la evaluación.

De esa forma, los cambios en las prácticas agrícolas y en la organización de los sistemas hacia situaciones de mayor sustentabilidad $^{1}$ (socio-económica y ambiental) son vistos como resultado de un proceso de aprendizaje colectivo que se denomina «coinnovación» (Pombo et al., 2010). Esta constituye una nueva forma de promover el cambio tecnológico, pero del cual, a nivel agropecuario, tanto en el ámbito internacional como nacional, no existen demasiados antecedentes.

El trabajo a nivel de predios de productores es la base elegida para implementar este enfoque, lo que permite el desarrollo de propuestas bajo condiciones reales. De esta manera, se aumentan las probabilidades de generar opciones adecuadas ya que se reflejan los objetivos y criterios de los productores familiares, teniendo en cuenta su disponibilidad de recursos, las limitaciones agronómicas del predio y las posibilidades de mercado, entre otros.

Los procesos basados en el aprendizaje colectivo deben considerar que los cambios no son lineales y los proyectos que se proponen intervenir a este nivel, con la participación de actores diversos, deben estar preparados para adaptarse a cambios inespera-

\footnotetext{
${ }^{1}$ En la publicación se usan de manera indistinta los términos sustentabilidad y sostenibilidad.
}

dos, y para redefinir sus metas y métodos frente a las complejidades emergentes. Para ello se requiere de un sistema de monitoreo y evaluación continuo que permita reflexionar de manera conjunta y que, a medida que el proyecto avanza, sea posible incorporar las lecciones aprendidas en tiempo real.

En definitiva, se entiende a la co-innovación como un proceso que focaliza en el sistema, en el aprendizaje social y en el monitoreo dinámico de los proyectos. Se trata de un proceso de aprendizaje evolutivo en el que las ideas generadas son evaluadas, reformuladas e incluidas en las prácticas habituales del predio (Douthwaite, 2002).

El enfoque para la evaluación de sustentabilidad en el trabajo con productores familiares fue el MESMIS (Marco para la Evaluación de Sistemas de Manejo incorporando Indicadores de Sustentabilidad) desarrollado por Massera et al. (2000). En él se incorporan indicadores de sustentabilidad, caracterizando propiedades o atributos socioeconómicos y biofísicos en los sistemas de producción que identifican de manera práctica los principales problemas y potencialidades con respecto a la sostenibilidad. Esto permite proponer, en base a esos indicadores, el rediseño de los predios para su mayor sustentabilidad, incorporando el análisis socio-económico y ambiental.

El concepto de sustentabilidad se concibe de manera dinámica, multidimensional y específica a un determinado contexto socioambiental y espacio temporal. Para realizar este análisis se debe caracterizar el comportamiento de un determinado número de indicadores relevantes que estén alineados con los objetivos establecidos. Estos indicadores permitirán evaluar el resultado de los cambios introducidos, contrastándolos con la situación inicial y ver los avances en función de lo que cada unidad productiva considera como sustentabilidad (Sarandón, 2002).

Los indicadores seleccionados deben conformar un conjunto sólido que proporcione información sobre los atributos de sustentabilidad y los procesos relevantes que tienen lugar en el sistema de manejo a evaluar (Gaeta y Muñoz, 2014); deben ser fáciles de medir, posibles de monitorear, prove- 
nir de una información confiable, claros y simples.

Uno de los puntos que requieren trabajo es la determinación de umbrales o valores de referencia para cada indicador. Se deben identificar los valores máximos posibles u óptimos en cuanto a sostenibilidad, así como los valores mínimos requeridos o aceptables de los indicadores estratégicos utilizados en la evaluación (Gaspar et al., 2009).

El valor de los indicadores (cada uno en su unidad respectiva) se convierte de esa forma a una escala de uno a cinco. El valor uno indica una situación de menor sustentabilidad para la variable considerada y el valor cinco revela la mejor situación de esa variable en la zona al momento de esta evaluación. Este puntaje máximo se plantea no como «óptimo» o «ideal», sino como un valor posible de alcanzar en las condiciones expuestas (Aguirre y Chiappe, 2009).

En síntesis, el MESMIS proporciona una metodología clara y efectiva para evaluar el estado de un sistema de manejo de recursos naturales en forma integrada y sistémica monitoreando el impacto de las intervenciones con el fin de proponer cambios para mejorarlo.

\section{I.2. ESTUDIO DE CASO}

El método de estudio de caso es una herramienta valiosa de investigación, principalmente en ciencias sociales, y su mayor fortaleza radica en que a través del mismo se mide y registra la conducta de las personas involucradas en el fenómeno estudiado, mientras que los métodos cuantitativos sólo se centran en información verbal obtenida a través de encuestas por cuestionarios (Yin, 1989). Chetty (1996) indica que el método de estudio de caso es una metodología rigurosa que es adecuada para investigar fenómenos en los que se busca dar respuesta a cómo y por qué ocurren, permite estudiar los fenómenos desde múltiples perspectivas y no desde la influencia de una sola variable y permite explorar en forma más profunda y obtener un conocimiento más amplio sobre cada fenómeno.
De todas formas, algunos autores señalan que el estudio de casos puede padecer de carencia de rigor, por permitir que el punto de vista del investigador influya en la dirección de los encuentros y en las conclusiones de la investigación, por lo que proporciona pocas bases para la generalización.

Respecto a la generalización a partir de casos, Rialp (1998) argumenta que debería aproximarse de manera distinta de la utilización de muestras estadísticas, y su representatividad reside tanto en el propósito y el diseño de la investigación como en las cualidades metodológicas del caso elegido a la vista de los resultados que ofrece su análisis. Así, el objetivo principal de los estudios de naturaleza cuantitativa, basados en un número elevado de observaciones, es determinar cuántos o con qué frecuencia ocurre un determinado suceso, mientras que los análisis de casos en profundidad, constituye un enfoque más bien cualitativo, tratando de comprender el proceso por el cual tienen lugar ciertos fenómenos.

Además de permitir captar adecuadamente la heterogeneidad y el rango de variación existente en una población determinada, la selección teórica o hecha a propósito de la investigación cualitativa (frente al muestreo probabilístico o aleatorio) facilita la selección deliberada de aquellos casos que se revelan críticos para valorar una teoría ya existente o en desarrollo. De esta manera, para Yin (1989) la cuestión de generalizar a partir del estudio de casos no consiste en una "generalización estadística» (desde una muestra o grupo de sujetos hasta un universo), como en las encuestas y en los experimentos, sino que se trata de una «generalización analítica» (utilizar el estudio de caso único o múltiple para ilustrar, representar o generalizar a una teoría).

Por tanto, el estudio de caso no radica en una muestra probabilística extraída de una población a la que se pueda extender los resultados, sino en el desarrollo de una teoría que puede ser transferida a otros casos. De aquí que algunos autores prefieran hablar de transferibilidad, en vez de generalización, en la investigación de naturaleza cualitativa (Maxwell, 1998). 
Así, «el objetivo de la muestra teórica es elegir casos que probablemente pueden replicar o extender la teoría emergente ...» (Eisenhardt, 1989). El autor argumenta que el número de casos apropiado depende del conocimiento existente, del tema y de la información que se pueda obtener a través de la incorporación de estudios de casos adicionales. De acuerdo con lo anterior, Perry (1998) indica que no hay una guía precisa acerca del número de casos que deben ser incluidos, no hay reglas para definir el tamaño de la muestra en un estudio cualitativo.

\section{I.3. ANTECEDENTES}

Existe en la región una larga experiencia de instituciones que han realizado diversas acciones de desarrollo rural. En ese sentido, este trabajo encara ese concepto vinculado al territorio, entendiendo por tal, de acuerdo con la definición de Echeverri (2003) a «la base de una definición concreta, de una integración de tiempo y espacio: entorno físico y geográfico con una dimensión histórica».

Según Gutman y Gorestein (2003) «los nuevos enfoques sobre dinámica del territorio proponen aproximaciones conceptuales que lo revalorizan a partir del cambio tecnológico, y las innovaciones tanto tecnológicas como organizativas, a través de procesos de conocimiento y aprendizaje en el seno de redes o conjunto de agentes». Es en ese sentido que la propuesta de intervención en este proyecto recoge las dos vertientes sugeridas: innovaciones tecnológicas y organizativas surgidas a través de la construcción de redes regionales que contemplen una participación efectiva de los actores en la búsqueda de oportunidades productivas y comerciales.

Entre los antecedentes a nivel nacional se encuentra el Proyecto Eulacias, desarroIlado en Canelones y Montevideo rural, que explícitamente se basó en un enfoque de coinnovación como base para la intervención en los sistemas de producción regional, utilizando herramientas de monitoreo y evaluación dinámica del proyecto (Dogliotti et al. 2012, 2014). Este proyecto se implementó con grupos piloto de productores, trabajando con 16 predios hortícolas y hortícola-ganaderos. El mismo concluyó en que los problemas de organización y funcionamiento de los sistemas de producción no se resuelven con ajustes en algunos componentes, sino que exigen un rediseño del sistema como un todo y cambios profundos en quienes participan en su funcionamiento.

También en el departamento de San José se trabajó con esta metodología en sistemas de producción familiar lechero, si bien su postura es algo más crítica en cuanto a las posibilidades reales de poder realizar una medición de sustentabilidad (Tommasino y Marzaroli, 2008). En ese sentido, los autores comentan que a través de este enfoque se puede entender la sustentabilidad en un determinado momento como el estado o nivel de los ingresos económicos, de la calidad de vida y de la conservación de los recursos naturales a nivel de los sistemas familiares.

Albicette et al. (2009) propusieron un conjunto de indicadores para evaluar la sostenibilidad a nivel predial de sistemas de producción agrícola-ganaderos, con base en un grupo de productores agropecuarios del litoral uruguayo.

A su vez, Aguirre y Chiappe (2009) trabajaron con productores hortícolas de Salto analizando sus sistemas productivos desde una perspectiva sistémica y multidimensional para conocer los aspectos que mejoran y favorecen su sostenibilidad.

Por su parte, Molina (2010) detalla un instrumento metodológico novedoso con el objetivo de aproximarse a determinar la sostenibilidad de los sistemas de producción ganaderos criadores familiares. El mismo se utilizó luego en un trabajo del Instituto Plan Agropecuario, en el cual se seleccionaron 11 predios y se identificaron y midieron 12 indicadores.

En el caso de este proyecto, en las dos zonas que constituyeron la unidad de estudio, concebida esta como ámbito físico de realización del trabajo, INIA ya ha realizado en los últimos años estudios de prospección, para caracterizar los sistemas de producción familiar predominantes y relevar sus principales demandas. 
En la región que abarca el área de influencia de la Estación Experimental de Tacuarembó se realizó una encuesta y estudios complementarios (entrevistas y trabajos de grupo foco) para una mejor comprensión de los sistemas productivos, básicamente ganaderos, insertos en ella (Gómez et al., 2011). Se realizaron además tres talleres con grupos de trabajo en Tacuarembó, Rivera y Cerro Largo, en los que se listaron problemas y oportunidades, priorizándose por importancia y por urgencia. Entre los problemas de índole tecnológico-productivo, los tres más importantes fueron: 1) extensión: falta asesoramiento de técnicos especializados y continuidad de asistencia; 2) falta de recursos humanos de INIA en la región para trabajar en producción familiar; 3) tecnologías adaptadas a la producción familiar; las mismas deberían tener como criterio que sean poco intensas en uso de capital e inclusive de mano de obra. Se destacó también la necesidad de adaptar/validar maquinaria apropiada para pequeñas áreas.

Por su parte, en el área de influencia de la Regional Salto Grande de INIA se realizó un relevamiento de productores familiares, a través de un diagnóstico que permitiera detectar problemas y necesidades (Courdin, 2011). El tipo de diagnóstico aplicado fue el Diagnóstico Rural Participativo (DRP), el cual pone énfasis en la participación de la población local, de tal modo que la misma pueda colaborar en el análisis de situación. Se realizaron en total 16 reuniones en los departamentos de Artigas, Salto y Paysandú. La modalidad empleada fue a través de talleres con productores y con técnicos, en forma separada, elaborándose a partir de este diagnóstico un árbol de problemas. Como corolario de este trabajo se sugirió implementar un proyecto territorial para la región litoral norte, que considere como ejes centrales de trabajo: a) la validación/investigación de tecnologías adaptadas a la producción familiar y b) el asociativismo como estrategia de desarrollo. En este informe aparece la sugerencia de que INIA desarrolle una estrategia de alianzas institucionales que amplíe la perspectiva local, consolidando un plan de trabajo con productores familiares.
Por otra parte, en los talleres realizados durante los años 2010 y 2011 en el marco del Plan Estratégico Institucional, surgió claramente la necesidad de buscar formas complementarias de trabajo para el abordaje de los sistemas de producción familiar, lo que constituye un antecedente fundamental para justificar la ejecución del proyecto.

En este nuevo paradigma, se buscó incursionar en un abordaje más amplio del complejo de toma de decisiones a nivel predial, con una visión integral de las limitantes que pudieran estar operando sobre el mismo, aportando así, y en acuerdo con los productores, mejores herramientas para la búsqueda de soluciones. En los últimos años, a nivel de los institutos de investigación científica y desarrollo tecnológico (I+D) de la región, viene cobrando fuerza el concepto de que, para abordar un trabajo efectivo en los sistemas de producción familiar, se deberán desarrollar y aplicar enfoques metodológicos más apropiados a sus particularidades. Esto implica integrar tecnologías diferenciadas y metodología participativa, en forma complementaria al esfuerzo tradicional realizado.

Mediante este proyecto se integró ese tipo de enfoques contribuyendo, por una parte, a definir una metodología de trabajo más ajustada a estos sistemas y, por otra parte, a establecer una plataforma regional con integración de la institucionalidad que opera en la misma, con una visión consensuada sobre las particularidades de la producción familiar y sus formas de abordaje.

En resumen, de los trabajos de prospección realizados en el área de influencia de ambas Estaciones Experimentales de INIA surge la necesidad de implementar desde la institución propuestas más ajustadas a las características de los sistemas de producción familiar, tanto en el contenido como en la forma. Esto implica modificar la modalidad de trabajo predominante hasta el momento, basada en propuestas productivistas, homogéneas, sin fragmentación de públicos y con la visión de una tecnología neutral de aplicación universal, por otra en la que se considera un enfoque de sistema, en el que existen múltiples elementos interconectados 
y con capacidad de cambiar y aprender de la experiencia (Axelrod y Cohen, 2000).

\section{I.4. EL PROYECTO}

El proyecto se implementó en dos territorios, con sistemas productivos representativos de cada uno de ellos:

1) predios ganaderos familiares ubicados en el área de influencia de INIA Tacuarembó,

2) sistemas de producción mixtos (con base en producción hortícola) en el área de influencia de INIA Salto Grande.

Se seleccionaron predios piloto, como estudios de caso representativos de los sistemas de producción de cada zona. A partir del trabajo conjunto entre productores y sus familias, técnicos locales y el grupo de investigación se procuró la mejora en la sustentabilidad a través del diagnóstico, elaboración de una propuesta de rediseño e implementación de la misma, en un proceso que fue evaluado y monitoreado continuamente.

Se articuló con actores locales (organizaciones de productores, instituciones con accionar en el ámbito local, técnicos locales) y se generaron instancias de reflexión para contribuir al fortalecimiento de los vínculos interinstitucionales.

\section{Componentes del proyecto}

Tal como fuera mencionado, el trabajo se centró en el estudio de sistemas de producción reales, actuando en forma directa con los productores y sus familias, empleando sus predios como estudios de caso, promoviendo procesos de aprendizaje colectivo, en base a un enfoque de co-innovación, entendiendo a esta como un proceso que focaliza en la teoría de sistemas complejos, en el aprendizaje social y en el monitoreo dinámico (Rossing et al., 2010).

El trabajo implicó las siguientes etapas:

- Predios piloto rediseñados

- Metodología de trabajo adaptada

- Propuesta de indicadores

- Generación de pautas para contribuir al desarrollo de la zona

\section{I.4.1. Predios piloto re-diseñados}

La base del proyecto fue el trabajo a nivel de predios piloto tomados como estudios de caso (Mohd Noor, 2008). El trabajo implicó las siguientes etapas:

a) Selección de predios piloto.

b) Caracterización y diagnóstico del predio.

c) Propuesta de re-diseño - Planificación estratégica.

d) Implementación de la propuesta, evaluación y ajustes.

\section{a) Selección de predios piloto}

Para la selección de predios piloto se consideró que fueran representativos de los sistemas de producción familiar vinculados a cada zona, considerando distintas combinaciones de rubros y dotación de recursos productivos. Para su selección se consideraron aspectos tales como: superficie, actividades productivas principales, recursos disponibles y características agro-ecológicas. En el caso del proyecto de la región norte se consideraron: predios ganaderos sobre suelos de basalto y predios con base en la producción hortícola en los alrededores de la ciudad de Salto.

A efectos de tener un número interesante de productores sobre los cuáles seleccionar los casos se pidió a las organizaciones de base de cada región su apoyo para definir un listado preliminar de potenciales candidatos. En el caso de la región ganadera de basalto se presentó la propuesta en: Sociedad de Fomento Rural Basalto ruta 31, Sociedad de Fomento Rural Mataojo Grande y la Sociedad de Fomento Rural Vera y Cañas. En el caso de los predios hortícolas de Salto la propuesta se formalizó a través de la Mesa Hortícola de Salto.

A su vez, se realizaron reuniones con instituciones de la región (MGAP, IPA, INC, SUL, agencia de desarrollo de la Intendencia de Salto, CNFR) para consensuar esos listados.

Al momento de definir la selección se consideró el interés y motivación en participar en el proyecto, la disposición a incorporar cambios en el sistema de producción (previo acuerdo de las partes), la disponibilidad 
de tiempo para participar en el proceso, la disposición para recibir visitas frecuentes al predio y la incorporación, en caso de no tenerla, de algún tipo de registro de información económico-productiva.

Se realizó una visita a cada uno de los candidatos potenciales presentados por las organizaciones de productores para explicarles en detalle el objetivo y funcionamiento del proyecto. En cada caso se les presentó la metodología a emplear, las responsabilidades y compromisos del productor y del equipo técnico. Se hizo un relevamiento preliminar sobre la visión del productor acerca de los problemas principales que enfrenta en el manejo del predio y sus motivaciones para participar en el proyecto.

Finalmente, una vez cumplida la etapa de visita a todos los candidatos propuestos, se seleccionaron seis predios piloto: tres de ellos ganaderos, en el eje de la ruta 31 , y tres con sistemas con base hortícola, en los alrededores de la ciudad de Salto.

Cabe destacar que la selección definitiva de los predios resultó un proceso largo, pues muchos de los productores visitados tenían otras expectativas, relacionadas por ejemplo a recibir apoyos financieros para inversiones no reembolsables, teniendo en cuenta otro tipo de proyectos que se han venido promoviendo desde el ámbito público.

\section{b) Caracterización y diagnóstico}

Una vez definidos los predios piloto, la primera etapa de trabajo consistió en la caracterización y diagnóstico de cada uno de ellos. Se trabajó en base a visitas frecuentes al predio con entrevistas a los integrantes del grupo familiar, recorridas de campo y relevamiento de información primaria y secundaria. El objetivo de esta etapa consistió en conocer en profundidad el sistema de producción y acordar con el productor y su familia las posibilidades de mejora del mismo.

La caracterización del sistema de producción implicó una descripción detallada de todos sus componentes y los procesos desarrollados, considerando el subsistema de gestión y el subsistema de producción. El subsistema de gestión incluye aspectos re- lativos a la gestión y toma de decisiones, para lo cual se relevó información acerca de la composición familiar, historia, objetivos y metas; y las herramientas e información utilizados para realizar la gestión. Por otra parte, el subsistema de producción incluye la caracterización de los recursos disponibles, los procesos productivos y los resultados de estos procesos. Se relevó información de:

- Recursos humanos: disponibilidad, capacitación y experiencia de la mano de obra familiar y contratada para el trabajo en el predio.

- Recursos naturales: a nivel predial (descripción y caracterización de suelos, fuentes de agua, pasturas nativas e implantadas, etc.).

- Infraestructura disponible: a nivel predial (vivienda, instalaciones para trabajo con animales, galpones, empotreramiento, maquinaria, etc.) y a nivel regional o local (caminería, acceso a servicios, etc.).

- Actividades productivas: identificación de actividades productivas y manejo general. Prácticas agrícolas y pecuarias.

- Resultados físicos y económicos de las actividades productivas. Registro de productividad por rubro y resultados económicos y financieros de los mismos, considerando además actividades e ingresos extraprediales.

El diagnóstico del sistema de producción implicó la identificación de fortalezas y debilidades del mismo en base a los objetivos y metas del productor. Este proceso involucró la identificación de puntos críticos. Los puntos críticos son aspectos o procesos (ambientales, técnicos, sociales o económicos) que limitan o fortalecen la capacidad de los sistemas para sostenerse en el tiempo. Son críticos porque facilitan u obstaculizan el agroecosistema en cualquiera de los atributos que lo definen como sustentable en el tiempo y pueden afectar de forma individual o combinada (Masera et al., 2000).

Al construir un árbol de problemas para cada caso se lograron establecer las relaciones de causa-efecto de los problemas identificados. Eso permitió ubicar los problemas centrales, analizando sus causas y sus 
efectos. Los puntos críticos y el árbol de problemas fueron discutidos con el productor, hasta alcanzar un acuerdo en las prioridades y el establecimiento de las líneas estratégicas de trabajo.

La información generada en la etapa de caracterización y diagnóstico constituyó el año cero o de referencia contra el cual se comparan los resultados de la evaluación de los cambios acordados.

\section{c) Propuesta de diseño - Planificación estratégica}

El proceso de diseño implicó la definición, en conjunto con el productor y su familia, de ajustes y cambios a nivel del sistema de producción, buscando mejorar los puntos críticos negativos y potenciar los puntos críticos positivos. Los criterios de diseño derivan de los problemas y sus causas, detectados durante la etapa de diagnóstico. Para ello se generaron distintas alternativas que fueron evaluadas a priori, tanto en aspectos de necesidades de recursos como de resultados esperados, para seleccionar la más adecuada.

El proceso de diseño puede dividirse en cuatro etapas: 1) exploración de planes de producción alternativos, 2) evaluación a priori de los planes, 3) selección y ajuste de la propuesta a implementar, 4) elaboración de un plan de implementación.

La primera etapa consistió en la elaboración de planes de producción alternativos al actual. Estos planes de producción pueden implicar desde ajustes de manejo dentro de los rubros y actividades en curso, la reasignación de recursos dentro del predio a las distintas actividades, hasta la incorporación o eliminación de actividades y/o rubros. En sistemas ganaderos se utilizaron presupuestaciones forrajeras y evolución de stock. El principal insumo para abordar esta etapa incluyó un relevamiento de la información tecnológica disponible y validada en la región.

La segunda etapa consistió en la evaluación a priori de los posibles planes de producción a implementar, mediante un análisis de sensibilidad. Se evaluó para cada plan el resultado económico- financiero potencial, el impacto en los recursos naturales, necesidades de mano de obra y de capacitación, sensibilidad frente a cambios de precios y clima, identificándose, junto al productor, las mejores alternativas.

La tercera etapa se basó en la discusión más en profundidad de las distintas propuestas con el productor y su familia. En este proceso de análisis se evacuaron dudas y se realizaron los ajustes necesarios hasta acordar en la definición de un plan que el productor estuviera dispuesto a implementar.

En todos los casos se analizaron diversas propuestas, compartiendo y evaluando con los productores las posibilidades de llevarlas adelante. Una vez definidos los planes de producción, de común acuerdo, se establecieron los pasos para su implementación.

\section{d) Implementación de la propuesta, evaluación y ajustes}

Para la implementación resultó fundamental el seguimiento regular de los predios por parte del técnico de campo (al menos mensual según el sistema de producción y la época del año). En el proyecto trabajaron dos técnicos de campo contratados con los recursos del proyecto; uno en cada región de acuerdo con su área de especialidad, ganadería u horticultura.

En cada caso, el equipo técnico discutió con el productor y su familia la implementación de las medidas propuestas, evaluando el nivel de dificultad, las prioridades, los plazos. Se realizaron, además, los ajustes tácticos y operativos necesarios para la puesta en funcionamiento del plan de trabajo. Se brindó apoyo para la sistematización del proceso a partir de herramientas simples de registro a nivel predial.

Tal como se mencionó, para evaluar la sostenibilidad de los predios piloto seleccionados se utilizó como herramienta el MESMIS, considerando el ajuste del mismo a los objetivos planteados en el proyecto.

La evaluación y monitoreo del proceso se centró en relevar la información necesaria 
para el cálculo de los indicadores definidos para monitorear la sustentabilidad. La implementación, monitoreo y evaluación se realizaron prácticamente de forma continua y simultánea.

Con periodicidad se realizaron devoluciones de los resultados (económicos, productivos, sociales, ambientales) a los productores, de forma de fortalecer el nivel de confianza e intercambio entre las partes.

\section{I.4.2. Metodología de trabajo adaptada para abordar el re- diseño de sistemas de producción familiar}

A lo largo del proyecto se realizaron actividades de intercambio, discusión y reflexión entre los diferentes actores, con el objetivo de monitorear y evaluar el estado de avance del proyecto, ajustando y re-planificando las actividades durante el transcurso del mismo.

A nivel del trabajo en predios, las visitas de los técnicos de campo y de investigadores fueron los espacios más frecuentes de intercambio y monitoreo. La implementación y evaluación de las nuevas alternativas en los sistemas resultó la etapa central del proceso de aprendizaje para todos los participantes.

A nivel del equipo de investigación, se implementaron reuniones periódicas de intercambio de información, visiones y planificación de las actividades del proyecto.

El análisis de la información generada en estas instancias permitió sistematizar el proceso de investigación y establecer pautas para adecuar y enriquecer la metodología de re-diseño de sistemas de producción familiar.

\section{I.4.3. Propuesta de indicadores para el monitoreo y evaluación de la sustentabilidad}

Tal como se dijo, para evaluar la sustentabilidad de los predios piloto se utilizó como herramienta el Marco para la Evaluación de Sistemas de Manejo de Recursos Naturales Incorporando Indicadores de Sustentabilidad (MESMIS) (Masera et al., 2000). La base de su concepción es el enfoque sistémico y brinda al investigador pautas para realizar el trabajo.

El equipo de investigación definió, en base a los puntos críticos identificados en el diagnóstico de los predios piloto, un conjunto de indicadores que permitiera evaluar la sustentabilidad en el marco de una serie de grupos de atributos definidos por el MESMIS (productividad, estabilidad, -adaptabilidad, confiabilidad y resiliencia-, autogestión o autodependencia) incluyendo aspectos económico-productivos, ambientales y sociales.

Se incluyeron indicadores para evaluar eficiencia productiva, eficiencia económica, calidad de vida, conservación de recursos naturales, fragilidad del sistema productivo, diversificación económica y productiva, diversificación ambiental, dependencia financiera y de insumos, acumulación de capital social y humano, entre otros.

\section{I.4.4. Generación de pautas para contribuir al desarrollo de la zona}

La información generada a nivel de los predios piloto se integró buscando identificar estrategias generales de mejora a nivel de sistemas de producción familiar que puedan tener impactos positivos en su sustentabilidad, pudiendo ser consideradas en programas de desarrollo de cada región.

Atendiendo este objetivo, desde el proyecto se procuró contribuir al fortalecimiento de los vínculos interinstitucionales y al aporte de información para el diseño de políticas regionales específicas. 


\section{II - PRODUCTORES GANADEROS}

\section{INTRODUCCIÓN}

Se trabajó con tres predios, tres casos representativos de sistemas de producción de la región basáltica en el área de influencia de la estación experimental de INIA Tacuarembó. Se definió esa representatividad en cuanto a recursos disponibles, infraestructura, sistema productivo, criterios de gestión, objetivos del productor y su familia, propensión a incorporar cambios, problemas productivos y limitantes.

A pesar de tener la característica común de ser productores que mostraron interés y motivación en participar en el proyecto, su disposición a introducir cambios en su sistema productivo (previo acuerdo de las partes) y su disposición para recibir visitas frecuentes en el predio, tenían puntos de partida y objetivos diversos.

De acuerdo a la premisa de estudios de caso, a través del mismo se mide y registra la conducta de las personas involucradas, tratando de comprender el proceso por el cual tienen lugar ciertos fenómenos. En este proyecto se evaluó la respuesta ante una propuesta de co-innovación, que supuso una planificación y rediseño de sus sistemas productivos.
En una rápida caracterización, uno de los productores ya tenía un nivel productivo muy bueno, con adecuada disponibilidad de recursos e infraestructura y mostraba interés en seguir haciendo ajustes, pensando principalmente en mejorar los ingresos y resolver la situación sucesoria del predio.

Otro caso representaba el paradigma del pequeño productor de ganadería extensiva, con bajos niveles productivos, escasa innovación, alta carga, y con el objetivo de tener la mayor cantidad de animales en el predio. Su prioridad era mantener o incrementar el capital semoviente, sin focalizar en aspectos de productividad o rentabilidad.

La tercera situación seleccionada fue la de una productora con bajos niveles iniciales de producción en el rodeo vacuno, con escasa incorporación tecnológica, pero muy receptiva para incorporar cambios en su sistema que le permitieran superar los niveles productivos y mejorar el ingreso,

Se realizó el análisis de la evolución de los tres casos mediante la definición de indicadores, contemplando la dimensión productivo-económica, ambiental y social de cada uno de los sistemas. 


\title{
II.1. DIMENSIÓN PRODUCTIVO-ECONÓMICA
}

\author{
Ing. Agr. (Mag) Raúl Gómez Miller ${ }^{1}$, Ing. Agr. Virginia Porcile²
}

El proyecto se basó en la hipótesis de que con una metodología capaz de combinar el asesoramiento técnico multidisciplinario (agronómico, veterinario, social, ambiental) con una visión global de la empresa familiar, que permita una mejor gestión de la pastura natural, se puede aumentar la productividad y el ingreso de las empresas familiares ganaderas conservando los recursos naturales y por ende la sostenibilidad de la familia.

Se definieron diversos indicadores para evaluar la evolución de los parámetros productivos y económicos y su incidencia en la sostenibilidad de los tres sistemas. En todos los casos, al momento de establecer con cada uno de los productores su definición de sostenibilidad, aparecieron claramente los temas relacionados a la productividad y el ingreso proveniente del predio como aquellos que se visualizan con mayor prioridad.

De esa manera, conceptos tales como "estabilizar y mejorar el sustento de la unidad familiar" o "planificar mejor el manejo y la gestión, mejorar el rodeo y los índices de producción", se dieron en los tres casos. Todos los productores identificaron áreas de mejora en la gestión del predio, mediante un uso más eficiente de los recursos forrajeros, para aumentar la productividad. En las distintas situaciones parecía asumirse que una mejora productiva se reflejaría en un mejor resultado económico.

A efectos de relevar diversos indicadores productivos y económicos y su evolución en el tiempo se hizo un seguimiento con el soporte del sistema de carpetas verdes del Plan Agropecuario. Con ellas se pudo sistematizar la información de manera de hacerla comparable durante el transcurso del proyecto, de forma de monitorear los cambios que se iban produciendo. Además, permitió que los productores se familiarizaran con el uso de registros y su análisis, como herramienta para tomar decisiones en base a datos objetivos.

Las carpetas verdes permiten extraer una variedad de índices: productivos, económicos y financieros.

Entre los productivos el \% de área mejorada, la dotación del predio y su composición (relación lanar/vacuno), la productividad por Unidad Ganadera (UG), el \% de parición, la tasa de extracción y la producción de carne equivalente/hectárea (ha), entre otros.

Con respecto a indicadores económicos: el ingreso bruto y los costos de producción por hectárea (fijos y variables), el ingreso neto, la rentabilidad, el capital manejado por unidad de superficie y el nivel de endeudamiento; así como indicadores comerciales que refieren al precio obtenido por unidad de producto comercializado ( $\mathrm{kg}$ de carne o de lana). A su vez, entre los indicadores financieros relevados se destaca el movimiento de caja y la capacidad de repago.

Si bien en los tres casos se hizo un análisis exhaustivo de esta diversidad de indicadores, a los efectos de este trabajo se seleccionaron aquellos que se entiende mejor reflejan el estado de situación y la evolución experimentada en los tres predios, y que mejor dan cuenta de la percepción de sostenibilidad productiva y económica de ellos.

Dotación: Considerando que la dotación manejada en el predio es la base para asegurar un ajuste entre la oferta forrajera y el consumo animal, conciliando la disponibilidad de pastura con los requerimientos de las diversas categorías del stock, se tomó ese indicador como una de las referencias para monitorear el manejo del recurso productivo básico (la pastura). Este fue el punto de partida para, en los casos necesarios, promo-

\footnotetext{
${ }^{1}$ Unidad de Comunicación y Transferencia de Tecnología.

2 Técnica Sectorial.
} 
ver ajustes en el rediseño predial. La dotación fue calculada como el promedio manejado en cada ejercicio, tomando como referencia las declaraciones juradas de principio y fin de ejercicio, multiplicando el total de animales de cada categoría por un coeficiente atribuido a la misma, en relación a la unidad ganadera (UG): una vaca de cría que pesa $380 \mathrm{~kg}$ que gesta y desteta un ternero.

$\%$ de destete: El porcentaje de destete vacuno se calculó como el número de terneros destetados sobre el total de vacas entoradas. Se trata de un indicador muy importante para definir la productividad de sistemas ganaderos de cría o ciclo completo en el rubro vacuno, ya que resume el esfuerzo de mantener todas las categorías que componen un rodeo (las vacas de cría y su reposición) en procura de lograr un producto final: el ternero. Considerando el peso relativo de la cría en estos sistemas en los predios de la región se decidió su inclusión en el set final de indicadores.

Producción de carne equivalente/ha: La productividad global del establecimiento se refleja en el indicador: $\mathrm{kg}$ de carne equivalente por hectárea. El mismo consolida tanto la producción vacuna como ovina del establecimiento. Se calcula de acuerdo a la siguiente fórmula:

\section{$\mathrm{kg}$ de carne vacuna/ha $+\mathrm{kg}$ de carne ovina/ha + (kg de lana/ha $\times 2,48$ )}

Los kg de carne producidos por hectárea (tanto en el caso de vacunos como ovinos) se estiman de la siguiente forma:

$\mathrm{kg}$ finales en stock $+\mathrm{kg}$ vendidos $-\mathrm{kg}$ comprados $-\mathrm{kg}$ iniciales en stock $+\mathrm{kg}$ consumo

$$
\text { Área pastoreo (ha) }
$$

Este es un indicador sólido que permite unificar en un solo número la productividad general del predio, ya que considera no solo las ventas y compras de hacienda registradas en el ejercicio sino además la diferencia de stock generada ya sea por retención o liquidación parcial de animales. En él se reflejan distintos componentes: carga, productividad por cabeza, y obviamente incide la performance que se tenga en aspectos tales como porcentaje de parición, mortandad, etc.
Incorporación de tecnología: Para establecer la incorporación tecnológica se definió un listado de doce tecnologías complementarias, con costos de aplicación reducidos, que apuntan a un manejo racional de los recursos forrajeros procurando atender las necesidades cambiantes de las distintas categorías de un rodeo a lo largo del año.

Las tecnologías seleccionadas fueron: ajuste de carga, adecuación de época de entore y encarnerada, manejo según condición corporal, diagnóstico de gestación para manejo diferencial, diagnóstico de actividad ovárica a mitad de entore, control del amamantamiento, destete en otoño, manejo y monitoreo preferencial de la recría, entore de vaquillonas a los dos años, asignación de potreros según altura y categoría animal, uso de registros y revisión y sanidad en reproductores.

Todas estas son tecnologías recomendadas para sistemas criadores sobre campo natural, aunque con diferente nivel de ordenamiento y priorización. En ese sentido, se buscó la adecuada jerarquización, procurando que se implementaran primero aquellas tecnologías de mayor impacto inmediato, en el caso de que no se estuvieran utilizando (ej. ajuste de carga, concentración del entore, destete otoñal de terneros).

La definición del indicador se hizo en base al número de tecnologías implementadas en el predio durante los tres años de duración del proyecto. Esto permite analizar la evolución del indicador, viendo cómo se implementaron las técnicas sugeridas en el rediseño predial.

Relación Insumo/Producto: La relación insumo/producto (I/P) se estableció en base al cierre económico del ejercicio, considerando los ingresos generados y los costos de producción. Resulta un buen resumen que permite saber cuánto se gasta por cada dólar que ingresó en el ejercicio, lo que da una pauta para establecer los márgenes que se obtienen por cada unidad monetaria percibida.

Ingreso neto: El ingreso neto (IN) define el resultado económico del predio, se mide en U\$S por hectárea, y es el ingreso efectivo una vez deducidos los costos de produc- 
Cuadro 1. Referencia de indicadores productivo-económicos (rango de 1 a 5).

\begin{tabular}{|lccccc|}
\hline Indicador & $\mathbf{1}$ & $\mathbf{2}$ & $\mathbf{3}$ & $\mathbf{4}$ & $\mathbf{5}$ \\
\hline Carga $(\mathrm{UG} / \mathrm{ha})$ & $>1,3$ & $1,10-1,30$ & $0,85-1,10$ & $0,75-0,85$ & $\leq 0,75$ \\
\hline \% destete vacuno & $<50$ & $50-60$ & $61-70$ & $71-80$ & $\geq 80$ \\
\hline kg carne equivalente/ha & $\leq 64$ & $65-79$ & $80-94$ & $95-110$ & $\geq 110$ \\
\hline Incorporación tecnológica $\left(\mathrm{N}^{\circ}\right)$ & $<5$ & $5-6$ & $7-8$ & $9-10$ & $11-12$ \\
\hline Relación I/P & $\geq 1$ & $0,76-1$ & $0,56-0,75$ & $0,45-0,55$ & $\leq 0,45$ \\
\hline IN/ha (U\$S/ha) & $\leq 10$ & $11-25$ & $26-40$ & $41-60$ & $>60$ \\
\hline
\end{tabular}

Nota: UG: Unidad Ganadera; ha: hectárea; I/P: insumo/producto; IN: ingreso neto

ción. Resulta un parámetro muy práctico que sintetiza el potencial económico por unidad de superficie.

Para los dos indicadores económicos seleccionados se definió de forma relativa la escala, tomando como referencia los resultados de cierre de carpetas verdes del Plan Agropecuario para productores con sistemas de producción similares.

El Cuadro 1 resume el gradiente total de los indicadores productivo-económicos seleccionados.

\section{Resultados productivo-económicos}

En relación con resultados productivos, en este trabajo se considera solamente al rubro vacuno, a pesar de tratarse de sistemas mixtos que incluyen también al rubro ovino. Este criterio permite poner más foco en el monitoreo de esta dimensión, considerando además la preeminencia del rubro en los tres casos.

El énfasis en todos los predios estuvo puesto en el ajuste de carga, considerando que es el punto de partida para realizar un ordenamiento en el manejo, mediante una correcta asignación de forraje a cada categoría de animales en función de sus necesidades (fisiológicas, de crecimiento, etc.). A partir de allí se fue acordando con cada productor la implementación de diversas tecnologías para mejorar o estabilizar la productividad del predio.

El punto de partida era bastante heterogéneo, pues dos de los productores no aplicaban prácticamente ninguna de las tecnologías sugeridas para el manejo de un rodeo de cría vacuno, en tanto otro de ellos ya al comienzo del proyecto tenía un manejo razonablemente ajustado que le permitía lograr buenos indicadores productivos. Esto se refleja en los resultados que se lograban al comienzo del proyecto: \% destete, kg carne equivalente. Esta situación se alinea con el concepto de estudio de caso, mostrando la diversidad de criterios de gestión predial que se verifican en la región.

Cabe mencionar que el concepto "aplica tal tecnología" no necesariamente significa que lo haga de la manera correcta. En algunos casos, al estar recién familiarizándose con ellas, podría implicar que aún se estén realizando de forma inadecuada, lo que obviamente repercute en el resultado esperado de su aplicación.

El productor 1 ya venía aplicando la mayoría de las tecnologías, pero durante el proyecto comenzó a organizar sus registros y aprendió a analizar los resultados económico-productivos. De acuerdo con su testimonio eso le ha ayudado a tomar decisiones con criterios más objetivos: cambios en el manejo, compras de suplementos o decisiones financieras y comerciales. Esto le ha permitido empezar a gestionar el predio con mayor seguridad, basándose en datos concretos. Además, realizó un ajuste en la carga al poder comprobar la importancia de la respuesta animal al trabajar con más pasto.

El productor 2 fue el que mostró una menor evolución, ya que no redujo la carga del predio en la medida de lo necesario, lo que conspiró para mejorar de manera significativa la productividad. Además, durante el periodo, aplicó sólo de manera fragmentaria el conjunto de tecnologías sugeridas. Lo que sí logró fue una mayor concentración del 
entore, incorporó la revisión de toros, empezó a familiarizarse con el manejo de la condición corporal del rodeo y a tener más criterio a la hora de asignar pastura en base a las necesidades de las distintas categorías y se comenzó a hacer un destete más temprano de los terneros. La puesta en práctica de estas técnicas le permitió mejorar en algo el destete y la productividad global (kg de carne equivalente), lo que se ha empezado a reflejar en un mejor ingreso.

El productor 3, por su parte, mostró una evolución muy positiva, incorporando prácticamente todas las tecnologías sugeridas. De hecho, pasó de hacer entore continuo sin tener un control adecuado de las distintas categorías que componían el rodeo, a concentrar el entore, hacer un manejo ajustado de la condición corporal de los animales, manejar el rodeo por lotes (terneras, vaquillonas, vacas primíparas y multíparas), realizar diagnóstico de gestación y manejar de forma diferencial a las vacas preñadas, y hacer los destetes en fecha. El conjunto de tecnologías fue rápidamente incorporado, mostrándose siempre abierto a la innovación. Eso permitió ir incrementando la productividad de manera consistente, consolidando la experiencia generada en el periodo.

En el Cuadro 2 se detalla, en cada caso, el uso de las tecnologías propuestas durante el proyecto. Este relevamiento se hizo dentro del componente social del proyecto para analizar los cambios efectuados por parte de cada productor, pero se ubicó en esta sección pues ayuda a explicar en buena medida los resultados productivos logrados en cada situación. El uso del set de tecnologías se valora al inicio del proyecto (Año 1) y al final del mismo (Año 3). Para cada una de las técnicas propuestas se asignó un valor de 1 si la misma era utilizada en el predio y de 0 si no se utilizaba.

Cuadro 2. Uso del conjunto de tecnologías de producción propuestas para el re-diseño.

\begin{tabular}{|c|c|c|c|c|c|c|}
\hline \multirow[t]{2}{*}{ Tecnología } & \multicolumn{2}{|c|}{ Productor 1} & \multicolumn{2}{|c|}{ Productor 2} & \multicolumn{2}{|c|}{ Productor 3} \\
\hline & Año 1 & Año 3 & Año 1 & Año 3 & Año 1 & Año 3 \\
\hline Ajuste de carga & 0 & 1 & 0 & 0 & 0 & 1 \\
\hline Adecuación época de entore & 1 & 1 & 0 & 1 & 0 & 1 \\
\hline Manejo según condición corporal & 1 & 1 & 0 & 1 & 0 & 1 \\
\hline Diagnóstico de actividad ovárica & 0 & 1 & 0 & 0 & 0 & 1 \\
\hline $\begin{array}{l}\text { Diagnóstico de gestación para } \\
\text { manejo diferencial }\end{array}$ & 1 & 1 & 0 & 1 & 0 & 1 \\
\hline Control de amamantamiento & 1 & 1 & 0 & 1 & 0 & 1 \\
\hline Destete a los 6 meses de edad & 1 & 1 & 0 & 1 & 0 & 1 \\
\hline Manejo preferencial de la recría & 1 & 1 & 0 & 0 & 0 & 0 \\
\hline Entore a los 2 años de edad & 1 & 1 & 0 & 0 & 0 & 1 \\
\hline $\begin{array}{l}\text { Asignación de potreros según altura } \\
\text { y categoría animal }\end{array}$ & 1 & 1 & 0 & 0 & 1 & 1 \\
\hline Uso de registros & 0 & 1 & 0 & 1 & 0 & 1 \\
\hline $\begin{array}{l}\text { Sanidad en toros. Campilobacter y } \\
\text { revisión pre-entore }\end{array}$ & 0 & 1 & 0 & 1 & 0 & 1 \\
\hline $\begin{array}{l}\text { \% de uso del set de tecnologías } \\
\text { propuestas }\end{array}$ & 67 & 100 & 0 & 58 & 8 & 92 \\
\hline
\end{tabular}

Nota: Valor 1 = usa la tecnología, Valor 0 = no usa la tecnología. Este relevamiento se realizó en el análisis de la dimensión social 
Por su parte, en el caso los indicadores económicos, si bien están relacionados a la productividad física del predio, durante el período fueron afectados por una disminución de los valores de venta de los productos pecuarios. Eso explica que, en algunos casos, a pesar de lograr niveles de productividad mayores se hayan conseguido resultados económicos más bajos. Además, debe consignarse que las mejoras en productividad y la consecuente repercusión financiera generalmente se reflejan en periodos mayores a los tres años que duró el proyecto (Cuadro $3)$.

Cuadro 3. Resultados productivo-económicos en los tres predios.

\begin{tabular}{|l|ccc|cc|cc|cc|}
\hline Indicador & \multicolumn{2}{|c|}{ Productor 1 } & & \multicolumn{2}{c|}{ Productor 2 } & \multicolumn{2}{c|}{ Productor 3 } \\
\cline { 2 - 3 } & Año 1 & Año 3 & & Año 1 & Año 3 & & Año 1 & Año 3 \\
\hline Carga (UG/ha) & 0,85 & 0,74 & 1,32 & 1,15 & & 0,69 & 0,86 \\
\hline \% destete vacuno & 80 & 78 & 52 & 66 & 53 & 74 \\
\hline kg carne equivalente/ha & 110 & 117 & 64 & 76 & 75 & 86 \\
\hline Incorporación tecnológica $\left(N^{\circ}\right)$ & 8 & 12 & 0 & 7 & 1 & 11 \\
\hline Relación I/P & 0,42 & 0,51 & 0,84 & 0,71 & 0,52 & 0,61 \\
\hline IN/ha (U\$S/ha) & 65 & 38 & 11 & 27 & 42 & 44 \\
\hline
\end{tabular}

Nota: UG: Unidad Ganadera; ha: hectárea; I/P: insumo/producto; IN: ingreso neto.

Cuadro 4. Indicadores relativos.

\begin{tabular}{|l|ccc|ccc|ccc|}
\hline \multirow{2}{*}{ Indicador } & \multicolumn{2}{|c|}{ Productor 1 } & \multicolumn{2}{c|}{ Productor 2 } & \multicolumn{2}{c|}{ Productor 3 } \\
\cline { 2 - 3 } & Año 1 & Año 3 & & Año 1 & Año 3 & & Año 1 & Año 3 \\
\hline Carga (UG/ha) & 3 & 5 & 1 & 2 & 5 & 3 \\
\hline \% destete vacuno & 5 & 4 & 2 & 3 & 2 & 4 \\
\hline kg carne equivalente/ha & 5 & 5 & 1 & 2 & 2 & 3 \\
\hline Incorporación tecnológica $\left(\mathrm{N}^{\circ}\right)$ & 3 & 5 & 1 & 3 & 1 & 5 \\
\hline Relación I/P & 5 & 4 & 2 & 3 & 4 & 3 \\
\hline IN/ha (USS/ha) & 5 & 3 & 2 & 3 & 4 & 4 \\
\hline
\end{tabular}




\section{INTRODUCCIÓN}

El foco del trabajo fue a escala predial, lo que hace posible trabajar en algunos indicadores con más precisión que en otros. A su vez, la escala temporal de tres años hace difícil la observación de cambios en ciertas variables.

Un orden de componentes ambientales analizados son los de alcance regional (ecosistema y/o paisaje del que forma parte el predio). En esta escala podemos considerar temas como calidad de agua y biodiversidad (especies, comunidades y ecosistemas), en los cuales la actividad del predio puede generar efectos en predios vecinos y viceversa.

Por último, existen aquellos que son de efecto local (en el propio predio) como la formación y conservación del suelo y algunos componentes de la biodiversidad, como comunidades herbáceas o mesofauna del suelo.

Considerando los alcances prediales y regionales, se seleccionó un set de indicadores para evaluar la situación inicial y eventuales cambios producidos por el proyecto en los establecimientos participantes. La elección de los indicadores consideró la duración acotada del proyecto (tres años), la metodología de estudio de caso y las posibilidades técnicas dadas por las capacidades del equipo de investigadores involucrados $y$ el equipamiento disponible.

\section{II.2.1. Estrategia de monitoreo}

El monitoreo ambiental, dentro del enfoque sistémico de análisis de este proyecto, pretende mantener una visión ecosistémica. Este enfoque contribuye a comprender los factores bióticos y abióticos como componentes interactuando en un solo sistema integrado y entender los procesos que suce- den a distintas escalas (Ågren y Bosatta, 1998). Este camino promete generar aportes y toma especial importancia en un contexto de crisis por deterioro de los sistemas naturales y servicios ecosistémicos, incluyendo el cambio climático global (Bennett et al., 2003).

La diversidad de organismos existentes y la complejidad de procesos presentes en el funcionamiento de los ecosistemas hace difícil relevarlos y monitorearlos exhaustivamente. Sin embargo, sigue siendo necesario generar bases de datos sistemáticas para entender su funcionamiento y manejarlos promoviendo su sustentabilidad. Una estrategia para salvar esta limitante es focalizar el monitoreo en variables indicadoras (Kremen, 1992). Estos indicadores deben cumplir una serie de criterios científicos y prácticos: deben ser sensibles a cambios, deben ser cuantitativos, representativos de la salud del ecosistema en general, estar vinculados a las causas o procesos detrás de las tendencias, ser medibles de forma eficiente y fácilmente entendibles (Gregory et al., 2005; Niemeijer y de Groot, 2008).

Para poder cumplir con estos criterios, en este proyecto se planteó la construcción de varios índices compuestos, uno por componente del ambiente de los agroecosistemas prediales: agua, suelo y dentro de biodiversidad, aves, arañas y pasturas, y otro para reflejar en forma amplia la integridad ecosistémica del predio en cuanto a formaciones vegetales, uso del suelo y modificación de los sistemas naturales y servicios ecosistémicos.

La utilización de índices compuestos, que integran información sobre cambios en las especies (ej. cambios en la abundancia) y cambios en el ecosistema, son importan-

\footnotetext{
${ }^{1}$ Programa Nacional de Producción y Sustentabilidad Ambiental.

2 Unidad de Agroclima y Sistemas de Información.

${ }^{3}$ Pasante Programa Nacional de Pasturas y Forrajes.

${ }^{4}$ Asesor privado.
} 
tes al comunicar información sobre las tendencias generales en un ecosistema. Estos índices compuestos deben mantener la suficiente simplicidad para que el significado de los cambios en el índice pueda ser entendido intuitivamente. Existen algunas propuestas de cómo construir estos índices. El "Natural Capital Index" desarrollado en Holanda (Brink et al., 2002) es una sumatoria ponderada de los productos del área que ocupa un ecosistema por su condición. En este caso la condición del ecosistema se mide como el cociente entre los niveles poblacionales de un grupo de especies indicadoras y su línea de base. Otra propuesta es la del "Biodiversity Intactness Index" que es similar conceptualmente, con la diferencia de que los distintos ecosistemas son ponderados según su riqueza de especies y la población de especies es estimada para cada uso del suelo existente en cada ecosistema (Scholes y Biggs, 2005).

\section{Carbono en el suelo}

La materia orgánica del suelo (MOS) está altamente correlacionada con la fertilidad, dada su influencia sobre las propiedades físicas y la capacidad de retener y suministrar nutrientes.

La MOS se clasifica según su asociación con el fraccionamiento físico por tamaño entre las partículas del suelo (fracción mineral). Esta clasificación tiene la ventaja de poder vincular más fácilmente la fracción de la MOS referida con diferentes propiedades físicas y químicas del suelo.

La clasificación de la MOS según el fraccionamiento físico puede ser por tamizado, densitometría o sedimentación. Considerando al fraccionamiento por tamizado propuesto por Cambardella y Elliot (1992):

- Materia Orgánica Particulada (MOP):

$\mathrm{MOP}_{200}$ - asociada a fracción de suelo de tamaño mayor a $200 \mu \mathrm{m}$

$\mathrm{MOP}_{50}$ - asociada a fracción de suelo de tamaño entre 50 y $200 \mu \mathrm{m}$

- Materia Orgánica asociada a la fracción mineral del suelo (MOAM)

MOAM- asociada a fracción de suelo de tamaño menor a $50 \mu \mathrm{m}$
Puede considerarse que cuanto mayor es el tamaño de la MOP mayor será su labilidad o facilidad de ser químicamente descompuesta por los microorganismos, por lo que esta fracción juega un papel importante en el ciclo de nutrientes del suelo y en el mantenimiento de energía para la actividad microbiana.

Cuanto menor es el tamaño de fraccionamiento, la asociación con las fracciones minerales del suelo es mayor, teniendo más incidencia en la estructura del suelo. En los últimos años se ha comenzado a utilizar esta clasificación de la MOS como indicador de cambios en corto plazo debido a diferencias de manejo del suelo. En términos generales, se puede asumir que los mayores cambios ocurren en la fracción de MOP y el contenido en suelo se ha vuelto un indicador más sensible que la medición de la MOS como único valor. Su valor como indicador, además de por las variaciones que presenta, radica en su vinculación con parámetros físicos vinculados con la estructura del suelo.

\section{Calidad de agua}

La calidad del agua se puede ver afectada por los distintos usos del suelo que se practican debido a la actividad económica que allí se desarrolla. Los programas de monitoreo de calidad de agua generalmente incluyen la determinación de una gran cantidad de variables físicas y químicas en diferentes sitios y, en función de los valores obtenidos, se realiza una estimación del estado del recurso hídrico (Chapman, 1992).

El análisis de los parámetros físicos y químicos por separado dan información valiosa, pero pueden tener restricciones para evaluar la situación de calidad de agua a nivel de cuencas (Debels et al., 2005). Por esta razón, varios autores han trabajado sobre Índices de Calidad de Agua (ICA) con el objetivo de obtener valores numéricos de un estado de situación que combina varias medidas realizadas. Los índices son una expresión más simple de parámetros de distinta complejidad y expresan una medida de la calidad del agua; un número, un rango o una definición. 
En el caso del proyecto se seleccionaron aquellos que poseen claras referencias de afección de la calidad de agua en cuanto a interferir con comunidades de organismos vivos. Estos son concentración de fósforo $(P)$, concentración de nitrógeno $(\mathrm{N})$, turbidez, sales totales disueltas y oxígeno disuelto (OD).

El fósforo es un elemento natural que puede estar en rocas y materia orgánica, pero también puede provenir del uso de fertilizantes y otros químicos, por lo que puede ser hallado en altas concentraciones en áreas con actividad humana.

Los contenidos de nitratos son importantes, ya que las fuentes de contaminación se asocian principalmente a actividades agrícolas y ganaderas (fertilización, estiércol), así como también a actividades agroindustriales (Vega, 2009).

La turbidez es una medida indirecta del arrastre de partículas hacia los cursos de agua por efecto de la erosión.

La concentración de oxígeno disuelto representa la cantidad de oxígeno disponible para el metabolismo/respiración de los organismos acuáticos (Kaurish y Younos, 2007). Por lo tanto, es un indicador de la capacidad de un cuerpo de agua de soportar vida acuática. Además, sus valores están directamente relacionados con el tamaño de las poblaciones y las comunidades de bacterias aeróbicas (Gyawali et al., 2013).

La evaluación ambiental de aguas superficiales se realiza a través de mediciones con un analizador multiparamétrico, determinando conductividad, turbidez, $\mathrm{pH}, \mathrm{T}^{\circ} \mathrm{C}, \mathrm{NH}_{4}$, $\mathrm{NO}_{3}, \mathrm{P}$ y $\mathrm{O}_{2}$. Las mediciones se realizan en cursos de agua de primer y segundo orden en dos puntos, a la entrada y la salida de potreros de referencia. A partir de esto, se construye un Índice de Calidad de Agua (ICA) para evaluar los cambios en la calidad de agua a través de los parámetros físico-químicos. El cálculo del índice se realiza a través de la siguiente fórmula:

$$
\text { ICA }=\sum \mathrm{n}_{\mathrm{i}=1}\left(C_{i} P_{i}\right) / \sum \mathrm{n}_{\mathrm{i}=1} P_{i}
$$

donde $\mathrm{n}$ representa el número total de variables, $C_{i}$ es el valor asignado a la variable i de la normalización y $P_{i}$ es un valor que va en- tre 1 y 4 , donde se le asigna 4 a aquellas variables de mayor importancia para la vida acuática (ej. oxígeno disuelto).

\section{Biodiversidad}

La biodiversidad es responsable de gran cantidad de procesos ecosistémicos y los cambios en su composición pueden afectar drásticamente el funcionamiento del ecosistema y su capacidad de proveer servicios (Pereira y David Cooper, 2006). La evaluación de estas metas depende en gran medida de los indicadores de biodiversidad que resumen la evolución observada en los ecosistemas (Gregory et al., 2005).

\section{Biomasa y diversidad de plantas herbáceas}

Las razones para elegir la comunidad de plantas herbáceas como grupo indicador son (i) las plantas son los principales productores primarios en ecosistemas terrestres y por lo tanto fundamentales para el funcionamiento ecosistémico, (ii) la diversidad de plantas es uno de los mejores predictores disponibles de la diversidad de otros taxones (Sala y Zaitsev, 2005), (iii) es un grupo del que se cuenta con avanzado conocimiento general, sobre todo de algunos subconjuntos (Lughadha et al., 2005).

El crecimiento se determinó mediante la técnica del rebrote utilizando tres jaulas móviles de $1 \mathrm{~m}^{2}$ por potrero, instaladas con homogenización previa de la vegetación a 1 $\mathrm{cm}$ de altura. La cosecha del rebrote se realizó cada 45-55 días en dos cuadros de 0,5 $x 0,2 \mathrm{~m}$ con tijeras de esquilar y una altura de rastrojo de $1 \mathrm{~cm}$.

Paralelamente, se realizaron estimaciones de eficiencia en el uso de la radiación (EUR) a través de medidas de absorción de radiación obtenidas por teledetección. El coeficiente EUR se estimó a partir de la radiación absoluta absorbida por la planta (APAR) y la productividad primaria neta aérea (PPNA) obtenida de los cortes de biomasa siguiendo la ecuación de Monteith (1972):

$$
E U R=P P N A /(A P A R \times 10)
$$


La APAR se calculó como producto de la fracción de la radiación fotosintéticamente activa absorbida por las plantas (fPAR), obtenida a partir de imágenes sintéticas de índice de vegetación mejorado (MODIS, resolución espacial 250x250m, U.S Geological Survey), y la radiación fotosintéticamente activa (PAR), calculada a partir de la radiación relevada en las estaciones agroclimáticas de INIA. Se utilizó la siguiente ecuación: APAR $=$ FPAR $\times$ PAR

La composición florística se estimó mediante la cobertura/abundancia de las especies utilizando la escala de Braun-Blanquet modificada por Lezama et al. (2006). En el caso de las Ciperáceas no se llegó al nivel de especie por lo que las determinaciones se realizaron a nivel de familia. Los registros se realizaron en un cuadro de $1 \mathrm{~m}^{2}$ dentro de la jaula cada vez que se realizaron cortes para determinar crecimiento y en cinco cuadros de tamaño similar fuera de la jaula, en otoño y primavera, para considerar posibles cambios estacionales.

En todos los casos se tomó como foco de estudio dos potreros por productor. Esos potreros representaban una situación histórica de manejo controlado del pastoreo (habitualmente potreros de invernada) y la contraparte en potreros llamados de manejo tradicional, en los cuales hubo pastoreo continuo en altas cargas.

\section{Aves}

Se utilizó la comunidad de aves como indicadora de la biodiversidad presente en los predios dado que son un grupo de organismos: (i) fácil de detectar en censos ya que muchas especies son diurnas, relativamente conspicuas y/o vocalizan frecuentemente; (ii) es un grupo del que, relativamente, se cuenta con un buen conocimiento general (ej. taxonómico, biológico, poblacional biogeográfico); (iii) presenta diversidad de especies y su biología, incluyendo muchos migrantes que son sensibles a diversos cambios ambientales; (iv) presenta especies que se ubican en todo el rango de niveles tróficos y por lo tanto pueden ser sensibles o causantes de cambios a otros niveles de la red trófica; (v) responden rápido a cambios en la estructura física del ambiente; vi) generan conexión y significado para las personas y sus vidas (Gibbons y Gregory, 2006; Butler et al., 2010).

Los indicadores construidos a partir de la estructura y/o dinámica de la comunidad de aves son muy utilizados en el mundo, en especial los índices compuestos de poblaciones de aves para evaluar la salud o sustentabilidad de agroecosistemas (Vickery et al., 2004). Su aplicabilidad para monitorear la salud de los ecosistemas se demuestra por la inclusión de un indicador basado en la tendencia poblacional de aves entre los principales indicadores de desarrollo sustentable del gobierno del Reino Unido y entre los indicadores estructurales y de sustentabilidad de la Unión Europea.

Una de las limitantes de usar a las aves como indicadores de la biodiversidad es que son el grupo menos amenazado para su conservación dentro de los vertebrados, lo que podría sugerir que son menos sensibles a los cambios antropogénicos que otros grupos, dada su alta movilidad. Sin embargo, estudios recientes han demostrado el valor de las especies comunes como indicadores (Butler et al., 2010) y para brindar servicios ecosistémicos, y por lo tanto, la importancia de conservar sus niveles poblacionales.

\section{Arañas}

Los artrópodos terrestres son indicadores biológicos convenientes debido a su sensibilidad y respuesta rápida a los cambios en su entorno. Además, pueden ser estudiados por medio de relevamientos simples y económicos (Gardner et al., 2008). Las arañas son los más abundantes artrópodos depredadores generalistas en la mayoría de los ecosistemas terrestres y ocupan una posición clave en las cadenas tróficas al regular las poblaciones de herbívoros (Lawrence y Wise, 2000; Ferris et al., 2000). Las arañas han sido utilizadas como indicadores de la diversidad de invertebrados (Gravesen, 2000) debido a su posición de predador en las redes tróficas y su relación con la estructura de la vegetación, puede estar relacionado con 
los cambios producidos en los ambientes por las decisiones de manejo productivo, estando involucradas en importantes procesos biológicos en la mayoría de los hábitats. Además del hecho de que este grupo es poco conocido en las praderas uruguayas, este estudio trató de adquirir conocimientos y comparar la estructura y composición de la fauna de arañas de pastizales naturales en dos zonas cercanas bajo un manejo diferencial del ganado.

Batáry et al. (2012) encontraron que los patrones de diversidad de organismos se ven afectados tanto por la gestión local, el tipo del agroecosistema y la posición dentro del campo, como por la intensidad de manejo. En este estudio la riqueza de arañas cazadoras disminuyó con el porcentaje de cobertura de agricultura intensiva. En contrapartida, las áreas con disminución de la productividad, por lo general las que son de menor intensidad de manejo, son a menudo las que más contribuyen a la biodiversidad dentro del paisaje agrícola (Downie et al., 1999).

Para campo natural en Uruguay, Laborda et al. (2013) encontraron que la abundancia y riqueza de especies obtenida alcanzó valores significativos si se comparan con otros estudios realizados en el país, tales como Pérez-Miles et al. (1999) y Costa et al. (1991). Por lo tanto, la diversidad de arañas en el pastizal natural muestra niveles relativamente altos en comparación con otros tipos de hábitat en el país. Entre los gremios que se encuentran, es notable destacar el predominio de las familias Araneidae y Lycosidae en la comunidad de arañas de pastizales.

\section{II.2.2. Integridad Ecosistémica}

Para el análisis de este componente se ha producido una herramienta específica que denominamos Indice de Integridad Ecosistémica -IIE- (Blumetto et al., 2016). La apli- cación del IIE es un análisis cuali-cuantitativo que implica la comparación del estado actual con un estado óptimo esperable para el ecosistema evaluado. Para ello se realizó una recorrida general del establecimiento evaluando el estado inicial y al final del proyecto. Este índice se construye por la suma de cinco calificaciones: estado de la formación vegetal, composición de especies del ecosistema, estructura física de la vegetación, conservación de suelos y estado de los cursos de agua. Se realiza para cada potrero y luego se pondera por el área que ocupan en el establecimiento.

Para realizar la evaluación se consideran los siguientes criterios:

- Como está el ecosistema respecto al mejor estado posible bajo el mismo uso.

- Puntos críticos, para cada productor, en restablecimiento de ecosistemas.

- Los índices de distintos establecimientos pueden ser comparados, aunque se encuentren en distintas bio-regiones.

- Los valores del IIE pueden compararse, a nivel del mismo establecimiento, en distintos momentos en el tiempo ya sea a nivel global o por potreros.

Se determinan los valores de cada potrero del predio y un valor general que se calcula prorrateando la contribución de cada área de potrero como se muestra en la siguiente ecuación:

$$
E I I=\sum_{\mathrm{n}=1}^{\mathrm{n}} \frac{\left(S t_{i}+S p_{i}+S o_{i}+R z_{i}\right) P A_{i}}{4 F A}
$$

donde, $S t_{i}=$ valor de la puntuación de la estructura de la vegetación del potrero i, $S p_{i}=$ valor de la puntuación de la presencia de especies del potrero i, So $=$ valor de la puntuación de suelo para el potrero i, $R z_{i}=$ valor de la puntuación de la zona riparia de cursos de agua del potrero i, $\mathrm{PA} i=$ área del potrero i y $F A$ = área total del establecimiento. 
Cuadro 1. Resumen de indicadores ambientales.

\begin{tabular}{|c|c|c|}
\hline Indicador & Justificación & Forma de registrarlo \\
\hline $\begin{array}{l}\text { Materia orgánica } \\
\text { particulada en el } \\
\text { suelo }\end{array}$ & $\begin{array}{l}\text { Propiedad del suelo que refleja, entre } \\
\text { otras, la capacidad de aportar nutrien- } \\
\text { tes, regular la dinámica del agua en el } \\
\text { perfil, contribuir a la estabilidad de los } \\
\text { agregados del suelo y su resistencia } \\
\text { a la erosión. }\end{array}$ & $\begin{array}{l}\text { Muestra compuesta de suelo } \\
0-3 \mathrm{~cm} \text { y de } 3-6 \mathrm{~cm} \text { de pro- } \\
\text { fundidad, en tres muestras } \\
\text { por potrero de referencia. } \\
\text { Frecuencia: anual en otoño. }\end{array}$ \\
\hline $\begin{array}{l}\text { Carbono orgánico } \\
\text { oxidable por per- } \\
\text { manganato }\end{array}$ & $\begin{array}{l}\text { Fracción de materia orgánica más } \\
\text { sensible a los cambios de manejo en } \\
\text { plazos cortos. }\end{array}$ & $\begin{array}{l}\text { Muestra compuesta de suelo } \\
0-5 \mathrm{~cm} \text { de profundidad, en tres } \\
\text { muestras por potrero de refe- } \\
\text { rencia. }\end{array}$ \\
\hline $\begin{array}{l}\text { ICA: índice de cali- } \\
\text { dad de agua }\end{array}$ & $\begin{array}{l}\text { Es un índice que integra medidas físi- } \\
\text { cas y químicas de aguas superficia- } \\
\text { les. Los valores son poderados de } \\
\text { acuerdo a la relevancia de cada varia- } \\
\text { ble en el mantenimiento de la sanidad } \\
\text { de los ecosistemas acuáticos. }\end{array}$ & $\begin{array}{l}\text { Muestreo estacional en cur- } \\
\text { sos de arroyos o cañadas } \\
\text { como fuentes naturales y } \\
\text { tajamares como reservas } \\
\text { construidas con medidor mul- } \\
\text { tiparamétrico. }\end{array}$ \\
\hline Poblaciones de aves & $\begin{array}{l}\text { Las aves ocupan todo el espectro de } \\
\text { niveles heterótrofos en las redes } \\
\text { tróficas, por lo que son un buen reflejo } \\
\text { de la sanidad general del ecosistema. }\end{array}$ & $\begin{array}{l}\text { Muestreo estacional por } \\
\text { transectas lineales de } 300 \mathrm{~m} \\
\text { con tres repeticiones en cada } \\
\text { manejo dentro del predio ( } 3 \\
\text { por predio). } \\
\text { Se evalúa composición y a- } \\
\text { bundancia relativa de espe- } \\
\text { cies. }\end{array}$ \\
\hline $\begin{array}{l}\text { Comunidad de arác- } \\
\text { nidos de pastizal }\end{array}$ & $\begin{array}{l}\text { Las arañas son predadoras tope entre } \\
\text { los artrópodos y son muy sensibles a } \\
\text { la estructura del tapiz, por lo que per- } \\
\text { miten tener una medida indirecta de } \\
\text { la evolución estructural del campo na- } \\
\text { tural. }\end{array}$ & $\begin{array}{l}\text { Muestreo estacional por se- } \\
\text { gado en potreros de referen- } \\
\text { cia. Se toman } 10 \text { muestras } \\
\text { por potrero compuestas por } \\
20 \text { pasadas rasas sobre la } \\
\text { pastura con red entomológica } \\
\text { de } 30 \mathrm{~cm} \text { de diámetro. }\end{array}$ \\
\hline \multirow[t]{2}{*}{$\begin{array}{l}\text { Comunidades de } \\
\text { herbáceas }\end{array}$} & $\begin{array}{l}\text { Es la comunidad soporte de gran par- } \\
\text { te de la fauna silvestre y del ganado } \\
\text { doméstico. Responsable de gran par- } \\
\text { te de los servicios ecosistémicos (pro- } \\
\text { ductividad primaria, control de erosión, } \\
\text { formación de suelo, retención de car- } \\
\text { bono, etc.). }\end{array}$ & Método Braun-Blanquet. \\
\hline & $\begin{array}{l}\text { Realiza una evaluación rápida sensi- } \\
\text { ble al manejo relacionada a caracte- } \\
\text { rísticas de resiliencia y estabilidad } \\
\text { ecosistémica. }\end{array}$ & $\begin{array}{l}\text { Aplicación del IIE al comien- } \\
\text { zo y final del proyecto }\end{array}$ \\
\hline
\end{tabular}




\section{II.2.3. Resultados}

\section{Carbono orgánico del suelo}

Como lo muestra el Cuadro 2, el carbono orgánico (CO) total se encuentra en niveles altos en todos los casos, y el análisis de las diferentes fracciones muestra que la mayor parte de ese carbono se encuentra ligado a la fracción mineral (MOAM). Sin embargo, en el caso del productor 2 aparecen dos particularidades, la primera es un valor más alto del CO total y la segunda es la proporción relativamente alta de la fracción $>212 \mu \mathrm{m}$ (Figura 1). En este último caso se trata de la materia orgánica menos estable y resultante de la más reciente incorporación al suelo, lo cual podría atribuirse en este caso a una alta carga animal que sobrecarga el pastoreo sobre el área de suelos profundos, produciendo una acumulación de deyecciones y aumento de la materia orgánica fresca en superficie. Esto también puede constatarse con la drástica disminución del contenido entre los primeros $3 \mathrm{~cm}$ y los siguientes $3 \mathrm{~cm}$ de profundidad de suelo.

Cuadro 2. Contenido de carbono orgánico g/100g de suelo en las diferentes fracciones del suelo.

\begin{tabular}{|lccccc|}
\hline & Profundidad & Total & $\begin{array}{c}\text { MOP } \\
\mathbf{2} \mathbf{2 1 2} \boldsymbol{\mu m}\end{array}$ & $\begin{array}{c}\text { MOP } \\
\mathbf{2 1 2 - 5 3} \boldsymbol{\mu m}\end{array}$ & $\begin{array}{c}\text { MOAM } \\
<\mathbf{5 3} \boldsymbol{\mu m}\end{array}$ \\
\hline Productor 1 & $0-3$ & 8,27 & 1,96 & 1,16 & 5,15 \\
Total & $3-6$ & 6,05 & 0,87 & 0,62 & 4,56 \\
Productor 2 & & $\mathbf{7 , 1 6}$ & $\mathbf{1 , 4 1}$ & $\mathbf{0 , 8 9}$ & $\mathbf{4 , 8 6}$ \\
& $0-3$ & 11,27 & 3,97 & 1,65 & 5,65 \\
Total & $3-6$ & 7,12 & 1,56 & 0,82 & 4,75 \\
& & $\mathbf{9 , 1 9}$ & $\mathbf{2 , 7 6}$ & $\mathbf{1 , 2 3}$ & $\mathbf{5 , 2 0}$ \\
Productor 3 & $0-3$ & $\mathbf{7 , 6 9}$ & $\mathbf{1 , 8 4}$ & 1,08 & 4,78 \\
Total & $3-6$ & 5,27 & 0,79 & 0,52 & 3,96 \\
& & $\mathbf{6 , 4 8}$ & $\mathbf{1 , 3 2}$ & $\mathbf{0 , 8 0}$ & $\mathbf{4 , 3 7}$ \\
\hline
\end{tabular}

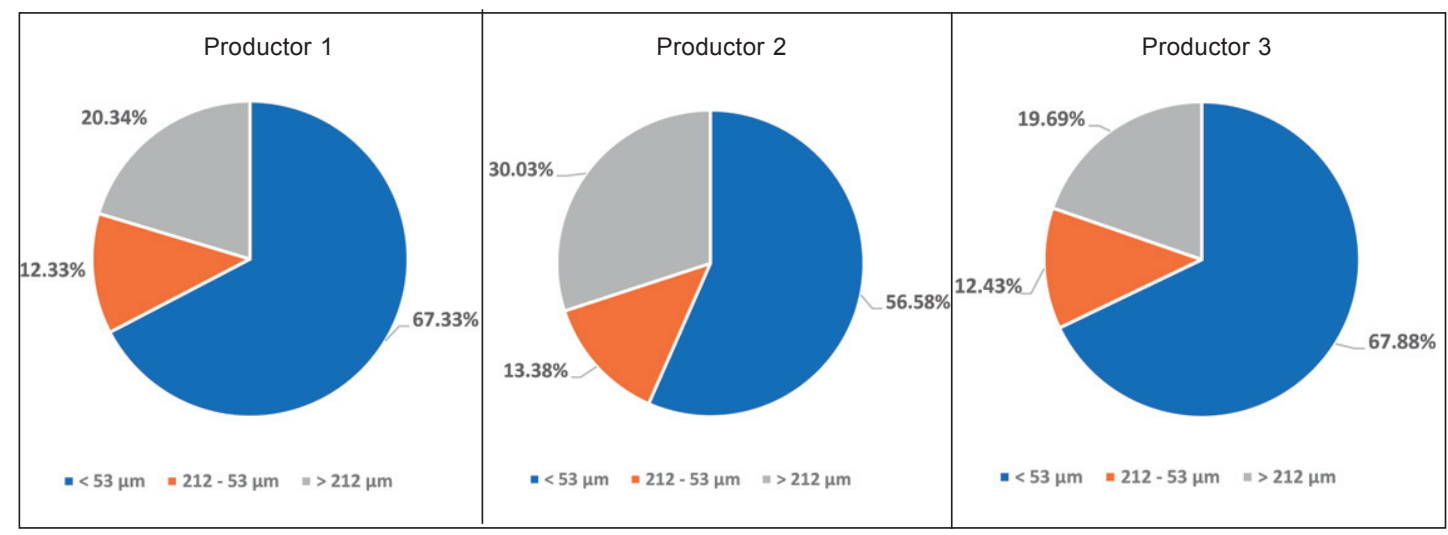

Figura 1. Contenido de carbono orgánico del suelo como \% del total para las diferentes fracciones para el promedio de 0 a $6 \mathrm{~cm}$. 
En el caso del carbono oxidable por permanganato, también llamado carbono activo, fue seleccionado como una medida de una fracción en proceso actual de incorporación al suelo. En los casos de estudio no se encontraron diferencias en esta variable para los tres años de proyecto, por lo cual no tenemos evidencia de que el rediseño operado en los sistemas haya influido en la tasa de incorporación de carbono al suelo, al menos en el breve plazo del estudio.

\section{Calidad de agua}

En el Cuadro 3 se presenta el índice de calidad de agua (ICA) resultante de la caracterización inicial para cañadas de los establecimientos involucrados en el proyecto.

Cuadro 3. Índice de calidad de agua en los tres predios.

\begin{tabular}{|c|c|}
\hline Predios & ICA \\
\hline Productor 1 & $.73,3$ \\
\hline Productor 2 & .72 \\
\hline Productor 3 & $.77,3$ \\
\hline
\end{tabular}

Los valores del índice obtenidos son considerados satisfactorios y no representarían problemas de calidad de agua en estos establecimientos.

\section{Composición florística}

Se registraron en total 157 especies diferentes de las cuales el $38 \%$ eran gramíneas, $8 \%$ leguminosas, $52 \%$ hierbas enanas y $3 \%$ especies arbustivas (Cuadro 4). Dentro de las gramíneas, el $35 \%$ eran especies de ciclo invernal y el $65 \%$ estivales.

No se encontraron diferencias significativas entre los manejos ganaderos en cuanto a la relación especies invernales/estivales.

Al inicio del estudio (primavera 2013-verano 2014), los potreros con manejo controlado tuvieron una mayor riqueza, un mayor índice de Shannon-Wiener y un menor valor del índice de Simpson que los potreros con manejo ganadero tradicional ( 60 vs $53 ; 2,70$ vs 2,$41 ; 0,12$ vs 0,16$)$. Esto implica que, en los potreros con manejo controlado, la comunidad vegetal de suelos profundos de Basalto tenía una mayor cantidad de especies, distribuidas de forma más equitativa y con un menor número de especies dominantes que en los potreros con manejo ganadero tradicional. Durante el verano 2015, es decir al final del estudio, no hubo diferencias en riqueza, índice de Shannon-Wiener e índice Simpson entre los potreros con manejo ganadero controlado y tradicional por lo que las diferencias habían desaparecido. Teniendo en cuenta que a los potreros con manejo tradicional se les aplicó un cambio de manejo a lo largo del proyecto, orientándolos hacia un manejo más controlado, los resultados muestran que la composición florística de los dos manejos se equiparó.

La disimilitud en la composición florística de la comunidad vegetal fue estadísticamente significativa, $p<0,05$ (Cuadro 5). Las especies que contribuyeron en una mayor proporción a esa disimilitud fueron: Paspalum notatum Flüggé, Axonopus fissifolius (Raddi) Kuhlm y la familia Ciperáceas para todos los

Cuadro 4. Número de especies registradas.

\begin{tabular}{|lcr|}
\hline Grupo funcional $^{*}$ & $\mathbf{N}^{\circ}$ de especies & $\%$ \\
\hline Gramíneas invernales & 21 & 13 \\
Gramíneas estivales & 39 & 25 \\
Leguminosas & 12 & 8 \\
Hierbas enanas & 81 & 52 \\
Arbustivas & 4 & 3 \\
\hline Total & $\mathbf{1 5 7}$ & $\mathbf{1 0 0}$ \\
\hline
\end{tabular}

* Las especies graminoides se registraron como la familia Ciperáceas. 
Cuadro 5. Análisis de similitud de la composición florística de los manejos ganaderos según predio.

\begin{tabular}{|cccl|}
\hline Predio & $\begin{array}{c}\text { Disimilitud } \\
\text { promedio (\%) }\end{array}$ & $\begin{array}{c}\text { Significancia } \\
\text { estadística }\end{array}$ & $\begin{array}{c}\text { Especies con mayor contribución a la } \\
\text { disimilitud }\end{array}$ \\
\hline \hline 1 & 61,8 & 0,0001 & Ciperáceas, $P$. notatum, Ax. fissifolius \\
2 & 45,3 & N.S. & Ciperáceas, $P$. notatum, Ax. fissifolius \\
3 & 55,7 & 0,0001 & Ciperáceas, $P$. notatum, Ax. fissifolius \\
\hline
\end{tabular}

predios. Las dos primeras son especies estivales y estoloníferas por lo que están altamente adaptadas al pastoreo y predominan en campos naturales sometidos a pastoreos intensos (Rosengurtt, 1946; Millot et al., 1987). La proporción tan alta de las Ciperáceas estaría asociada a la elevada humedad del suelo durante el período del estudio, dada por las precipitaciones que se registraron, que estuvieron por encima de la media histórica.

Los componentes principales de la varianza de la composición florística agrupada según el tipo productivo explicaron el $83 \%$ de la variación total. En la primavera 2013-verano 2014 , la composición florística de los potreros con manejo ganadero controlado estaba compuesta por especies ordinarias-duras (OD) como Sporobolus indicus y malezas de campo sucio (MCS) como Baccharis coridifolia y Baccharis trimera, mientras que al final del estudio en la primavera 2014-verano 2015 se caracterizó por la presencia de especies duras (D) como Andropogon lateralis y Stipa charruana, finas (F) como Paspalum dilatatum, Poa lanigera y la briófita musgo. En estos potreros, el mantener un manejo ganadero controlado en el tiempo favoreció un aumento en la cobertura de especies finas pero también de especies de tipo duro. Esto concuerda con Rosengurtt (1943) que indica que los manejos del pastoreo aliviados favorecen tanto a las especies tiernas y finas como a las ordinarias y duras que generan el endurecimiento del campo.

En los potreros con manejo ganadero tradicional, la composición florística fue similar al inicio y al final del estudio, y se caracterizó por la presencia de especies ordinarias (O) como Paspalum plicatulum, Eragrostis lugens y Schizachyrium spicatum y especies tiernas-ordinarias (TO) como Piptochaetium montevidensis, Andropogon ternatus y Aristida uruguayensis (Figura 2). La presencia de estos grupos de especies implica co-

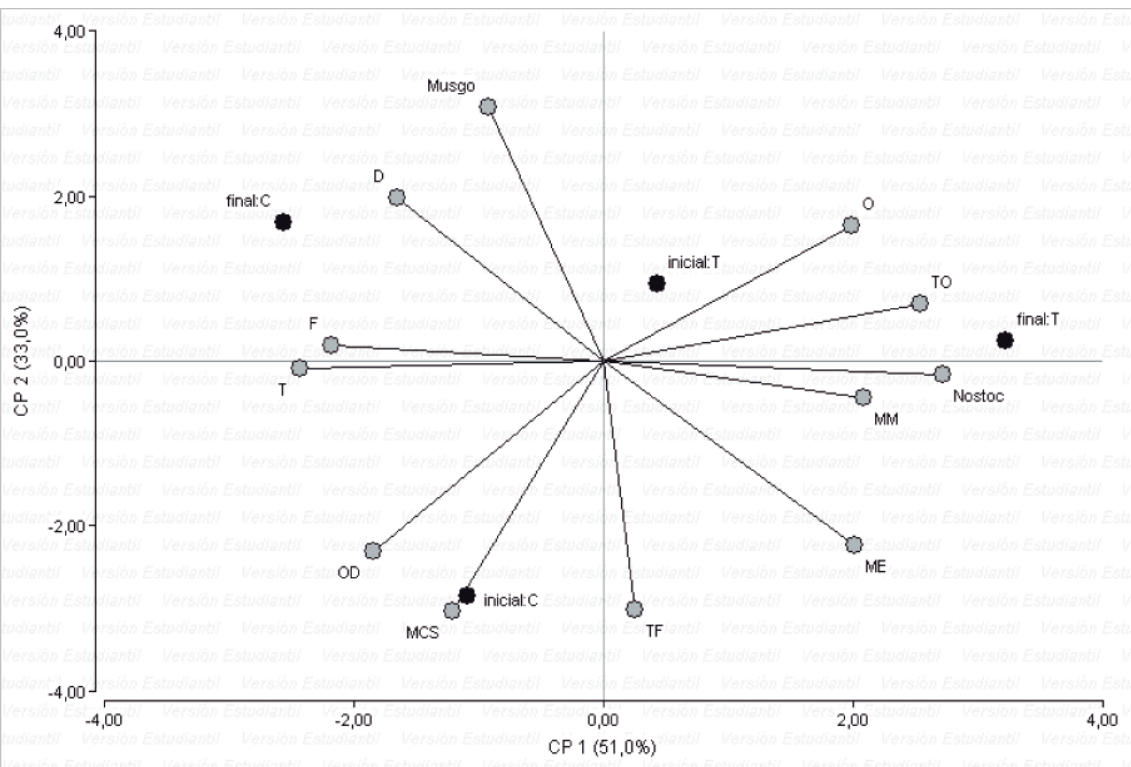

Figura 2. Análisis de componentes principales según grupos productivos. 
munidades vegetales de calidad forrajera media a baja y con una gran acumulación de material pajizo y seco (Rosengurtt, 1946). Si bien no hubo cambios claros en la composición florística del potrero con manejo tradicional durante el estudio, es posible observar una tendencia hacia una composición florística con mayor presencia de especies tiernas y finas.

Se encontraron tres especies indicadoras del manejo ganadero con valor superior a 40\%: Mnesithea selloana (Hackel) (60\%),
Paspalum dilatatum (Poir) $(45,8 \%)$ y Sporobolus indicus (L.) R.Br. (42,3\%). La cobertura de las tres especies indicadoras fue mayor en los potreros con manejo controlado que en los que tuvieron un manejo tradicional. Esto demuestra que el manejo del pastoreo controlado favorece la presencia de especies cespitosas de tipo productivo tierno y fino muy apetecidas y castigadas por el ganado con pastoreos tradicionales. Sin embargo, también favorece la presencia de especies cespitosas ordinarias y duras.

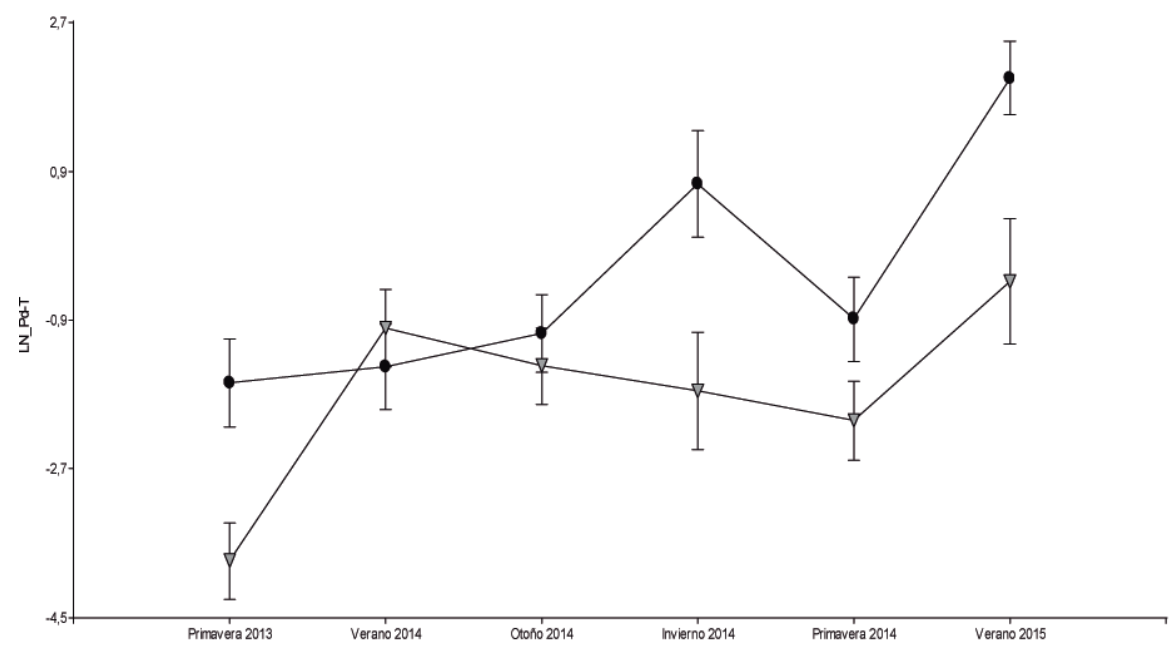

Figura 3. Comparación de medias de la cobertura de Paspalum dilatatum; círculos: manejo ganadero controlado; triángulos: manejo ganadero tradicional.

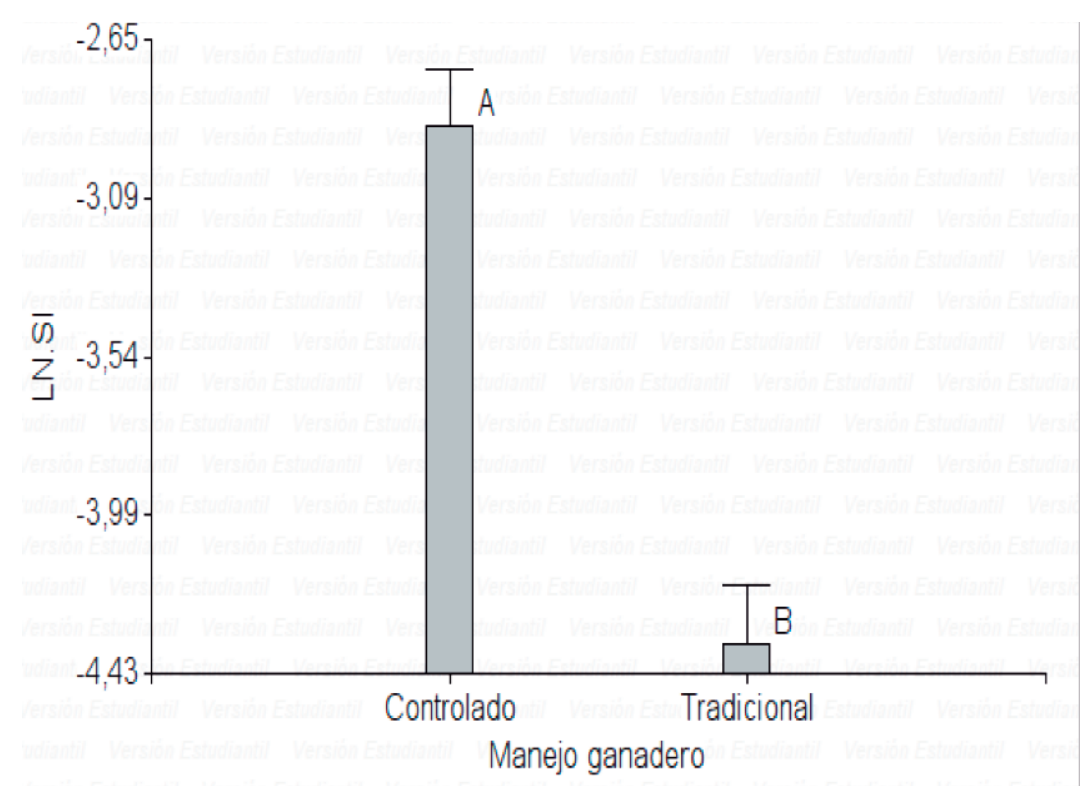

Figura 4. Comparación de medias de la cobertura de Sporobolus indicus; letras diferentes indican diferencias estadísticamente significativas. 


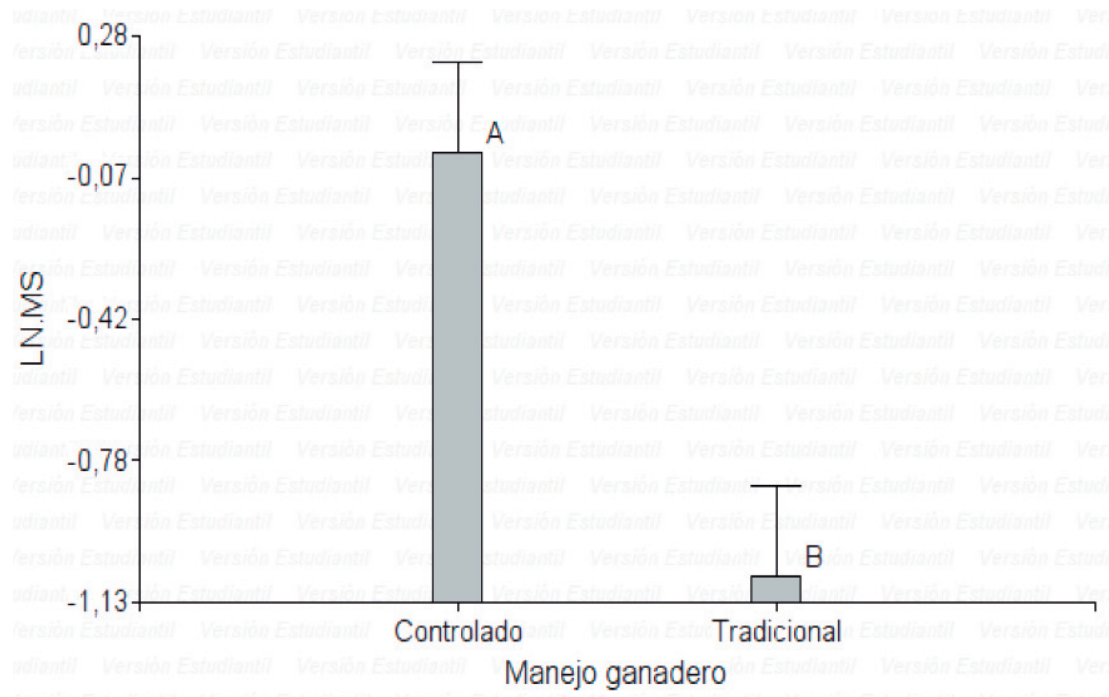

Figura 5. Comparación de medias de la cobertura de Mnesithea selloana; letras diferentes indican diferencias estadísticamente significativas.

En los siguientes gráficos se presentan las coberturas de $P$. dilatatum (Figura 3 ), $S$. indicus (Figura 4) y M. selloana (Figura 5 ). La cobertura de $S$. indicus y $M$. selloana tuvieron una variación estacional pero no fue diferente significativamente $(p<0,05)$ entre el manejo controlado y el tradicional.

\section{Producción de biomasa}

En el total del período en estudio, la pastura de los potreros con manejo ganadero controlado tuvo en promedio una tasa de crecimiento mayor $(p<0,05)$ que la de los potreros con manejo tradicional (15,6 vs. $14,6 \mathrm{~kg}$ $\mathrm{MS} / \mathrm{ha} / \mathrm{día}$, Cuadro 6). Estos valores concuerdan con los obtenidos por Berreta y Bemhaja (1997) en campos naturales sobre suelos profundos de Basalto en años similares a los del estudio, con excesos hídricos. Sin embargo, ya al cabo del segundo año las tasas de crecimiento promedio no fueron diferentes $(p>0,05)$. Esto implicaría que el cambio de manejo en el potrero con manejo tradicional permitió aumentar la producción de forraje de la comunidad vegetal de suelos profundos.

\section{Estimación del coeficiente EUR}

El coeficiente EUR fue un 44\% mayor en los potreros con manejo ganadero controlado que en los que tuvieron un manejo tradicional (Cuadro 7).

Durante el período en estudio, la altura promedio del tapiz fue mayor en los potreros con manejo controlado que en los potreros con manejo tradicional $(6,36$ vs. $5,02 \mathrm{~cm})$. Esta variable explica los mayores valores de EUR en los potreros con manejo ganadero controlado, ya que existe una relación lineal positiva entre el EUR y la altura del tapiz $Y=0,32+0,01 x$ aunque con un $R^{2}$ muy bajo $(0,08)$, lo que indica una gran dispersión.

Cuadro 6. Tasas de crecimiento promedio ( \pm error estándar) de la comunidad vegetal de suelos profundos de Basalto según manejo ganadero.

\begin{tabular}{|ccc|}
\hline Predio & Controlado (kgMS/ha/día) & Tradicional (kgMS/ha/día) \\
\hline \hline 1 & $16,3 \pm 1,64$ & $14,2 \pm 1,58$ \\
2 & $13,4 \pm 1,04$ & $12,6 \pm 1,02$ \\
3 & $17,2 \pm 1,67$ & $17,0 \pm 1,76$ \\
\hline Media & $\mathbf{1 5 , 6}$ & $\mathbf{1 4 , 6}$ \\
\hline
\end{tabular}


Cuadro 7. Coeficientes EUR según predio y manejo ganadero.

\begin{tabular}{|ccc|}
\hline Predio & Controlado $(\mathbf{g} / \mathbf{M J})$ & Tradicional $\mathbf{( g / M J )}$ \\
\hline 1 & 0,52 & 0,41 \\
2 & 0,39 & 0,11 \\
3 & 0,56 & 0,47 \\
\hline Media & $\mathbf{0 , 4 9} \mathbf{a}$ & $\mathbf{0 , 3 3} \mathbf{~ b}$ \\
\hline
\end{tabular}

Letras diferentes indican diferencias estadísticamente significativas.

\section{Fauna asociada}

\section{Aves}

Los monitoreos de aves realizados revelaron la presencia de 121 especies que, de forma permanente o temporal, utilizan los ambientes comprendidos dentro de los establecimientos, incluyendo las transectas realizadas en potreros de referencia y aquellas registradas fuera de transecta. De estas especies, 11 son consideradas prioritarias para la conservación en Uruguay (Cuadro 8).

Analizando la composición de especies del ensamble de aves de la región es posible encontrar un balance entre las funciones ecológicas de las mismas. Entre las especies registradas existen generalistas (viven en varios ambientes) y otras que son especialistas y viven solo en determinados ambientes, ej.: espejos de agua, montes o vegetación de bañados. Otra forma de clasifi- car las especies presentes es por sus fuentes alimenticias, conocidos como gremios, donde se destaca la presencia de especies en todos los gremios, lo cual resulta un buen indicador de salud ambiental y la gran riqueza de especies insectívoras, que refuerza el valor de las aves como controladores biológicos de las poblaciones de insectos. A la interna de cada establecimiento es notorio que existen diferencias entre potreros como puede verse en el análisis de rarefacción presentado en la Figura 6.

La principal variable que afecta la riqueza registrada en los potreros de referencia son los aspectos estructurales, tales como presencia de árboles y cuerpos de agua. El tercer factor estructural que aparece con efecto en la riqueza de cada potrero está relacionado a la homogeneidad del tapiz, situación que es constatable en potreros utilizados con cargas promedios menores con pe-

Cuadro 8. Especies prioritarias para la conservación registradas en el proyecto.

\begin{tabular}{|lccc|}
\hline Nombre científico & Nombre común & Frecuencia & Abundancia \\
\hline Bartramia longicauda & Batitú & ocasional & escaso \\
Cariama cristata & Seriema & habitual & poco común \\
Circus cinereus & Gavilán ceniciento & ocasional & escaso \\
Geranoaetus melanoleucus & Águila movil & habitual & poco común \\
Gnorimopsar chopi & Mirlo charrúa & habitual & poco común \\
Nothura maculosa & Perdíz & habitual & común \\
Oreopholus ruficollis & Chorlo cabezón & ocasional & escaso \\
Paroaria coronata & Cardenal copete rojo & habitual & común \\
Pyrrhura frontalis & Chiripepe & ocasional & escaso \\
Rhea americana & Nandú & habitual & común \\
Rynchotus rufescens & Martineta & habitual & escaso \\
\hline
\end{tabular}




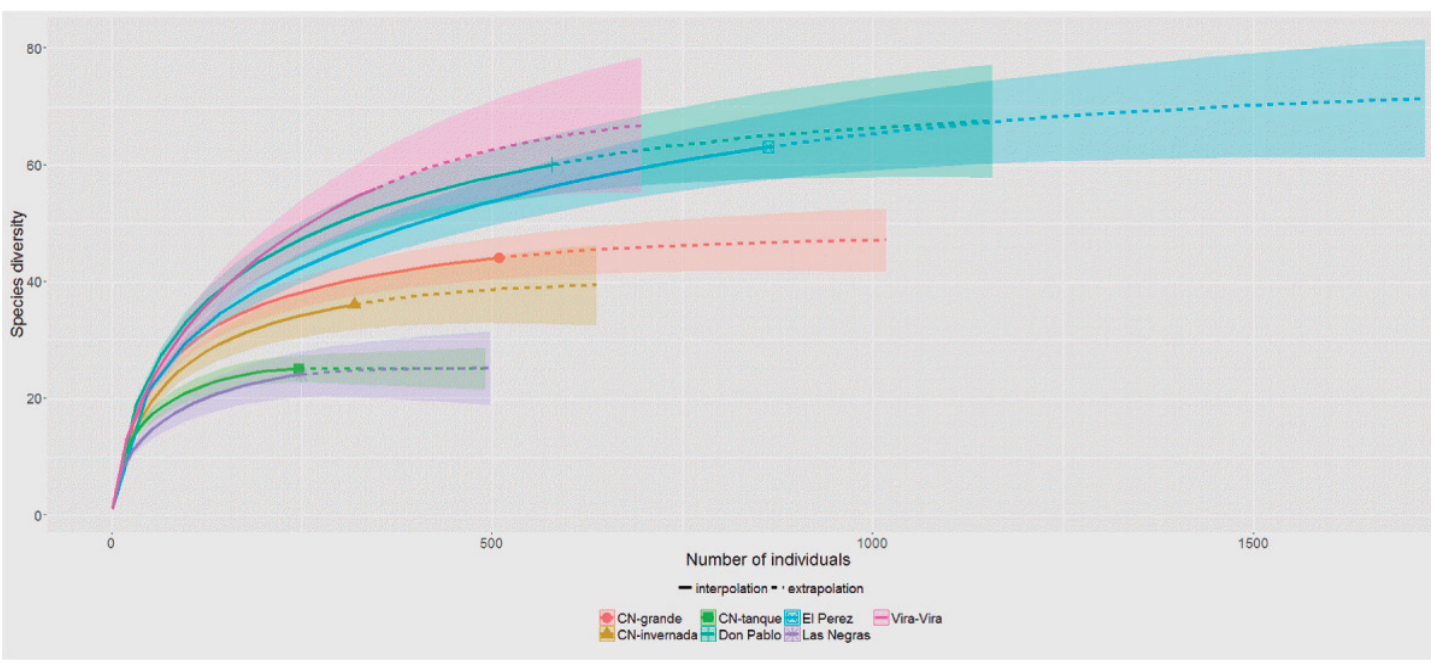

Figura 6. Rarefacción por cobertura y extrapolación (Chao y Jost, 2012) con límites de confianza.

ríodos de exclusión del pastoreo. En estas situaciones, el tapiz suele ser denso, homogéneo y de altura promedio mayor, lo cual reduce el número total de especies. Sin embargo, es en estos potreros donde también aparecen especies en forma exclusiva como Pecho colorado (Sturnella supercilliaris) durante la época reproductiva.

\section{Araneofauna}

El análisis de caracterización de las poblaciones de arañas encontradas en los pre-

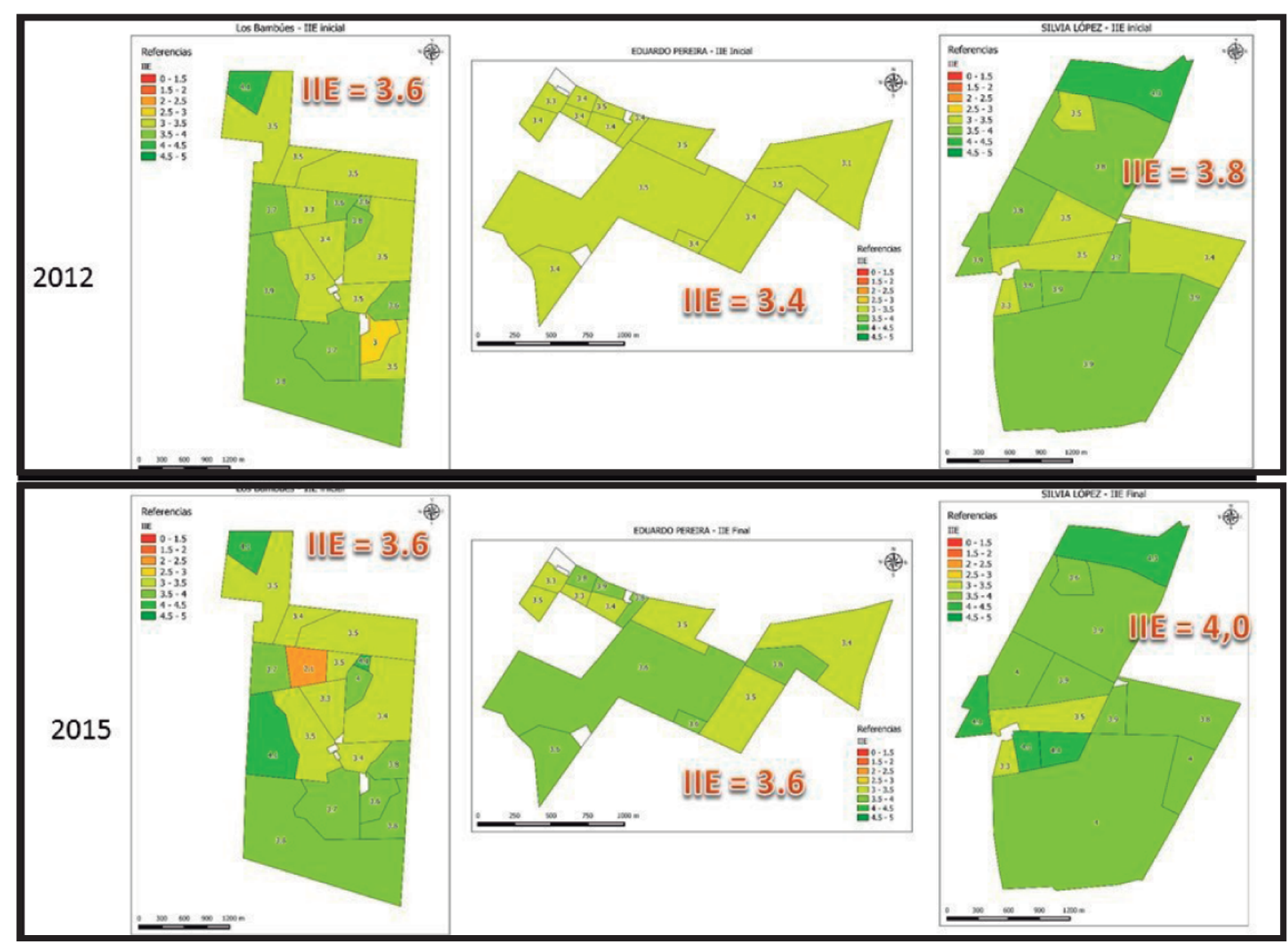

Figura 7. Índices de integridad ecosistémica por potrero y global para los tres establecimientos, al inicio y final del proyecto. 
dios muestra una clara dominancia de las especies tejedoras de telas orbiculares, lo cual es normal para ambientes de pastizal. Se denota una tendencia diferente a la de las aves, donde los potreros cuyo manejo tiende a mantener tapices más densos y altos presenta una mayor diversidad de gremios.

\section{Integridad ecosistémica}

Se aplicó el índice de integridad ecosistémica (IIE), obteniéndose un valor general para cada establecimiento y valores para cada potrero. La Figura 7 presenta los resultados obtenidos al inicio del proyecto y los registrados al cierre del mismo.

Del análisis de la comparación de los resultados de los tres años de proyecto se puede concluir que en todos los casos la estrategia de manejo adoptada como consecuencia del proceso de co-innovación, permitió mantener en buenos niveles este indicador ambiental, observándose mejoras en algunos potreros.

\section{Indicadores para marco MESMIS}

Con el objetivo de incluir en el análisis conjunto de indicadores, se seleccionaron tres indicadores ambientales. Estos fueron seleccionados por considerarse que la me- todología empleada y las variables evaluadas los hacen sensibles a posibles cambios en el plazo analizado.

\section{Índice de Integridad Ecosistémica}

Cuadro 9. IIE por predio y su evolución.

\begin{tabular}{|cccc|}
\hline PRODUCTOR IIE inicial & IIE final & Cambio \\
\hline 1 & 3,6 & 3,6 & 0,0 \\
2 & 3,4 & 3,6 & 0,2 \\
3 & 3,8 & 4,0 & 0,2 \\
\hline
\end{tabular}

\section{Ensamble de Aves}

Riqueza estimada (S) de especies de aves en relación a un potencial de referencia que hemos definido como la riqueza estimada determinada por Tosi et al. (2013) para un establecimiento ganadero de la región de la cuesta basáltica (Cuadro 10).

\section{Carbono activo}

La medida de carbono activo del suelo es considerada la más sensible a cambios en el corto plazo, y se utiliza como potencial el máximo valor encontrado para campos de basalto en el período 2013 a 2015 correspondiente a $1400 \mathrm{mg}$ por $\mathrm{kg}$ de suelo (Cuadro 11).

Cuadro 10. Riqueza de aves por predio y su evolución.

\begin{tabular}{|cccccc|}
\hline PRODUCTOR & $\mathbf{2 0 1 3}$ & $\mathbf{2 0 1 5}$ & Referencia & Inicial (base 5) & Final (base 5) \\
\hline 1 & 51 & 70 & 101 & 2,5 & 3,5 \\
2 & 49 & 49 & 101 & 2,4 & 2,4 \\
3 & 42 & 41 & 101 & 2,1 & 2,1 \\
\hline
\end{tabular}

Cuadro 11. Carbono activo del suelo por predio y su evolución.

\begin{tabular}{|cccccc|}
\hline PRODUCTOR & $\mathbf{2 0 1 3}$ & $\mathbf{2 0 1 5}$ & Referencia & Inicial (base 5) & Final (base 5) \\
\hline 1 & 1063 & 1104 & 1400 & 3,8 & 3,9 \\
2 & 1198 & 1212 & 1400 & 4,3 & 4,3 \\
3 & 1231 & 1155 & 1400 & 4,4 & 4,1 \\
\hline
\end{tabular}




\section{II.3. DIMENSIÓN SOCIAL}

Ing. Agr. (Mag) María Marta Albicette*

En base al análisis de las entrevistas realizadas en Tacuarembó al inicio y al final del proyecto y a reuniones con otros integrantes del equipo de trabajo y con la técnica de campo, se arribó a componentes del área social que dan cuenta del proceso ocurrido durante la implementación del proyecto. Los aspectos sociales que se destacan en este trabajo y los indicadores utilizados fueron seleccionados tomando como base el aprendizaje realizado durante el desarrollo del proyecto "Co-innovando para el desarrollo sostenible de sistemas ganaderos familiares de Rocha - Uruguay", ejecutado por INIA entre 2012 y 2015 (Albicette et al., 2016; Aguerre y Albicette, 2018).

En este capítulo se presentan los tres informes prediales de los productores ganaderos de Tacuarembó vinculados al proyecto de producción familiar del norte. Se detaIlan los componentes que han sido descritos como aspectos sociales destacados o los indicadores valorados para cada productor como forma de describir los procesos sociales ocurridos. La lista de aspectos sociales que se presentan para cada productor son los siguientes:

1. Caracterización de cada productor (descriptivo).

2. Definición de sustentabilidad (descriptivo).

3. Calidad de vida estructural.

4. Calidad de vida subjetiva.

5. Sucesión.

6. Planificación.

7. Aprendizajes y cambios más relevantes.

8. Relación técnico- productor.

La incorporación de tecnología a lo largo de los tres años también fue relevada en este componente, pero se presentó en la dimensión productiva-económica para poder contrastar de mejor manera la evolución productiva con la incorporación tecnológica realizada.

En una primera etapa se caracterizaron los predios considerando diversos aspectos de composición familiar, lugar de residencia, sistema productivo, trayectoria en el campo, tenencia de la tierra, fuerza de trabajo, trabajo extrapredial y otros ingresos. Asimismo, se consensuó con cada productor y su familia la visión de futuro-sustentabilidad, que de acuerdo a Sarandón (2002) es el primer paso para orientar un proceso para evaluar la sustentabilidad. La misma da idea clara de cuál es la visión de futuro que tiene cada familia. Posteriormente se definieron indicadores sociales para evaluar el resultado de los cambios introducidos. Para ello se tomó como base el Marco para la Evaluación de Sistemas de Manejo de Recursos Naturales Incorporando Indicadores de SustentabilidadMESMIS (Masera et al., 2000) relacionados con calidad de vida, sucesión, valoración y uso de la planificación. Los mismos se complementaron con un indicador cualitativo que denominamos "aprendizajes y cambios más relevantes". Además, se destacan las principales características valoradas por los productores de la forma de trabajo y del vínculo con el técnico de campo, aspecto relevante para el logro de resultados.

Los dos primeros aspectos (caracterización y definición de sustentabilidad) se detallan al momento de realizar la descripción de cada caso.

\section{Calidad de vida estructural}

La calidad de vida estructural se presenta con 11 variables cuya escala y valoración fueron:

Vivienda: Muy Mala=1: Rancho de adobe con número de habitaciones insuficiente 
para los integrantes de la familia y baño fuera de la casa. Mala=2: Igual a la categoría anterior con mejoras recientes (techos, paredes, pintura, equipamiento y/o otras mejoras) o vivienda de material precario con número de habitaciones acorde a los integrantes de la familia. Regular=3: Igual a la categoría anterior con mejoras o casa de ladrillo y/o número de habitaciones insuficiente para los integrantes de la familia. Buena=4: Igual a la categoría anterior con mejoras recientes o casa de material con revoque en piso y paredes y número de habitaciones acorde para los integrantes de la familia. Muy buena $=5$ : Igual a la categoría anterior y con mejoras recientes en techos, paredes, pintura, equipamiento $y / o$ otras mejoras.

Energía eléctrica: $\mathrm{No}=0, \mathrm{Sí}=5$.

Acceso a agua potable: Pozo o cachimba fuera de la casa $=1$, Pozo o cachimba con ingreso parcial en la casa $=3$, Pozo o cachimba con cañería en toda la casa $=5$.

Conectividad vial: Muy Mala $=1$, Mala $=2$, Regular=3, Buena=4, Muy buena=5.

Disponibilidad de vehículo: No tiene vehículo $=0$, Tiene moto $=1$, Tiene auto o camioneta $=3$, Tiene más de un vehículo $=5$.

Distancia a centros poblados: A más de $30 \mathrm{~km}=1$, Entre 30 y $10 \mathrm{~km}=3$, Menos de $10 \mathrm{~km}=5$.

Conectividad digital: Ausencia total $=0$, Tiene teléfono fijo $=1$, Tiene teléfono fijo $\mathrm{y} / \mathrm{o}$ celular $=3$, Tiene teléfono fijo y/o celular e internet $=5$.

Acceso a salud básica: No tiene $=0$; Tiene $=5$.

Nivel educativo formal: Primaria incompleta $=1$, Primaria completa $=2$, Secundaria incompleta $=3$, Secundaria completa/ UTU $=4$, Inició nivel terciario $=5$.

Acceso a capacitación: No tiene $=0$, Tiene $=5$.

Nivel de endeudamiento: $>0.15=1$, Entre 0,1 y $0,15=2$, Entre 0,05 y $0,1=3,<0,05$ $0>0=4$ No tiene deuda $=5$.

Calidad de vida estructural integrada: $\leq 20=1$, Entre 20 y $30=2$, Entre 30 y $40=3$, Entre 40 y $50=4, \geq 50=5$.
Las mediciones se realizaron al principio (Año 1) y al final del proyecto (Año 3). En este indicador las variaciones entre años son mínimas coincidiendo con lo observado por Tommasino et al. (2012) y Molina (2009). Las variables que evidenciaron cambios se destacan con un sombreado. Con las variables consideradas se construyó un índice denominado calidad de vida estructural integrada que suma los valores de cada variable, el cual se valora con escala de 1 a 5 .

\section{Calidad de vida subjetiva}

La calidad de vida subjetiva considera la valoración que los individuos hacen de su calidad de vida de acuerdo a sus criterios de satisfacción. Malaquín et al. (2012) destacan que una evaluación eficaz de un sistema ganadero de producción extensivo requiere de la valoración de indicadores productivos, pero también del grado de satisfacción del productor y su familia. El indicador calidad de vida subjetiva se valoró de acuerdo a la percepción de la satisfacción con el modo de vida del productor, utilizando la siguiente escala: 5=Muy satisfecho, 4=Medianamente satisfecho, 3=Satisfecho, 2=Poco satisfecho, $1=$ Insatisfecho. Complementariamente se presentan factores asociados a la calidad de vida subjetiva en frases dichas por los productores durante la entrevista, que permiten un mejor entendimiento de la valoración numérica del indicador.

\section{Sucesión}

Por sucesión nos referimos a la situación del tema relevo generacional considerando la existencia de sucesores y predisposición a permanecer en el predio. De acuerdo a Tommasino et al. (2012) se trata de la viabilidad de continuidad del predio familiar considerando un horizonte temporal de 10 años teniendo en cuenta tanto la existencia de integrantes de la familia que lleven adelante la explotación, así como la expectativa de continuarla. Las expectativas de sucesión de un sistema de explotación dependen del bienestar económico y laboral y de la percepción que tengan los ganaderos y sus familias de su propia imagen social (Malaquín et al., 2012). Tanto para Malaquín et al. (2012) 
como para Perrachón (2011) se trata de un tema relevante en la ganadería familiar uruguaya. Los autores señalan como uno de los problemas la falta de atractivo de la actividad para las nuevas generaciones para darle continuidad de la explotación. Según Perrachón (2011), ese punto también constituye un reto para la investigación y extensión.

La valoración del indicador "sucesión" se realizó utilizando tres valores: Valor $5=$ La sucesión está resuelta o en transición. Valor $3=$ El tema está hablado en la familia, pero no definido. Valor $1=E I$ tema no está planteado o no hay sucesores. Esta propuesta coincide con lo planteado en predios hortícola-ganaderos por Dogliotti et al. (2014).

\section{Valoración de la planificación}

La planificación es clave a la hora de gestionar un establecimiento, tanto a largo plazo (LP) como a mediano plazo (MP). A través de la misma se pueden ordenar registros, elaborar proyectos, hacer previsiones de entradas/gastos, realizar una mejor gestión financiera, organizar un calendario de actividades y tareas operativas a fin de lograr una mejor eficiencia de la mano de obra, etc. Los rangos utilizados para esta variable fueron:

Valor $5=$ valora la planificación y tiene planes de LP. Valor 4=valora la planificación y tiene planes de MP. Valor 3= valora la planificación y tiene algunas áreas con planificación. Valor 2=valora la planifica- ción, pero no usa planes. Valor $1=$ ni valora ni usa planes

\section{Aprendizajes y cambios más relevantes}

Una forma cualitativa de evaluar los cambios y aprendizajes en las personas es con el análisis de los cambios en los conocimientos, actitudes, habilidades y aspiraciones (KASA por su sigla en inglés) (Rockwell y Bennett, 2004). Los aprendizajes y cambios más relevantes se valoran por un lado con la descripción realizada por los productores de los cambios que ellos incorporaron en los predios y, por otro, con una descripción de los cambios en KASA que manifestaron los productores durante las entrevistas.

\section{Relación técnico-productor}

Durante la investigación se indagó sobre las principales características valoradas por los productores de la forma de trabajo y del vínculo con el técnico de campo, a través de las impresiones recabadas en la entrevista.

\section{RESULTADOS}

\section{II.3.1. Predio 1}

\section{Caracterización del productor}

Las principales características que describen la unidad de producción y la unidad familiar del predio 1 se presentan en el Cuadro 1. 
Cuadro 1. Caracterización del predio 1.

\begin{tabular}{|c|c|}
\hline \multicolumn{2}{|l|}{ Categorías consideradas } \\
\hline $\begin{array}{l}\text { Composición familiar y } \\
\text { edad (al inicio del trabajo) }\end{array}$ & $\begin{array}{l}\text { El titular tiene } 70 \text { años y vive en Tacuarembó con su esposa. } \\
\text { Tienen } 4 \text { hijos y uno de ellos, de } 37 \text { años, se encarga del predio } \\
\text { y tiene la familia en la ciudad. }\end{array}$ \\
\hline Lugar de residencia & $\begin{array}{l}\text { El hijo encargado del predio vive en el predio. Los padres en } \\
\text { Tacuarembó. }\end{array}$ \\
\hline Sistema productivo & Ciclo completo en vacunos y cría en ovinos \\
\hline Superficie manejada (ha) & 1226 ha en el Año 1. 1399 ha en el Año 3 \\
\hline \multirow[t]{2}{*}{ Tenencia de la tierra } & 700 ha en propiedad y 526 arrendadas en el Año 1 \\
\hline & 700 ha en propiedad y 693 arrendadas en el Año 3 \\
\hline $\begin{array}{l}\text { Mecanismo de acceso } \\
\text { a la tierra }\end{array}$ & Herencia de la familia y arrendamiento \\
\hline Trayectoria en el campo & $\begin{array}{l}\text { El titular desde hace muchos años, y su hijo desde hace } 8 \text { años } \\
\text { en el predio y desde siempre ha estado vinculado al rubro. }\end{array}$ \\
\hline Historia laboral & $\begin{array}{l}\text { El hijo estudió dos años de Agronomía y vino a encargarse del } \\
\text { campo }\end{array}$ \\
\hline Trabajo extra predial & $\begin{array}{l}\text { Cuida y recorre } 450 \text { ha de una tía y otro vecino, por lo que percibe } \\
\text { un ingreso adicional }\end{array}$ \\
\hline Mano de obra contratada & 3 permanentes y contrata zafrales \\
\hline $\begin{array}{l}\text { Participación en } \\
\text { instancias colectivas }\end{array}$ & No \\
\hline
\end{tabular}

\section{Definición de sustentabilidad}

Las principales ideas asociadas con la visión de futuro-sustentabilidad del predio y la familia se pueden resumir con los siguientes conceptos.

\section{Sustentabilidad para integrantes de la familia 1 significa:}

- Mantener el campo para sustento como una unidad productiva y familiar en el futuro.

- Instalar paneles solares, al no poder tener acceso a la luz eléctrica.

- Mejorar el rodeo vacuno y lanar aumentando las cabezas y los índices reproductivos.

- Planificar mejor el manejo del rodeo vacuno y pensar en engordar novillos.

- Mejorar las pasturas con algo de verdeos anualmente y realizar un manejo adecuado del campo natural evitando el sobrepastoreo.
- Poder tener ingresos que permitan la contratación de mano de obra en los momentos en los que sea necesario.

- Conversar e ir planificando el traspaso de la gestión del predio a la nueva generación.

- Procurar que el hijo, que es el que trabaja en el predio, reciba un sueldo y eventualmente incentivos.

- Esclarecer quién realiza la toma de decisiones sobre aspectos productivos y económicos.

- Considerar la visión de los hermanos de realizar un nuevo emprendimiento y procurar dejarlo claro en un documento.

\section{Calidad de vida estructural}

En el caso de esta familia las mejoras en la calidad de vida estructural se relacionan con la vivienda, ya que realizaron arreglos y se pintó la casa. También restauraron la casa del personal dejándola a nueva. Compraron un vehículo para que la familia use en la ciudad, manteniendo la camioneta para el campo. 
Cuadro 2. Calidad de vida estructural.

\begin{tabular}{|l|c|c|}
\hline \multirow{2}{*}{ Variables } & \multicolumn{2}{|c|}{ Productor 1 } \\
\cline { 2 - 3 } & Año 1 & Año 3 \\
\hline Vivienda & 4 & 5 \\
\hline Energía eléctrica & 5 & 5 \\
\hline Acceso a agua potable & 5 & 5 \\
\hline Conectividad vial & 5 & 5 \\
\hline Disponibilidad de vehículo & 3 & 1 \\
\hline Distancia a centros poblados & 1 & 5 \\
\hline Conectividad digital & 3 & 5 \\
\hline Acceso a salud básica & 5 & 5 \\
\hline Nivel educativo formal & 5 & 5 \\
\hline Acceso a capacitación & 5 & 5 \\
\hline Nivel de endeudamiento & 5 & Valor absoluto $=51$ \\
\hline CALIDAD DE VIDA ESTRUCTURAL & Valor absoluto $=\mathbf{4 6}$ & Valor del índice $=5$ \\
\hline INTEGRADA & Valor del índice $=4$ & (n) \\
\hline
\end{tabular}

Calidad de vida estructural integrada: $\leq 20=1$, entre 20 y $30=2$, entre 30 y $40=3$, entre 40 y $50=4, \geq 50=5$.

Además, se logró la conexión a internet. Estas variables dan lugar a un cambio del valor absoluto de calidad de vida estructural integrada de 46 a 51 y de 4 a 5 en el índice.

\section{Calidad de vida subjetiva}

Cuadro 3. Calidad de vida subjetiva.

\begin{tabular}{|lcc|}
\hline & Año 1 & Año 3 \\
\hline Productor 1 & 3 & 3 \\
\hline
\end{tabular}

Muy satisfecho $=5$. Medianamente satisfecho $=4$.

Satisfecho=3. Poco satisfecho=2. Insatisfecho=1.
Para este indicador se mantuvo un valor 3, satisfecho.

Algunos factores asociados a la calidad de vida mencionados por la familia fueron: "Me gustaría tener más tiempo libre para estar con la familia que vive en Tacuarembó". "Estoy de lunes a viernes acá y no tengo mucho para el fútbol y los amigos". "Cada vez se hace más larga la semana".

Cuadro 4. Valoración del estado de la sucesión.

\begin{tabular}{|c|c|c|c|c|}
\hline & Año 1 & Año 3 & Comentarios & Palabras del productor \\
\hline Productor 1 & 1 & 3 & $\begin{array}{l}\text { Durante el proyecto } \\
\text { se generó la instan- } \\
\text { cia para que la fami- } \\
\text { lia hablara del tema. } \\
\text { A raíz de ello, se de- } \\
\text { cidió concretar un pri- } \\
\text { mer arreglo familiar } \\
\text { (formación de una } \\
\text { sociedad de hecho } \\
\text { entre los hermanos). }\end{array}$ & $\begin{array}{l}\text { "Capaz que cuando tengamos el gru- } \\
\text { po se puede hablar del tema traspa- } \\
\text { so generacional ya que hay varias } \\
\text { situaciones similares". "La sucesión } \\
\text { no está planteada ni planificada" } \\
\text { "Sigo al frente del campo con las } \\
\text { decisiones grandes tomadas con mi } \\
\text { padre". "Mi señora no entra en el ne- } \\
\text { gocio y no opina". "Quisiera tener una } \\
\text { cuenta bancaria propia." }\end{array}$ \\
\hline
\end{tabular}

Valor $5=$ La sucesión está resuelta o en transición. Valor 3=El tema está hablado en la familia, pero no definido. Valor 1=El tema no está planteado o no hay sucesores. 


\section{Sucesión}

Se partió de una situación en la que el tema de sucesión no estaba planteado, a hablarlo en la familia, aunque sin llegar a acuerdos formales (Cuadro 4).

\section{Planificación}

La valoración y uso de la planificación a mediano (MP) y largo plazo (LP) que realiza el productor al inicio del proyecto (Año 1), a la mitad del proyecto (Año 2) y al final del proyecto (Año 3 ) se presenta en el Cuadro 5.

Cuadro 5. Grado en el productor valora y usa la planificación

\begin{tabular}{|c|c|c|l|}
\hline \multicolumn{3}{|c|}{ Productor 1 } & \multirow{2}{*}{ Comentarios } \\
\cline { 1 - 2 } Año 1 & Año 2 & Año 3 & \\
\hline 3 & 4 & 5 & $\begin{array}{l}\text { El valor 5 se alcanza debido a su integración al Proyecto Mejora de la } \\
\text { Sostenibilidad de la Ganadería uruguaya -UFFIP- como predio foco, en } \\
\text { el cual se elaboró un plan predial con metas claramente definidas. A } \\
\text { su vez lleva y analiza registros mediante el uso de carpeta verde. }\end{array}$ \\
\hline
\end{tabular}

5=valora la planificación y tiene planes de LP. 4= valora la planificación y tiene planes de MP 3= valora la planificación y tiene algunas áreas con planificación. 2=valora la planificación, pero no usa planes. 1= ni valora ni usa planes.

Al respecto de la planificación el productor manifestó durante las entrevistas que trata de pensar en procesos largos a varios años y también el año a año. Va a hablar con el

padre para reservar cierta cantidad de dólares para gastos de la empresa como forma de administrar mejor el riesgo financiero.

Cuadro 6. Aprendizajes y cambios más relevantes.

\begin{tabular}{|l|l|}
\hline Cambios en el predio & $\begin{array}{l}\text { Cambios en conocimientos, habilidades, actitudes } \\
\text { y aspiraciones (KASA) del productor }\end{array}$ \\
\hline Trabaja con más pasto. & $\begin{array}{l}\text { Tiene aspiraciones de aprender y probar nuevas técni- } \\
\text { cas. }\end{array}$ \\
\hline Bajó la carga animal. & $\begin{array}{l}\text { Aspira a tener mejores resultados productivos y eco- } \\
\text { nómicos. }\end{array}$ \\
\hline $\begin{array}{l}\text { Reafirmó la importancia y la puesta } \\
\text { en práctica del empotreramiento }\end{array}$ & $\begin{array}{l}\text { Quiere una reunión familiar para mostrar los datos y } \\
\text { que todos puedan opinar. Va a invitar a la señora a las } \\
\text { reuniones para que comprenda del tema. }\end{array}$ \\
\hline $\begin{array}{l}\text { Comprueba anualmente que los toros } \\
\text { estén sanos. }\end{array}$ & Quiere que el campo tenga la chance de agrandarse. \\
\hline $\begin{array}{l}\text { Se han ido llevando registros y desde } \\
\begin{array}{l}\text { V13 se comenzó a llevar la Carpeta } \\
\text { Verde. }\end{array}\end{array}$ & Mayor tranquilidad al saber trabajar con más pasto. \\
\hline $\begin{array}{l}\text { Inició la proyección de gastos e in- } \\
\text { gresos. }\end{array}$ & $\begin{array}{l}\text { Conoce los números del predio y eso le ha "abierto la } \\
\text { cabeza". }\end{array}$ \\
\hline $\begin{array}{l}\text { Tiene un plan detallado de lo que va a } \\
\text { hacer, con metas definidas. }\end{array}$ & $\begin{array}{l}\text { Al planificar piensa más y tiene más elementos para } \\
\text { resolver. }\end{array}$ \\
\hline $\begin{array}{l}\text { Arregló la casa donde vive en el cam- } \\
\text { po y la vivienda para el personal e ins- } \\
\text { talaciones. }\end{array}$ & $\begin{array}{l}\text { Tiene más tiempo libre para conectarse por celular con } \\
\text { su familia y amigos. }\end{array}$ \\
\hline $\begin{array}{l}\text { Se arregló y acordó con los padres la } \\
\text { donación de unas vaquillonas para la } \\
\text { empresa familiar con los hermanos. }\end{array}$ & $\begin{array}{l}\text { No tiene que recorrer tanto porque a través de un me- } \\
\text { jor ordenamiento de las tareas se simplificó el trabajo. }\end{array}$ \\
\hline $\begin{array}{l}\text { Concretaron una sociedad con los her- } \\
\text { manos. }\end{array}$ & $\begin{array}{l}\text { Tratan de mostrar a otros lo que hacen para que todos } \\
\text { aprendan. }\end{array}$ \\
\hline
\end{tabular}




\section{Aprendizajes y cambios más relevantes}

En el cuadro 6 se indica los aprendizajes y los cambios más relevantes

\section{Relación técnico-productor}

Durante la investigación se indagó sobre las principales características valoradas por el productor de la forma de trabajo y del vínculo con el técnico de campo. Los factores destacados por el productor fueron: "Las charlas con la asesora técnica han sido momentos de aprendizaje. Me hace pensar y reafirmo cosas o cambio de idea. El he- cho de que estén los técnicos y puedas discutir con ellos te hace ver las diferencias y si está bien se sigue y si no se replantea. La relación con la técnica es más flexible comparada con otros técnicos asesores".

\section{II.3.2. Predio 2}

\section{Caracterización del productor}

Las principales características que describen la unidad de producción y la unidad familiar del predio 2 se presentan en el Cuadro 7.

Cuadro 7. Caracterización del predio 2.

\begin{tabular}{|l|l|}
\hline Categorías consideradas & \\
\hline $\begin{array}{l}\text { Composición familiar y } \\
\text { edad (al inicio del trabajo) }\end{array}$ & $\begin{array}{l}\text { El titular está casado y tiene } 3 \text { hijos. En el predio vive su madre } \\
\text { sola de } 82 \text { años. }\end{array}$ \\
\hline Lugar de residencia & El productor vive en el predio de su esposa a $3 \mathrm{~km}$ de distancia. \\
\hline Sistema productivo & Cría vacuna y ovina. \\
\hline Superficie manejada (ha) & 170 ha. \\
\hline Tenencia de la tierra & $\begin{array}{l}170 \text { ha en propiedad, una parte es de la madre y otra de la } \\
\text { hermana. }\end{array}$ \\
\hline $\begin{array}{l}\text { Mecanismo de acceso } \\
\text { a la tierra }\end{array}$ & Predio comprado por sus padres en 1982. \\
\hline Trayectoria en el campo & $\begin{array}{l}\text { Toda la vida. Está vinculado al predio desde } 1999 \text { y desde 2010 } \\
\text { se encarga directamente. }\end{array}$ \\
\hline Historia laboral & Trabajó en estancias hasta 2010. \\
\hline Trabajo extra predial & Ayuda a su señora con el campo que está cercano. \\
\hline Mano de obra contratada & No \\
\hline $\begin{array}{l}\text { Participación en } \\
\text { instancias colectivas }\end{array}$ & $\begin{array}{l}\text { En la Sociedad Fomento Basalto Ruta 31 y en el campo de } \\
\text { recría. }\end{array}$ \\
\hline
\end{tabular}




\section{Definición de sustentabilidad}

Las principales ideas asociadas con la visión de futuro-sustentabilidad del predio y la familia se pueden resumir con los siguientes conceptos.

- Realizar una mejor gestión y procurar que el predio esté mejor, con entrada de dinero por la venta de lana, terneros y corderos. Considerando que el productor está conforme con lo que hace y con lo que le ingresa, está interesado en hacer algunas inversiones: arreglo de la casa, tener el agua corriente y contar con un galpón nuevo, sin descuidar la entrada de dinero.

- Atender el predio donde vive su madre manteniendo el hogar con su señora sin pensar en irse para Salto. No tiene sueldo y no hay reparto formal de las ganancias con su madre, pero no hay planteo de cambio en el sistema usado.

- Pensar en estrategias de manejo de campo y manejo de pastoreo y analizar detenidamente el ajuste de la carga. Le gustaría realizar mejoramientos de campo sin tener que mover tierra.
- Considera que para el productor familiar las propuestas tecnológicas tienen que ser de bajos insumos para que puedan ser aplicadas.

- Tiene como meta tener todos los alambrados nuevos y el campo con ovejas y vacas.

- Se ve produciendo bien tanto en vacunos como en ovinos, mejorando las pasturas y terminando con el pasto serrucho que ya empezó a combatir. Si bien tiene mayor gusto por el ganado vacuno es consciente de la necesidad del ovino, planificando el pastoreo conjunto para lograr buenos resultados.

- Participaría de cursos que se realicen en la zona sobre temas tecnológicos, así como de computación.

- Se ve acompañando las actividades de la Sociedad de Fomento, pero no necesariamente como presidente o con un cargo de dirigente y ve la necesidad de que las diferentes organizaciones de productores de la zona tengan instancias de coordinación entre ellas.

Cuadro 8. Calidad de vida estructural.

\begin{tabular}{|l|c|c|}
\hline \multirow{2}{*}{ Variables } & \multicolumn{2}{|c|}{ Productor 2 } \\
\cline { 2 - 3 } & Año 1 & Año 3 \\
\hline Vivienda & 4 & 5 \\
\hline Energía eléctrica & 5 & 3 \\
\hline Agua potable & 1 & 4 \\
\hline Conectividad vial & 4 & 5 \\
\hline Disponibilidad de vehículo & 5 & 1 \\
\hline Distancia a centros poblados & 1 & 3 \\
\hline Conectividad digital & 3 & 5 \\
\hline Acceso a salud básica & 5 & 1 \\
\hline Nivel educativo formal & 1 & 5 \\
\hline Acceso a capacitación & 5 & 5 \\
\hline Nivel de endeudamiento & 5 & Valor absoluto $=40$ \\
\hline CALIDAD DE VIDA ESTRUCTURAL & Valor absoluto $=38$ \\
INTEGRADA & Valor del índice $=3$ & Valor del índice $=3$ \\
\hline
\end{tabular}

Calidad de vida estructural integrada: $\leq 20=1$, entre 20 y $30=2$, entre 30 y $40=3$, entre 40 y $50=4, \geq 50=5$. 


\section{Calidad de vida estructural}

En el caso del productor 2, las mejoras en la calidad de vida estructural se relacionan con la vivienda, ya que conectaron el agua a través de cañería. Estas variables dan lugar a un cambio del índice de calidad de vida estructural integrada de 38 a 40 en valor absoluto y manteniendo el valor de 3 del índice.

\section{Calidad de vida subjetiva}

Cuadro 9. Calidad de vida subjetiva.

\begin{tabular}{|lcc|}
\hline & Año 1 & Año 3 \\
\hline Productor 2 & 3 & 3 \\
\hline
\end{tabular}

Muy satisfecho $=5$. Medianamente satisfecho $=4$. Satisfecho $=3$. Poco satisfecho $=2$. Insatisfecho $=1$

Para este indicador se mantuvo un valor 3, satisfecho.
Algunos factores asociados a la calidad de vida mencionados por el productor fueron: "Estoy medianamente satisfecho con mi vida, pero no la cambio. Me gusta la vida en el campo".

\section{Sucesión}

Se mantuvo la situación que el tema de sucesión no está planteado para hablarlo con la familia (Cuadro 10).

\section{Planificación}

El productor valora la planificación (Cuadro 11), pero no la realiza en su predio, manifestando: "Pienso en algunos años para adelante. No se resuelve tanto sobre la marcha y no se hace tanto cuando las papas queman. No se ha hecho mucho eso de planificar en el predio, aunque se ve bien".

Cuadro 10. Valoración del estado de la sucesión.

\begin{tabular}{|c|c|c|c|c|}
\hline & Año 1 & Año 3 & Comentarios & Palabras del productor \\
\hline Productor 2 & 1 & 1 & $\begin{array}{l}\text { No se habla del tema para nada. } \\
\text { Su madre vive en el predio y él pien- } \\
\text { sa siempre en mejorarle las como- } \\
\text { didades, pero no se habla del tema } \\
\text { sucesión. El futuro con sus hijos } \\
\text { en temas sucesorios tampoco está } \\
\text { planteado y ni se habla del día que } \\
\text { se jubile. La hija estudia veterina- } \\
\text { ria y viene en las vacaciones y se } \\
\text { interesa por el predio. El otro hijo } \\
\text { que se puede interesar trabaja en } \\
\text { una veterinaria. El tercer hijo tra- } \\
\text { baja en la construcción. }\end{array}$ & $\begin{array}{l}\text { "En los predios familia- } \\
\text { res está el tema del re- } \\
\text { levo generacional y en- } \\
\text { tonces la persona a car- } \\
\text { go no toma decisiones } \\
\text { porque no sabe cómo } \\
\text { va a ser el futuro". }\end{array}$ \\
\hline
\end{tabular}

Valor 5=La sucesión está resuelta o en transición. Valor 3=El tema está hablado en la familia, pero no definido. Valor $1=$ El tema no está planteado o no hay sucesores.

Cuadro 11. Grado en el productor valora y usa la planificación.

\begin{tabular}{|c|c|c|l|}
\hline \multicolumn{2}{|c|}{ Productor 2 } & \multicolumn{2}{l|}{ Comentarios } \\
\cline { 1 - 2 } Año 1 & Año 2 & Año 3 & \\
\cline { 1 - 2 } 1 & 2 & 3 & $\begin{array}{l}\text { "Tengo un plan a más tiempo. Uno piensa y baja la pelota y pien- } \\
\text { so un poco más y pienso dos veces y si hay una manera que } \\
\text { puede salir mal o a veces veo algo que puede salir mejor". }\end{array}$ \\
\hline
\end{tabular}

Valor $5=$ valora la planificación y tiene planes de LP. Valor $4=$ valora la planificación y tiene planes de MP Valor $3=$ valora la planificación y tiene algunas áreas con planificación. Valor 2=valora la planificación pero no usa planes. Valor $1=$ ni valora ni usa planes. 


\section{Aprendizajes y cambios más relevantes}

Cuadro 12. Aprendizajes y cambios más relevantes.

\begin{tabular}{|l|l|}
\hline Cambios en el predio & $\begin{array}{l}\text { Cambios en conocimientos, habilidades, } \\
\text { actitudes y aspiraciones (KASA) del productor }\end{array}$ \\
\hline $\begin{array}{l}\text { Comenzó a ver los números del pre- } \\
\text { dio y se inició con la carpeta verde. }\end{array}$ & $\begin{array}{l}\text { A nivel familiar han conversado y no se ha cambiado } \\
\text { mucho. La madre y las hermanas han visto bien el } \\
\text { proceso cuando se hizo la presentación y quedaron } \\
\text { conformes. Antes nunca había mostrado el predio a } \\
\text { la familia. "Fue buenazo". }\end{array}$ \\
\hline $\begin{array}{l}\text { Toma la decisión de vender o aflojar } \\
\text { animales y lo hace convencido de } \\
\text { que va a ser así y será bueno. }\end{array}$ & $\begin{array}{l}\text { Le comenta a la esposa sobre lo que ha aprendido, } \\
\text { ya que ella es productora pero no es muy curiosa. }\end{array}$ \\
\hline $\begin{array}{l}\text { Bajó el stock ganadero llevando ga- } \\
\text { nado al campo de recría. }\end{array}$ & $\begin{array}{l}\text { Para la toma de decisiones siente más confianza, } \\
\text { porque tiene las pruebas. }\end{array}$ \\
\hline Mejoró el manejo de lotes. & $\begin{array}{l}\text { Algo que no sabía y realmente aprendió fue a juntar } \\
\text { boletas. }\end{array}$ \\
\hline Comprueba la sanidad de los toros & $\begin{array}{l}\text { Tiene la idea de haber aprendido todo y ahora tiene } \\
\text { las herramientas para seguir adelante. }\end{array}$ \\
\hline $\begin{array}{l}\text { Utilizó la ecografía, pero no hizo ma- } \\
\text { nejo diferente }\end{array}$ & $\begin{array}{l}\text { Aprendió mucho de campo natural y en la Colonia } \\
\text { aplica todo lo aprendido. }\end{array}$ \\
\hline $\begin{array}{l}\text { Hay más subdivisiones de las pas- } \\
\text { turas }\end{array}$ & $\begin{array}{l}\text { Aprendió de manejo de lotes, dividir el predio y aho- } \\
\text { ra lo sabe hacer sólo y lo aplica en la Colonia. }\end{array}$ \\
\hline $\begin{array}{l}\text { Se instaló un tanque de agua con } \\
\text { bomba eléctrica y pozos con bebe- } \\
\text { deros para animales y cañería para } \\
\text { abastecer la casa. Se hizo un co- } \\
\text { rral y un tubo. }\end{array}$ & $\begin{array}{l}\text { Se convenció que está bueno tener al toro con las } \\
\text { vacas por determinado tiempo, pero no lo hace. Se } \\
\text { refugaron algunos toros por el brote de Campylo- } \\
\text { bacteriosis y se concentró un poco el entore. }\end{array}$ \\
\hline $\begin{array}{l}\text { Ahora está nominado para predio de } \\
\text { referencia del MGAP }\end{array}$ & $\begin{array}{l}\text { En el proyecto aprendió sobre calidad de pastos y } \\
\text { el entablillado de terneros para separarlos de las } \\
\text { madres y luego hacer el destete. }\end{array}$ \\
\hline
\end{tabular}

\section{Relación técnico-productor}

Durante la investigación se indagó sobre las principales características valoradas por el productor de la forma de trabajo y del vínculo con el técnico de campo. Los factores destacados fueron: "Tomo decisiones con más confianza por lo que me dijeron los téc- nicos. La forma en la que me convencí fue por el contacto con los ingenieros y uno siempre va aprendiendo. En este proyecto ha sido más seria la relación con los técnicos. Con las visitas son puntuales y se han dedicado mucho." 


\section{II.3.3. Predio 3}

\section{Caracterización de la productora}

Se presentan en el Cuadro 13 las principales características que describen la unidad de producción y la unidad familiar del predio 3.

\section{Definición de sustentabilidad}

Las principales ideas asociadas con la visión de futuro-sustentabilidad del predio y la familia se resumen en los siguientes conceptos:

- Quedarse en el predio y completar el campo con ganado Angus, de acuerdo a la carga que le mencionaron los técnicos del proyecto.

- No tener más animales ajenos y mantener las ovejas de lana fina. Traer las vacas que tienen en el campo de Colonización.
- Construir un galponcito de material para poner la camioneta y dejar el otro galpón para la esquila, la lana y las bolsas.

- Algún día tener un tractorcito para poder hacer algunos laboreos básicos.

- Manejar bien el pasto, sin romper tierra ni plantar pradera, porque se ha regenerado la pastura natural.

- Calcular la cantidad de vacas a entorar y de ovejas a encarnerar, y la producción y la entrada de dinero. Para que dé para todo, llevarle a su madre y para vivir.

- Mantenerse vinculada a la Sociedad de Fomento

- Terminar los estudios básicos si se abren en la zona y continuar las capacitaciones.

- Poner la luz cuando se concrete para la zona.

Cuadro 13. Caracterización del predio 3.

\begin{tabular}{|l|l|}
\hline Categorías consideradas & \\
\hline $\begin{array}{l}\text { Composición familiar y } \\
\text { edad (al inicio del trabajo) }\end{array}$ & La productora trabaja con su pareja. \\
\hline Lugar de residencia & En el predio. \\
\hline Sistema productivo & Cría en vacunos y ovinos, exclusivamente sobre campo natural. \\
\hline Superficie manejada (ha) & 441 ha. \\
\hline Tenencia de la tierra & 187 en propiedad, 255 en arrendamiento. \\
\hline $\begin{array}{l}\text { Mecanismo de acceso } \\
\text { la tierra }\end{array}$ & Parte en herencia y parte se compró. \\
\hline Trayectoria en el campo & Toda la vida. \\
\hline Historia laboral & $\begin{array}{l}\text { Desde chica ayudaba a su padre y a su tío en las labores } \\
\text { del campo. }\end{array}$ \\
\hline Trabajo extra predial & $\begin{array}{l}\text { Su pareja hace algún trabajo fuera del predio como alambrador } \\
\text { y algunas manualidades en la casa. }\end{array}$ \\
\hline Otras fuentes de ingreso & Pastoreo de ganado ajeno en el predio. \\
\hline Mano de obra contratada & Contratan un zafral para esquila y vacunaciones. \\
\hline $\begin{array}{l}\text { Participación en } \\
\text { instancias colectivas }\end{array}$ & En la Sociedad de Fomento Mataojo. \\
\hline
\end{tabular}




\section{Calidad de vida estructural}

Cuadro 14. Calidad de vida estructural.

\begin{tabular}{|l|c|c|}
\hline \multirow{2}{*}{ Variables consideradas } & \multicolumn{2}{|c|}{ Productor 3 } \\
\cline { 2 - 3 } & Año 1 & Año 3 \\
\hline Vivienda & 3 & 5 \\
\hline Energía eléctrica & 5 & 5 \\
\hline Agua potable & 5 & 3 \\
\hline Conectividad vial & 3 & 5 \\
\hline Disponibilidad de vehículo & 5 & 1 \\
\hline Distancia a centros poblados & 1 & 5 \\
\hline Conectividad digital & 3 & 5 \\
\hline Acceso a salud básica & 5 & 2 \\
\hline Nivel educativo formal & 2 & 5 \\
\hline Acceso a capacitación & 5 & 5 \\
\hline Nivel de endeudamiento & 4 & Valor absoluto $=45$ \\
\hline CALIDAD DE VIDA ESTRUCTURAL & Valor absoluto $=\mathbf{4 1}$ \\
INTEGRADA & Valor del índice $=4$ & Valor del índice $=4$ \\
\hline
\end{tabular}

Calidad de vida estructural integrada: $\leq 20=1$, entre 20 y $30=2$, entre 30 y $40=3$, entre 40 y $50=4, \geq 50=5$.

En el caso del predio 3, las mejoras en la calidad de vida estructural se relacionan con la vivienda, ya que pintaron toda la casa e hicieron un tinglado para las reuniones de grupo. Asimismo, al inicio del proyecto solo tenían teléfono fijo y actualmente tienen celular y conexión a internet. Esas variables dan lugar a un cambio en el valor absoluto de calidad de vida estructural de 41 a 45 y el índice se mantuvo en 4.

\section{Calidad de vida subjetiva}

Cuadro 15. Calidad de vida subjetiva.

\begin{tabular}{|lcc|}
\hline & Año 1 & Año 3 \\
\hline Productor 3 & 5 & 5 \\
\hline
\end{tabular}

Muy satisfecho $=5$. Medianamente satisfecho $=4$. Satisfecho=3. Poco satisfecho=2. Insatisfecho=1

Para este indicador se mantuvo un valor 5, muy satisfecho.

Algunos factores asociados a la calidad de vida mencionados: "Amo la vida en el campo y la tranquilidad. Vivimos felices trabajando con lo que nos gusta". 


\section{Sucesión}

Cuadro 16. Valoración del estado de la sucesión.

\begin{tabular}{|c|c|c|c|c|}
\hline & Año 1 & Año 3 & Comentarios & Palabras del productor \\
\hline Productor 3 & 1 & 1 & $\begin{array}{l}\text { No se piensa por ahora en el tema } \\
\text { de la sucesión, no se habla ni con } \\
\text { la madre ni con la hermana. Se su- } \\
\text { pone que seguirá así hasta que la } \\
\text { madre falte porque hay un proble- } \\
\text { ma de herencia que para solucio- } \\
\text { narlo deberían pagar mucho. La } \\
\text { hermana nunca le dijo que le iba a } \\
\text { arrendar a otra persona. }\end{array}$ & $\begin{array}{l}\text { "No tengo muy claro si } \\
\text { uno de mis hijos puede } \\
\text { estar interesado en se- } \\
\text { guir adelante. Tal vez } \\
\text { es el que está en la } \\
\text { zona trabajando con la } \\
\text { maquinaria.» }\end{array}$ \\
\hline
\end{tabular}

Valor 5=La sucesión está resuelta o en transición. Valor 3=El tema está hablado en la familia, pero no definido. Valor $1=\mathrm{El}$ tema no está planteado o no hay sucesores.

Se mantuvo la situación en que el tema de sucesión no está planteado para hablarlo con la familia.

\section{Planificación}

La valoración y uso de la planificación a mediano (MP) y largo plazo (LP) que realiza la productora al inicio del proyecto (Año 1), a la mitad del proyecto (Año 2) y al final del proyecto (Año 3 ) se presenta en el Cuadro 17.

Cuadro 17. Valoración y uso de la planificación a mediano (MP) y largo plazo (LP).

\begin{tabular}{|c|c|c|c|}
\hline \multicolumn{2}{|c|}{ Productor 2 } & \multirow{2}{*}{ Comentarios } \\
\cline { 1 - 2 } Año 1 & Año 2 & Año 3 & \\
\hline 1 & 3 & 5 & $\begin{array}{l}\text { El valor 5 se alcanza debido a su participación en Proyecto Mejora } \\
\text { de la Sostenibilidad de la Ganadería uruguaya -UFFIP- como predio } \\
\text { foco en el cual se elaboró un plan predial con metas claramente } \\
\text { definidas }\end{array}$ \\
\hline
\end{tabular}

$5=$ valora la planificación y tiene planes de LP. 4= valora la planificación y tiene planes de MP $3=$ valora la planificación y tiene algunas áreas con planificación. 2=valora la planificación, pero no usa planes. 1= ni valora ni usa planes

Al respecto de la planificación la productora manifestó durante las entrevistas que piensa en un plazo de varios años para adelante y comentó que: "Cuando vamos a hacer las cosas sabemos porque las hacemos y podemos dar pasos más seguros".

\section{Aprendizajes y cambios más relevantes}

Una forma cualitativa de evaluar los cambios y aprendizajes en las personas es con el análisis de los cambios en los conocimientos, actitudes, habilidades y aspiraciones (KASA por su sigla en inglés) (Rockwell y Bennett, 2004), considerando los cambios incorporados en el predio y lo manifestado durante las entrevistas. 
Cuadro 18. Aprendizajes y cambios más relevantes.

\begin{tabular}{|l|l|}
\hline Cambios en el predio & $\begin{array}{l}\text { Cambios en conocimientos, habilidades, } \\
\text { actitudes y aspiraciones (KASA) del productor }\end{array}$ \\
\hline $\begin{array}{l}\text { Aumentó la producción de carne y } \\
\text { lana. }\end{array}$ & La productora aspira a terminar secundaria. \\
\hline Mejoró el destete. & Se casó con su compañero en 2014. \\
\hline $\begin{array}{l}\text { Tiene menor cantidad de ganado a } \\
\text { capitalización y pastoreo. }\end{array}$ & Tiene interés por aprender y capacitarse. \\
\hline $\begin{array}{l}\text { Ahorra para pagar cuentas y salir de } \\
\text { vacaciones. }\end{array}$ & $\begin{array}{l}\text { Toma las decisiones con su esposo conversando y } \\
\text { considerando el consejo técnico. }\end{array}$ \\
\hline Mejoró el ingreso. & Hacen todos los meses el cálculo de la carga. \\
\hline $\begin{array}{l}\text { Con el resultado de la DAO hace cla- } \\
\text { sificación de los animales. }\end{array}$ & $\begin{array}{l}\text { Conoce más sobre el manejo de las divisiones. Hoy } \\
\text { sabe que animal llevar a cada potrero y cuánto tiem- } \\
\text { po debe comer allí. }\end{array}$ \\
\hline $\begin{array}{l}\text { Hace revisión de toros previo al en- } \\
\text { tore. }\end{array}$ & $\begin{array}{l}\text { Sabe qué pasturas tiene y cómo están y cómo es la } \\
\text { medida de la altura del pasto. }\end{array}$ \\
\hline $\begin{array}{l}\text { Tiene noción de lo que se gasta y y } \\
\text { de los ingresos. }\end{array}$ & Sabe algo más del tema contable. \\
\hline $\begin{array}{l}\text { Vacuna para controlar Campylobac- } \\
\text { teriosis, que causa infertilidad y se } \\
\text { traduce en bajos porcentajes de pre- } \\
\text { ñez y procreo. }\end{array}$ & $\begin{array}{l}\text { Aprendieron a llevar las boletas para saber lo que } \\
\text { gasta y lo que ingresa. Eso ha cambiado mucho, } \\
\text { pero todavia no lleva sola la carpeta verde. }\end{array}$ \\
\hline $\begin{array}{l}\text { Tiene la posibilidad de consultar a } \\
\text { un veterinario. }\end{array}$ & $\begin{array}{l}\text { Tiene orgullo por ser predio foco: "A mí me eligieron } \\
\text { para ayudarme con el tema conocimiento" }\end{array}$ \\
\hline $\begin{array}{l}\text { Construyó cepo y tubo e instalacio- } \\
\text { nes para trabajar con los animales. }\end{array}$ & $\begin{array}{l}\text { Si bien no tiene facilidad de palabra ha perdido el } \\
\text { miedo a hablar y le muestra a los vecinos lo que ha } \\
\text { ido logrando en el predio. }\end{array}$ \\
\hline
\end{tabular}

\section{Relación técnico-productor}

Durante la investigación se indagó sobre las principales características valoradas por la productora de la forma de trabajo y del vínculo con el técnico de campo. Los factores destacados por la productora fueron: "La relación con la técnica es distinta. Conversamos lo que me pasa, tengo más confianza. Y salimos al campo a caballo, nos contamos cosas. Es importante, uno habla con más confianza. Antes a otros técnicos los veíamos en la reunión".

\section{II.4 INDICADORES}

Considerando las tres dimensiones evaluadas, se presentan de una manera visual los indicadores de sustentabilidad con un esque- ma gráfico. Esta manera gráfica de presentar la evolución en el tiempo de los indicadores seleccionados para valorar la sustentabilidad de los predios tuvo su origen en los llamados diagramas de araña, herramienta desarrollada por Lynam (1999), para observar, monitorear y medir los cambios en el uso de recursos. Con el tiempo fueron derivando en el gráfico de amibas, el cual ha sido usado con éxito en los casos de MESMIS analizados por Astier et al (2012). Su utilidad radica en que destacan el carácter multidimensional del manejo de recursos naturales en una forma holística, permitiendo rápidamente tener una visión general de los avances logrados en determinado periodo de tiempo. 


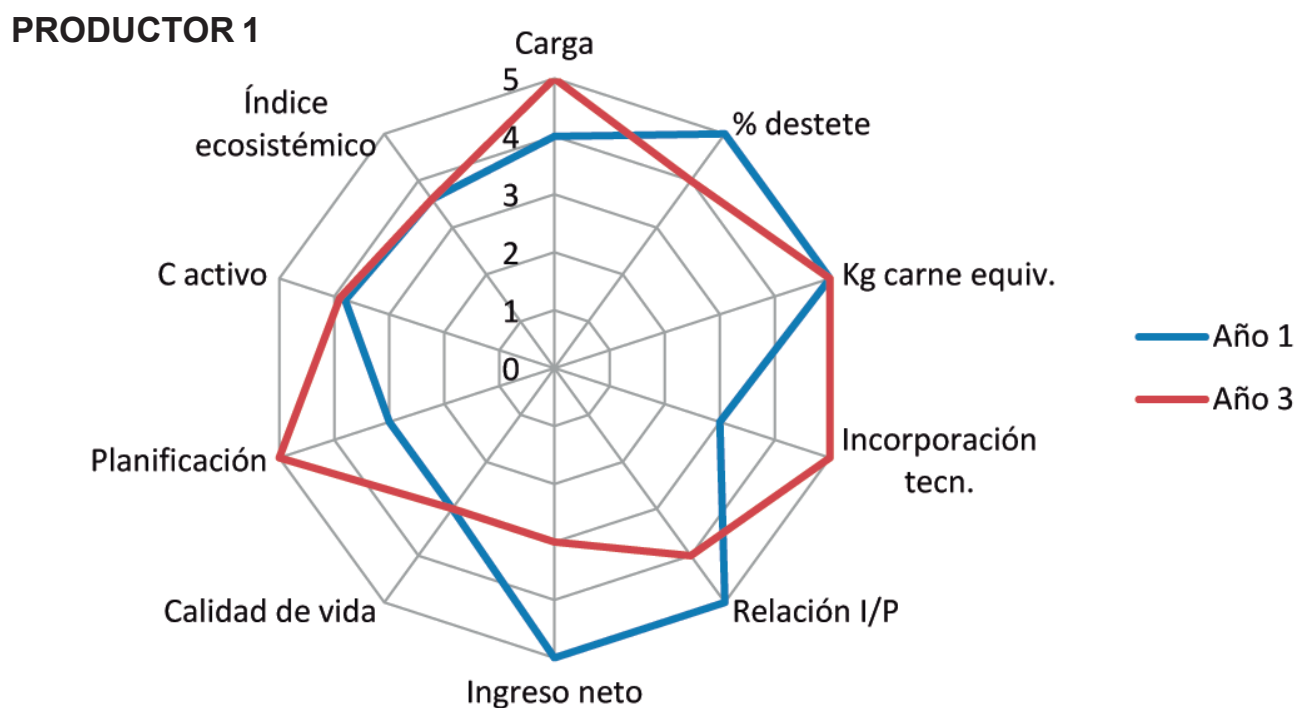

Figura 1. Evolución de indicadores predio 1.

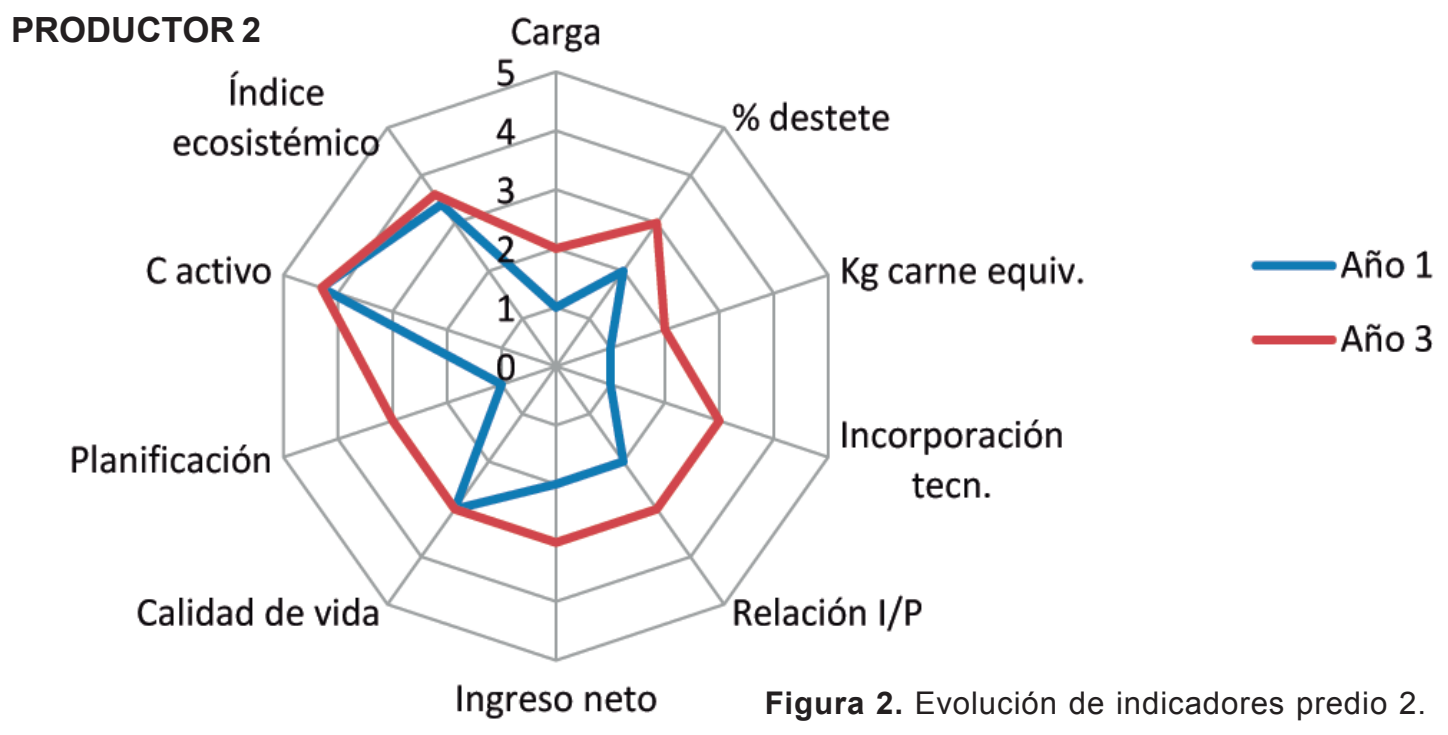

\section{PRODUCTOR 3}

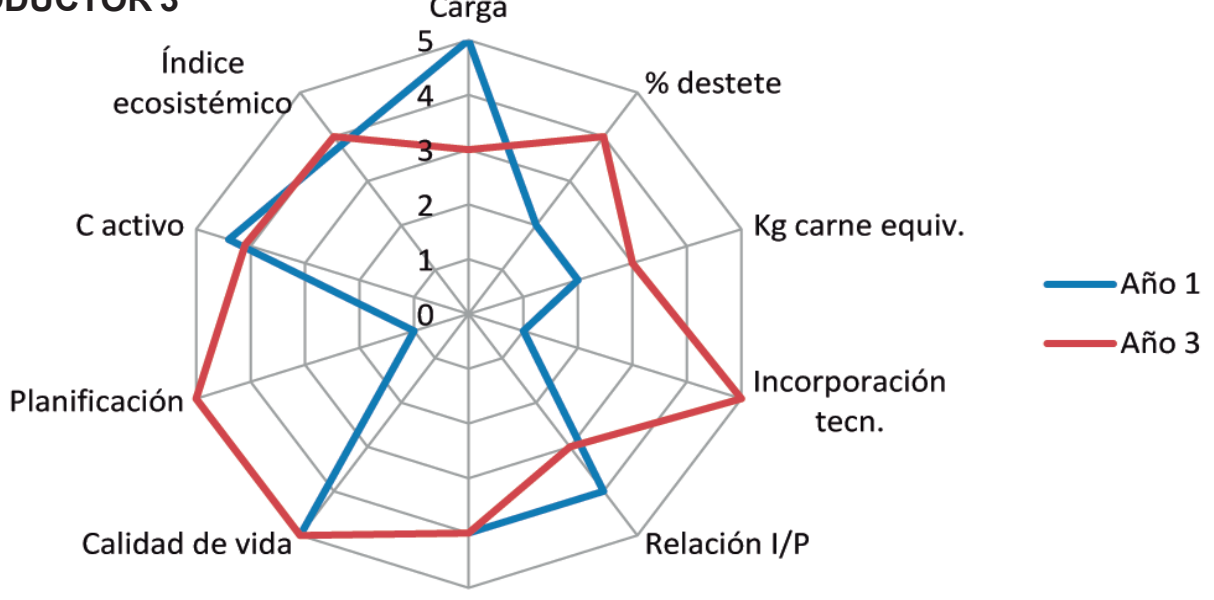

Ingreso neto

Figura 3. Evolución de indicadores predio 3. 


\title{
II.5. CONCLUSIONES
}

\author{
Ing. Agr. (Mag) Raúl Gómez Miller ${ }^{1}$ Ing. Agr. Virginia Porcile²,
} Ing. Agr. (Mag) María Marta Albicette ${ }^{1}$

En este trabajo se comprobó el potencial de mejora de los resultados productivos en predios ganaderos familiares, trabajando con el productor y su familia, aplicando un enfoque de sistemas. En base al apoyo de un equipo técnico multidisciplinario se pudieron abordar las metas y expectativas de los distintos productores. El uso del rediseño, con una concepción amplia de los diversos factores que inciden en la gestión del predio, apuntando a la interacción y al desarrollo de conocimientos y habilidades, contribuye a la mejora de su sostenibilidad. Es de resaltar que un abordaje global, concibiendo tanto aspectos productivo-económicos como sociales y ambientales, permitió una mejor conceptualización por parte de los productores al momento de analizar la incidencia de ciertas decisiones sobre el sistema. Si bien las estrategias de mejora se deben definir caso a caso las bases técnicas para lograrlo son las mismas.

A pesar de que el periodo de ejecución del proyecto fue relativamente breve, considerando los ciclos biológicos de sistemas ganaderos y las características extensivas de los mismos, fue posible evidenciar una mejora de los resultados productivos. Cabe esperar que este proceso se profundice, una vez que los productores internalicen plenamente las lógicas de manejo de la pastura natural en función de las necesidades de las diversas categorías del stock. Quedó además en evidencia que para lograr esos cambios de manera durable es necesario promover procesos de aprendizaje en todos los actores involucrados. Entre ellos es muy importante el vínculo productor-técnico, ese acompañamiento en el tiempo permite que el productor vaya generando confianza y autonomía y propicia tanto la generación de nuevos vínculos como el acceso a nuevas fuentes de información.
De todas formas, la respuesta obtenida fue dispar. Eso da cuenta de que, aún compartiendo un espacio territorial común, con recursos y accesibilidad a servicios similares, la incorporación de cambios es evaluada de manera diferencial y está muy asociada a un componente actitudinal. En el mismo pesa la diversidad de objetivos y estrategias de los productores agropecuarios, que muchas veces aparece mediada por factores tales como su origen, la escala disponible, la aversión al riesgo, la etapa del ciclo de vida por la que están transitando, etc. Esto ratifica que el agro, y la ganadería extensiva en particular, es un espacio económico marcado por la heterogeneidad. En este contexto, es que se deduce la importancia de aplicar enfoques como los desarrollados en este proyecto para promover cambios efectivos en los ganaderos familiares.

En ese sentido, el trabajo refleja el espíritu del método de estudio de casos, registrando la diversidad de conductas asociadas a una determinada propuesta. Se seleccionaron tres casos con puntos de partida diferentes en cuanto a resultados productivoeconómicos, con expectativas y disposición a los cambios también diferentes y en consecuencia con una evolución disímil a lo largo del proyecto.

En lo que refiere a la dimensión productivo-económica, en todas las situaciones se evidenciaron mejoras, aunque de diversa magnitud. En uno de los casos ya se partía de una situación relativamente consolidada del punto de vista productivo y el proyecto contribuyó a reafirmar conceptos de manejo del pastoreo, al tiempo de organizar sus registros y con ello poder cuantificar el impacto de ciertas decisiones. En otra situación se incorporó prácticamente la totalidad de las tecnologías sugeridas, partiendo de una

\footnotetext{
${ }^{1}$ Unidad de Comunicación y Transferencia de Tecnología

2 Técnica Sectorial.
} 
línea de base en la que el manejo era muy elemental, con resultados productivos bajos. La propuesta evidenció la capacidad de innovación y proyectó a la empresa hacia una situación de mayor solvencia. En el tercer caso, el productor no estuvo dispuesto a introducir mayores cambios en su sistema, lo que representa un estilo de manejo más tradicional, basado en la propia experiencia y que resulta una situación relativamente frecuente en ganadería extensiva. Por lo tanto, aquí se comprobó una evolución menor, a pesar de contar con el mismo apoyo e información que el resto.

En cuanto a la dimensión ambiental, se evidenció que, en un lapso relativamente breve, no superior a los dos años, en este tipo de suelos se puede mejorar la producción de pastura de aquellos potreros que han estado sometidos a sobrepastoreo, una vez que se ajusta la carga y se realiza un sistema de pastoreo controlado, con criterios para medir la disponibilidad forrajera.

En lo que refiere al componente social, se comprobó una mejora en la capacidad de planificación de los productores, al tiempo que se verificaron cambios personales de autoestima y orgullo, junto al planteo de perspectivas futuras de seguir intensificando los cambios positivos en los predios. De hecho, dos de ellos se incorporaron a un nuevo proyecto, de carácter nacional, integrando una red de predios ganaderos familiares, vinculados a grupos de productores y organizaciones de base regionales.

Desde INIA se abordó una estrategia de intervención nueva para la institución, trabajando en forma estrecha con los productores, procurando cambios positivos en sus sistemas de manera acordada y en condiciones reales de producción. Eso generó aprendizajes en el equipo técnico participante que seguramente se podrán capitalizar en futuros proyectos.

La información generada a partir de este trabajo con predios piloto podrá servir de insumo para la formulación de políticas orientadas al desarrollo regional, mediante una estrategia de articulación interinstitucional, con una agenda de trabajo común. 


\section{III - PRODUCTORES HORTÍCOLAS}

En torno a la ciudad de Salto, debido a las condiciones agroecológicas favorables, se ha desarrollado y profundizado la horticultura denominada "de primor" o "de contraestación". En las últimas décadas se ha promovido la adopción de paquetes tecnológicos que incluyen estructuras de protección, variedades de alto rendimiento y un importante uso de insumos, que ha permitido producir hortalizas de alta uniformidad, rendimiento y calidad visual. Como contrapartida, estos cultivos tienen elevados costos de producción y causan importantes desequilibrios sociales y ambientales. Esta situación, junto con un mercado inestable y los riesgos que implica la producción intensiva (exigencias mayores de gestión, financieras, etc.), han provocado el debilitamiento y abandono progresivo de la producción de muchos productores pequeños (Aguirre y Chiappe, 2009). En este trabajo se caracterizaron casos que contemplan estas estrategias y se evaluó su sustentabilidad contemplando aspectos económico-productivos, sociales y ambientales, utilizando el MESMIS.
Se trabajó con tres predios, dos de ellos con sistemas básicamente hortícolas y el restante un sistema mixto, con base hortícola, pero que además contaba con un monte de citrus y algunas cabezas de ganado.

Se trataba de predios distintos en cuanto a su nivel de evolución, complejidad y objetivos familiares. Este hecho pone de manifiesto la diversidad de situaciones que se dan en la región, con una heterogeneidad en la gestión productiva y estrategia priorizada, pero con el común denominador de hacer un uso más eficiente de insumos (productividad, relación insumo/producto), el cuidado de los recursos: suelo y agua y la calidad de productos, aspectos todos que tienen incidencia en el ingreso predial.

Se hace una breve descripción de cada uno de los casos, con un diagnóstico de situación que remarca los puntos críticos y principales problemas y el trabajo desarrollado para contribuir a levantar esas limitantes. Luego se presentan los resultados productivo-económicos, ambientales y sociales logrados durante el proyecto y las principales conclusiones. 


\title{
III.1. DIMENSIÓN PRODUCTIVO-ECONÓMICA
}

\author{
Ing. Agr. Franco Bordenave ${ }^{1}$; Ing. Agr. Pablo Varela;
}

Ing. Agr. (Mag) Raúl Gómez Miller

\section{III.1.1. Predio 1}

La familia 1 conformada por cuatro hermanos y sus padres se ha ido consolidando productivamente en los últimos años. En el inicio del proyecto mostraba problemas de escala que impedían generar ingresos satisfactorios para toda la familia. Existía, a su vez, una alta carga de trabajo y un uso intensivo de insumos con la utilización generalizada de bromuro de metilo para la desinfección de suelos, lo que permitía tiempos de espera cortos entre cultivos, sin realizar rotaciones. A partir de las nuevas reglamentaciones que prohibieron el uso de este agroquímico para la desinfección de suelo, debió replantearse el uso intensivo de los invernaderos en la región, fomentándose el uso de prácticas más conservacionistas.

Al realizar un primer diagnóstico de situación, se puede concluir en que la explotación tuvo un desarrollo rápido, con un adecuado recambio generacional que permitió insertar en la gestión a los cuatro hermanos, menores de 30 años, quienes trabajan con mucho dinamismo y visión. La superficie destinada a cultivos protegidos se mantiene en permanente expansión, con la construcción de nuevos invernaderos -se pasó de 8.000 a $12.000 \mathrm{~m}^{2}$ en el periodo del proyecto-, micro y macrotúneles. Este sistema de producción se complementa con cultivos a campo que permiten nivelar los ingresos a lo largo del año. Un objetivo central es la productividad y la calidad, haciendo una estricta clasificación de producto. Se han preocupado por ver otras situaciones, capitalizando experiencias para "aprender la diferencia entre hacer las cosas bien o mal". Se dio un proceso de tecnificación en cuanto a la presentación del producto: máquinas clasificadoras, lavadoras, un galpón para el empaque y acopio, el uso de envases según clien- te, lo que ha permitido el acceso a mercados más exigentes.

La totalidad de la superficie productiva se encuentra bajo riego, con buen caudal de agua y ya existía la previsión de invertir en una red de distribución de agua subterránea en PVC para todo el predio.

En el inicio ya se contaba con un parque de maquinaria completo, incluyendo una máquina lavadora de boniato, adquirida en el 2010, y una clasificadora de tomate adquirida durante la ejecución del proyecto, implementos que permiten mayor eficiencia en el uso de mano de obra y aportan a la presentación y calidad de producto.

En el transcurso del proyecto, la familia accedió a una nueva fracción del Instituto Nacional de Colonización (INC) que permitió lograr una escala que le da mayor proyección como unidad productiva. Esto implicó un gran desafío, ya que supuso empezar a trabajar prácticamente desde cero un nuevo predio, con la consecuente planificación y reorganización de tareas, generando una nueva dinámica laboral.

Para este caso, y en base a las limitantes mencionadas por el productor y algunas otras que se detectaron en las visitas del técnico de campo, se planteó una propuesta de trabajo en diferentes áreas, teniendo en cuenta las fortalezas y los objetivos de la empresa.

En primer lugar, se trabajó en la jerarquización de la planificación anual de los cultivos: fechas de siembra, insumos necesarios para los mismos, manejo a realizar, etc. Esta estrategia de trabajo se basó en distribuir la mano de obra a lo largo del año mediante cambios en los cultivos y escalonando las fechas de siembra y cosecha, para aumentar la eficiencia en el uso de los recursos y poder generar ingresos más constantes en

\footnotetext{
${ }^{1}$ Asesor privado

${ }^{2}$ Unidad de Comunicación y Transferencia de Tecnología
} 
el año. Para ayudar a esta planificación anual se comenzaron a llevar registros productivos y económicos.

Otra área de trabajo fue la de técnicas de desinfección de suelo, sistematización de cuadros e invernaderos y mejora de las propiedades físico-químicas del suelo. Se fue incluyendo de manera progresiva tecnologías más amigables con el ambiente (solarización, abonos verdes), para eliminar el uso de agroquímicos de alta categoría toxicológica para la desinfección de suelo en los cultivos protegidos.

Los resultados fueron variables y se pueden clasificar en cualitativos y cuantitativos.

En cuanto a los resultados cualitativos se observó un cambio en el manejo del sistema productivo y la actitud en la gestión de la empresa. Esto incluyó una mayor capacidad de análisis de los resultados productivos y la incorporación de criterios más objetivos para la toma de decisiones.

En este mismo aspecto, se percibió un gradual aumento de la vinculación técnicoproductor, con mayor receptividad al planteo de cambios tanto de corto como de largo plazo. En las frecuentes visitas se pudo monitorear el seguimiento de lo planificado, lo que ayudó a los productores a tener un seguimiento cercano del plan de trabajo acordado. Se destaca que durante el proyecto se cambió al asesor técnico del predio, contratando a un técnico joven que entendió los principales problemas y afianzó la propuesta de trabajo.
En lo referente al cuidado del ambiente y calidad de suelos, se priorizó el manejo de los cultivos en invernadero para tener una ventana de 30 días sin cultivo en el periodo de diciembre a febrero para realizar la técnica de solarización y evitar la desinfección con productos químicos.

En los siguientes cuadros se detallan los avances logrados y las técnicas utilizadas por el productor.

\section{Diversidad de actividades productivas (rubros)}

La realización de diferentes actividades es un signo de la estrategia productiva para obtener un ingreso continuo y de diferentes rubros, tratando de acotar la incidencia de precios coyunturales y reducir riesgos. En cambio, la alta diversificación requiere una buena planificación de los recursos disponibles, de lo contrario puede tener un efecto negativo, por lo que en base a características del productor y del sistema, se debe ir ajustando para llegar a un balance adecuado. En el Cuadro 1 se presenta el resultado de diversificación del productor donde, si bien a partir del año 2 existió un aumento de la diversidad de rubros, a lo que contribuyó la planificación realizada, no se refleja en el indicador ya que se mantiene dentro del mismo rango (4 a 6 actividades). La diversidad productiva se determinó en base a los diferentes cultivos y actividades que se realizaron durante los tres años de duración del proyecto.

Cuadro 1. Diversidad de actividades productivas

\begin{tabular}{|l|lll|}
\hline & \multicolumn{3}{c|}{ Años } \\
\cline { 2 - 4 } & 1 & 2 & 3 \\
\hline 1= Una sola actividad productiva & & & \\
\hline 2= Entre 2 y 3 actividades productivas & & & \\
\hline 3= Entre 4 y 6 actividades productivas & $X$ & $X$ & $X$ \\
\hline 4= Entre 6 y 7 actividades productivas & & & \\
\hline 5= Más de 7 actividades productivas & & \\
\hline
\end{tabular}




\section{Distribución de ingresos anual}

En el Cuadro 2 se observan los flujos de fondo del sistema productivo en el año. El productor pasó de tener 4 o 5 meses en el año con saldo negativo (año 1) a solo 2 o 3 meses en los años siguientes; lo que también se explica por el aumento en la diversidad productiva.
Los saldos negativos se dan en los primeros meses del año donde se requiere mayor capital para iniciar el año productivo, principalmente por la compra de insumos para la producción. Lo que se intenta es, con la suma de cultivos y actividades que se realizan en el predio, lograr un ciclo completo de mercadería para que haya ingresos todos los meses.

Cuadro 2. Flujo financiero anual.

\begin{tabular}{|llcc|}
\hline & \multicolumn{3}{c|}{ Años } \\
\cline { 2 - 4 } & $\mathbf{1}$ & $\mathbf{2}$ & 3 \\
\hline 1= Existen más de 7 meses con egresos superiores a ingresos & & & \\
\hline 2= Existen entre 6 y 7 meses con egresos superiores a ingresos & & & \\
\hline 3= Existen entre 4 y 5 meses con egresos superiores a ingresos & $X$ & & \\
\hline $\begin{array}{l}\text { 4= Existen entre } 2 \text { y } 3 \text { meses con egresos superiores a ingresos } \\
\text { 5= No existen momentos críticos con egresos superiores a los } \\
\text { ingresos }\end{array}$ & & & \\
\hline
\end{tabular}

\section{Comercialización, grado de conformidad}

La comercialización de los productos la realizan en Montevideo a través de un intermediario que obtiene su comisión por esta tarea. El productor realiza esta actividad desde hace varios años con un solo agente comercial y se encuentra conforme con el desempeño del mismo, conformando una alianza que permitió desarrollar una relación de confianza. Este tipo de situaciones no es muy frecuente en la zona y se asume que, en parte, el crecimiento de la familia está basado en esa alianza estratégica.
Se presenta un producto de calidad consistente, fundamentalmente en tomate, y piensan seguir diferenciándolo, a través del uso de envasado con un logo de la empresa. El boniato es comercializado a Tienda Inglesa, con mejor precio que el boniato común. En cuanto a frutilla, la llevan directo a Punta del Este por su buena presentación, principalmente las variedades Yuri y Festival. EI aspecto comercial es un punto fuerte del establecimiento, en base al énfasis que se pone en la calidad de producto, pero aún se visualiza un margen de mejora en aspectos de presentación y presencia permanente en el mercado.

Cuadro 3. Conformidad con la comercialización de productos.

\begin{tabular}{|llcc|}
\hline & \multicolumn{3}{c|}{ Años } \\
\cline { 2 - 4 } & $\mathbf{1}$ & $\mathbf{2}$ & $\mathbf{3}$ \\
\hline 1= Muy desconforme & & & \\
\hline 2= Desconforme & & & \\
\hline 3= Parcialmente conforme & & & \\
\hline 4= Conforme & $X$ & $X$ & $X$ \\
\hline 5= Muy conforme & & & \\
\hline
\end{tabular}




\section{Uso de registros}

Se realizó con el productor un calendario con las fechas de las principales actividades durante el año. Ejemplo: fechas de siembra de los cultivos en invernadero y a campo, fechas de trasplantes, momentos de solarización, laboreo de suelo, fecha de abonos verdes, etc. Se fue generando la rutina de registrar estas actividades para un mejor ordenamiento.
Con la planificación se logró tener cultivos durante todo el año con la pretensión de generar ingresos todos los meses. Pese a no considerar en el inicio del proyecto a los registros como una herramienta de gestión, básicamente por la alta carga de trabajo que implica llevarlos de manera ajustada, se han ido incorporando de manera paulatina para la toma de decisiones.

Cuadro 4. Uso de registros.

\begin{tabular}{|llcl|}
\hline & \multicolumn{3}{c|}{ Años } \\
\cline { 2 - 3 } & $\mathbf{1}$ & $\mathbf{2}$ & 3 \\
\hline 1= Ningún registro & & \\
\hline 2= Registro de compras o ventas & \\
\hline 3= Registros económicos & & \\
\hline 4= Registros de rendimientos y económicos & $X$ & $X$ \\
\hline 5= Registros completos (cuadernos de campo) & & \\
\hline${ }^{*}$ Cuaderno de campo con registro de aplicaciones y manejos.
\end{tabular}

\section{Riego}

La actividad productiva intensiva que se realiza en el predio depende fundamentalmente de la disponibilidad de riego y esta determina la realización de un cultivo o no. Desde hace bastante tiempo la familia ha priorizado las inversiones para no tener limitantes de agua para la actividad productiva. Este aspecto ya estaba jerarquizado desde el inicio del proyecto. Se dispone del recurso como para asegurar el $80 \%$ del predio bajo riego en caso de necesitarlo.

Cuadro 5. Disponibilidad de riego.

\begin{tabular}{|c|c|c|c|}
\hline & \multicolumn{3}{|c|}{ Años } \\
\hline & 1 & 2 & 3 \\
\hline \multicolumn{4}{|c|}{$1=$ Agua disponible para regar menos del $20 \%$ del predio } \\
\hline \multicolumn{4}{|l|}{$2=$ Agua disponible para regar $20-50 \%$ del predio } \\
\hline \multicolumn{4}{|l|}{$3=$ Agua disponible para regar $50-65 \%$ del predio } \\
\hline $4=$ Agua disponible para regar $65-80 \%$ del predio & $\mathrm{x}$ & $\mathrm{X}$ & $\mathrm{X}$ \\
\hline $5=$ Agua disponible para regar todo el predio & & & \\
\hline
\end{tabular}




\section{Desinfección de suelos y uso de alternativas amigables con el ambiente}

Uno de los resultados más esperados era bajar la dependencia de productos químicos para la desinfección de suelo. Se ha logrado con el productor y la familia incorporar y mantener nuevas técnicas de desinfección.

Uno de los problemas detectados era la alta intensidad de uso del suelo, típica de estos sistemas de producción, y frecuentemente con la misma especie o especies relacionadas, lo que provoca el aumento de patógenos en el suelo. En este caso, la planificación anual ayudó tanto a introducir las rotaciones de cultivos con abonos verdes $\mathrm{u}$ otros cultivos en un mismo cuadro, como a realizar actividades entre cultivos para mejorar la calidad de los suelos.

A su vez, se realizó un plan de manejo para los cuadros con inconvenientes de malezas, consistente en una rotación de cultivos y herbicidas, haciendo foco en el control de la maleza como actividad estratégica vinculada al cuadro y no al cultivo.

En el año 2 se realizó la desinfección de suelo con la técnica de solarización en un $65 \%$ del área total de los invernaderos, la que se extendió a la totalidad de la superficie de invernadero y al cultivo de frutilla en el verano siguiente.

Cuadro 6. Estrategias para desinfección de suelos.

\begin{tabular}{|llc|}
\hline & \multicolumn{2}{c|}{ Años } \\
\cline { 2 - 3 } & $\mathbf{1}$ 2 & 3 \\
\hline 1= Desinfección con bromuro de metilo & \\
\hline 2=Desinfección químicos diferente al bromuro de metilo. \\
\hline 3= Solarización y productos químicos diferente al bromuro de metilo \\
\hline 4= Solamente solarización & $X$ \\
\hline 5= Solarización e incorporación de abonos orgánicos & \\
\hline
\end{tabular}




\section{III.1.2. Predio 2}

La familia vive y trabaja en un predio que es sucesión familiar. Al titular le corresponde un tercio del total de esa explotación, que se dedica a horticultura y citrus.

En los años previos al inicio del proyecto la familia, compuesta por el matrimonio y tres hijos menores de edad, accedió a una fracción del Instituto Nacional de Colonización (INC) de 36 hectáreas, cercano al lugar donde viven, en el que se fueron realizando diversas inversiones: abastecimiento de agua, invernadero, plantación de montes de citrus, etc. El objetivo que se planteó fue poner foco en ese predio nuevo, desarrollarlo, mudarse allí y poder vivir de lo que en él se genere, lo que constituía un importante desafío.

En ese nuevo predio se instaló un invernáculo para producir principalmente tomate y morrón, complementado con cultivos de campo. Además, se plantaron 4000 plantas de citrus $(20 \%$ de mandarina Satsuma y el resto con naranja Valencia y Navel) y se contaba con 36 vacas de cría, usando en forma complementaria al predio, como área de pastoreo, un campo de recría.

Entre los objetivos planteados estaban los de aumentar la superficie de cultivos protegidos (inversión en nuevos invernáculos) y el área de montes de citrus.

Al momento de realizar un diagnóstico del predio y elaborar un árbol de problemas, los aspectos que surgieron como más relevantes fueron: ingresos reducidos y falta de planificación productiva. A eso se sumaba una reducida aplicación de tecnología para sistemas intensivos -con la consecuente baja productividad y calidad-y problemas de comercialización. Otro problema sentido era la alta carga de trabajo que no permitía hacer un uso eficiente de los tiempos operativos.

La maquinaria utilizada era la existente en el predio de sucesión, de la que el productor tiene una cuota parte.

Al inicio del proyecto el productor no llevaba registros de producción de ningún tipo y la desinfección de suelo se hacía con bromuro de metilo.

En lo referente a fuentes de información y vinculación con el medio, se recibía ase- soramiento parcial suministrado por la empresa a la que se le compran insumos. La esposa formaba parte de la directiva de la Sociedad de Fomento de la Colonia Gestido, con activa participación en proyectos para jóvenes.

En base a las limitantes mencionadas por la familia, sus objetivos y necesidades, se planteó una propuesta de trabajo en diferentes áreas, teniendo en cuenta las fortalezas y los objetivos de la empresa.

En primer lugar, se hizo un plan de trabajo con un calendario anual de los cultivos, priorizando las variedades a utilizar, fechas de siembra, necesidad de insumos, tipos de manejo a realizar, etc. También se hizo énfasis en la necesidad de llevar registros productivos y económicos para analizar objetivamente los resultados.

La premisa era que este plan de trabajo ayudara a la planificación anual, para una mejor distribución durante el año de la mano de obra familiar y tener una menor dependencia en la contratación de jornales. Además, al tener un escalonamiento de las siembras se preveía mejorar la distribución de los ingresos y un manejo financiero más ajustado.

Otro punto trabajado junto al productor fue la ampliación del área de invernadero, el análisis de un posible aumento del área de citrus y el dimensionamiento del riego.

Se identificaron los cultivos mejor adaptados al sistema productivo teniendo en cuenta los recursos disponibles: mano de obra, infraestructura y financieros. A partir de este punto se elaboró un calendario de las principales actividades durante el año: fechas de siembra de los cultivos en invernadero y a campo, fechas de trasplantes, momentos de solarización, laboreo de suelo, fecha de abonos verdes, etc. La intención fue mejorar el desempeño productivo, apuntando a aumentar los rendimientos y la calidad de producto. El productor incorporó los registros a través del uso de un cuaderno de campo para hacer todas las anotaciones. Además, se priorizó el manejo de los cultivos en invernadero para comenzar a aplicar la técnica de solarización y evitar la desinfección con productos químicos. 
En los cítricos se buscó mejorar la entre fila de los cuadros de Naranja Valencia para poder ingresar con la maquinaria después de las precipitaciones, dejando empastado y con pendiente para permitir el desagüe. Esta medida permitió mejorar la estrategia de combate del cancro cítrico en naranja y la sarna en mandarina Satsuma, con la aplicación de productos químicos. El encare productivo del predio estuvo basado en la experiencia previa, en la explotación común con los hermanos, incorporando prácticas poco recomendables: elección de variedades de cítricos, el plan de curas inadecuado, el uso de productos químicos no ajustado a las enfermedades (dosis y época de aplicación), sistema de riego, etc. En horticultura existían estructuras poco funcionales, con problemas sanitarios y calidad de producto.

En el rubro ganadero no se percibieron grandes cambios a pesar de los planteos propuestos: concentración de la fecha de entore, vender todos los terneros y comprar vaquillonas preñadas. Esto puede ser atribuido a que el productor tiene al rubro vacuno como una caja de ahorro y no es su principal fuente de ingreso.

\section{Diversidad de actividades productivas (rubros)}

Existió un cambio en la utilización de variedades más adaptadas y que mejoran la calidad del producto final para los cultivos de tomate, zapallito y el maíz. Se ajustaron las fechas de siembra y trasplante para obtener ingresos más continuos y distribuir la mano de obra. Si bien el productor ya manejaba un sistema mixto (horticultura, citrus y ganadería) se enfatizó en el rubro hortícola, que es el generador de mayores ingresos, proponiendo el uso de variedades de mejor respuesta, con el consecuente impacto productivo.

Cuadro 7. Diversidad de actividades productivas.

\begin{tabular}{|llll|}
\hline & \multicolumn{3}{c|}{ Años } \\
\cline { 2 - 4 } & 1 & 2 & 3 \\
\hline 1= Una sola actividad productiva & & & \\
\hline 2= Entre 2 y 3 actividades productivas & $X$ & $\times$ & $X$ \\
\hline 3= Entre 4 y 6 actividades productivas & & & \\
\hline 4= Entre 6 y 7 actividades productivas & & & \\
\hline 5= Más de 7 actividades productivas & & & \\
\hline
\end{tabular}

\section{Distribución de ingresos anual}

Se incorporaron técnicas de manejo, a partir de las recomendaciones, que permitieron mejorar el desempeño productivo: manejo nutricional, fertilización de base y fertirriego, densidad de los cultivos y manejo sanitario. El uso de un paquete tec- nológico más ajustado a las posibilidades y expectativas del productor dieron como resultado, ya hacia el final del proyecto, una mejora relativa en la distribución anual de ingresos, si bien este hecho aún no se ve reflejado en el indicador del último año, de acuerdo a los registros relevados (Cuadro 8). 
Cuadro 8. Flujo financiero anual.

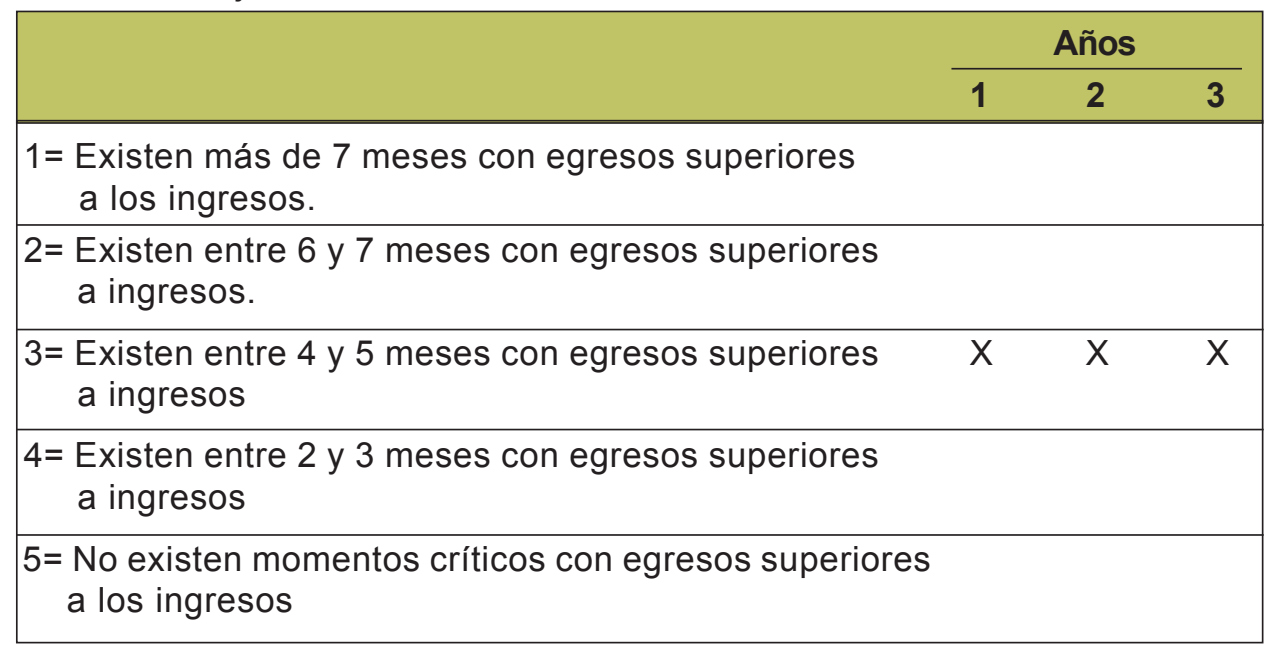

\section{Comercialización, grado de conformidad}

Se dio una mejoría en la percepción del productor en aspectos comerciales al empezar a tener algunos productos con mejor calidad. Cabe resaltar que esta valoración es subjetiva y por lo tanto el nivel de conformidad es relativo a las expectativas del productor.

\section{Uso de registros}

En cuanto a la toma de registros, se notó un avance durante la ejecución del proyecto. La tarea fue realizada por la hija del productor. Más allá de realizar los registros, estos en escasas oportunidades fueron utilizados como un instrumento para la toma de decisiones por parte del productor. Vale de-

Cuadro 9. Conformidad con la comercialización de productos.

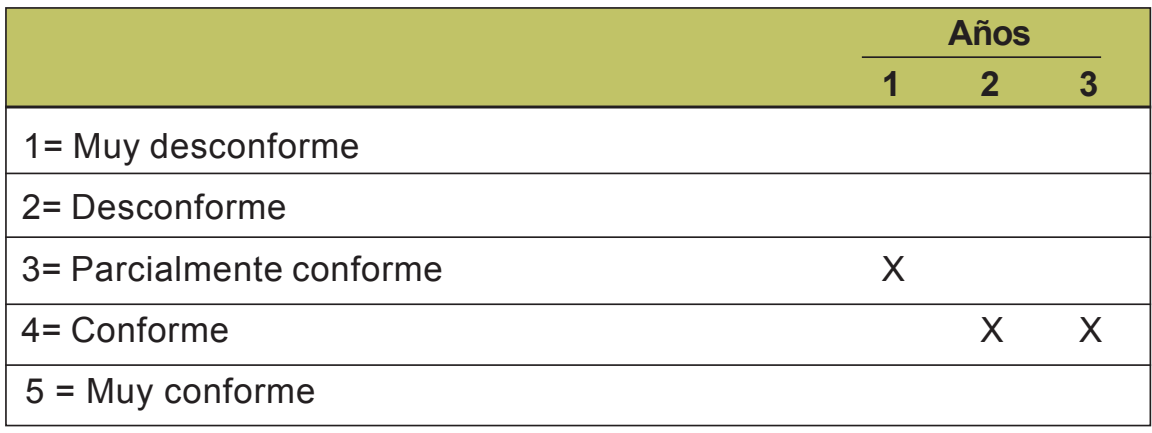

Cuadro 10. Uso de registros.

\begin{tabular}{|c|c|c|c|}
\hline & \multicolumn{3}{|c|}{ Años } \\
\hline & 1 & 2 & 3 \\
\hline \multicolumn{4}{|l|}{ 1= Ningún registro } \\
\hline $2=$ Registro de compras/ventas & $\mathrm{x}$ & & \\
\hline 3= Registros económicos & & $\mathrm{X}$ & $x$ \\
\hline \multicolumn{4}{|l|}{$4=$ Registros de rendimientos y económicos } \\
\hline $5=$ Registros completos (cuadernos de campo) & & & \\
\hline
\end{tabular}


cir que, si bien hubo un acercamiento al uso de la herramienta, con involucramiento de otros integrantes del núcleo familiar, desde el punto de vista práctico aún el productor no visualiza la ventaja de llevar números y analizarlos. Por lo tanto, si bien se dio cierta evolución en la toma de registros, se estima que no se convertirán en una herramienta estratégica que aporte a la toma de decisiones.

\section{Riego}

Para el cultivo de cítricos se necesitaba mejorar el sistema de riego e instalar un equipo de fertirriego. En este caso, y utilizando la ventanilla abierta del MGAP en el llamado para "Proyectos de riego", se presentó una propuesta para instalar una red de cañerías en PVC que permitiera distribuir el agua en todo el predio, aumentar el caudal disponi- ble en los cuadros, disminuir pérdidas y maximizar la eficiencia y uniformidad de conducción del agua, disminuyendo costos de energía. Esto se logró en el ejercicio final, lo que se refleja en el indicador (Cuadro 11).

\section{Desinfección de suelos y uso de alternativas amigables con el ambiente}

En cuanto a los cultivos protegidos, se realizó un cambio importante en la técnica de desinfección de suelo, dejándose de usar el bromuro de metilo y pasando a solarización con Metan Potasio. Se pretende seguir avanzando en este tema para descartar los productos químicos para la desinfección. En ese sentido, a partir del proyecto se generó un punto de inflexión en cuanto a la sensibilización por el cuidado de este recurso.

Cuadro 11. Disponibilidad de riego.

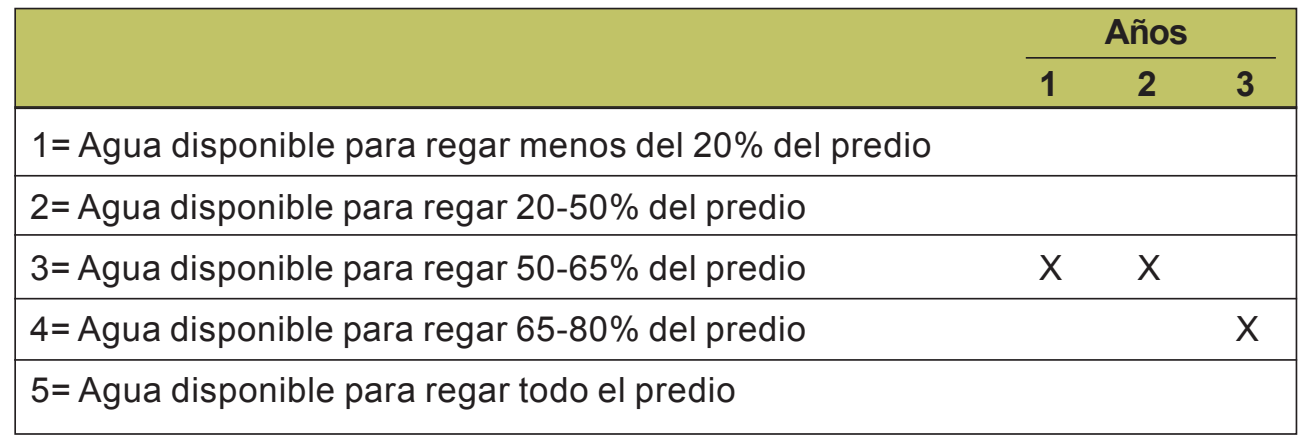

Cuadro 12. Estrategias para desinfección de suelos.

\begin{tabular}{|c|c|c|c|}
\hline & \multicolumn{3}{|c|}{ Años } \\
\hline & 1 & 2 & 3 \\
\hline 1= Desinfección con bromuro de metilo & $\mathrm{x}$ & & \\
\hline 2= Desinfección químicos diferente al bromuro de metilo. & & & \\
\hline 3= Solarización y productos químicos diferente al bromuro de metilo & & $x$ & $\mathrm{x}$ \\
\hline 4= Solamente solarización & & & \\
\hline 5= Solarización e incorporación de abonos orgánicos & & & \\
\hline
\end{tabular}




\section{III.1.3. Predio 3}

El productor es propietario de 9 hectáreas en la Colonia 18 de julio, en las que vive con su señora y sus dos hijos pequeños.

Empezó a manejar ese predio en 2012, al heredarlo de su abuelo; anteriormente trabajaba como asalariado en el rubro hortícola haciendo una transición gradual hasta dedicarle el $100 \%$ del tiempo a su predio.

En el primer año solo se realizaron cultivos a campo y ya en 2013 se construyen dos invernaderos, con un área total cubierta de $1800 \mathrm{~m}^{2}$.

Al realizar un primer diagnóstico y consultar al productor sobre sus prioridades y expectativas, manifestó una clara intención de aumentar la productividad de los cultivos protegidos, ya que tienen altos costos fijos por la amortización de la estructura. En cuanto a los cultivos a campo, se realizan lo más temprano posible en la primavera, para poder ingresar con menor competencia al mercado y lograr mejores precios. Complementando esta estrategia, se intenta no hacer cultivos tradicionales (tomate o morrón), ya que a pesar de que estos tienen mayor productividad, su precio siempre es errático.

Una de las limitantes productivas del predio era la disponibilidad de agua para riego. En el año de inicio existía un pozo que daba 3.000 litros/hora (L/h), pero lo ideal sería pensar en un caudal de $10.000 \mathrm{~L} / \mathrm{h}$, para lograr una adecuada cobertura de todo el área. La falta de un volumen de agua adecuado determinaba que parte de los criterios de selección de los cultivos fuera inclinándose por aquellos que requirieran la menor cantidad de agua posible.

Para las labores agrícolas contrata el servicio de maquinaria a un vecino, aunque reconoce que hay momentos en los que se atrasa el servicio, generando retraso en las tareas lo que repercute en el cultivo a instalar.

La toma de decisiones y la planificación de los cultivos es una tarea que se hace en conjunto entre el productor y su señora, también es muy receptivo a nuevas propuestas y sugerencias.

En base al diagnóstico de situación de la empresa familiar se desarrolló un plan de trabajo para levantar las principales limitantes teniendo como eje los objetivos familiares.
En primer lugar, se trabajó en una etapa de gabinete donde se tuvieron en cuenta las limitantes, restricciones y los recursos disponibles para la producción. En esta etapa se organizó el esquema de trabajo anual de los cultivos, variedades a utilizar, fechas de siembra, insumos para los mismos, densidad, manejo a realizar, etc. También se sistematizó el predio considerando las pendientes, de forma tal que los cuadros no acumularan agua, y el empastamiento de los lugares de circulación de agua.

También se realizó un estudio de la viabilidad para las inversiones que el productor pensaba realizar como forma de levantar las principales restricciones del predio y aumentar la productividad: sistemas de protección para los cultivos, compra de un equipo de maquinaria, abastecimiento de agua, etc.

\section{Inversiones}

Las inversiones en infraestructura para protección de los cultivos era la prioridad del productor al inicio del proyecto. Para evaluar su viabilidad se realizó un análisis económico, a partir del cual se priorizó el incremento en el área de macrotúneles para el cultivo de frutilla, principalmente, que también se podría utilizar para melón y cultivos de verano con malla sol y sombra.

Este tipo de estructura tiene como ventajas, en comparación a los microtúneles para frutilla, que mejora el ambiente, reduce costos de apertura y cierre y aumenta la densidad del cultivo por superficie. La desventaja es la baja resistencia a los fuertes vientos lo que hay que tener en cuenta a la hora de la construcción. Otro punto desfavorable es que se trata de estructuras que no están contempladas por las compañías de seguros para granjeros.

En lo relativo a una posible inversión en maquinaria, se proyectó la posibilidad de realizar una inversión en un equipo de maquinaria con herramientas básicas para las labores: un tractor de 30 a $60 \mathrm{HP}$, una rastra de discos, un cincel y un encanterador. Considerando la inversión y los costos que se tienen anualmente por servicios de maquinaria, este equipamiento se amortizaría en 
10 años. Más allá de este análisis, el contar con maquinaria propia implicaría hacer todas las labores necesarias y de manera oportuna, lo que obviamente repercute en el potencial de producción de los cultivos.

Al momento de elaborar el plan de trabajo con el productor, se consideró que al levantar la limitante del agua para riego se podría ampliar el área de cultivo a campo y tener nuevos cuadros para realizar una rotación adecuada para el cultivo de frutilla.

En la proyección se planificó ampliar el área de cultivo protegido incorporando un nuevo macrotúnel para frutilla y un invernáculo más. Al aumentar la densidad de plantación y al contar con nuevas estructuras mejoraron los rendimientos, lo que generó mayores ingresos por superficie. Con esos resultados se cubrieron los costos de amortización de las estructuras. Inclusive, al momento de hacer la evaluación económica no se consideraron los menores costos en mano de obra para apertura y cierre de los macrotúneles.

El productor siguió estrictamente lo planificado, lo que le ayudó a ordenarse en cuanto a las grandes tareas a realizar: siembra de los cultivos en fecha y consideración de cultivos que pudieran generar ingresos en periodos críticos de saldos de caja negativos.

\section{Diversidad de actividades productivas (rubros)}

A nivel productivo se diagnosticó una alta diversificación de cultivos y bajos rendimientos, determinado por una escasa planificación, lo que complicaba el manejo.

En esta situación se planteó disminuir el número de cultivos y no realizar cultivos "esporádicos", con pocas posibilidades de ser bien cuidados.

En los casos de los cultivos bajo invernadero se mejoró en las fechas de siembra y trasplante, lo que permitió lograr cultivos de mayor productividad y reducir la competencia de mano de obra con el cultivo de frutilla, que es el de mayor impacto en los ingresos prediales.

La ampliación del área bajo cultivo no implica un aumento de los cultivos realizados sino un aumento en los cuadros para la rotación de los cultivos, por tal motivo se determina una misma área para los diferentes cuadros.

Cuadro 13. Diversidad de actividades productivas.

\begin{tabular}{|llll|}
\hline & \multicolumn{3}{c|}{ Años } \\
\cline { 2 - 4 } & $\mathbf{1}$ & $\mathbf{2}$ & 3 \\
\hline 1= Una sola actividad productiva & & & \\
\hline 2= Entre 2 y 3 actividades productivas & & & \\
\hline 3= Entre 4 y 6 actividades productivas & $X$ & $X$ & $X$ \\
\hline 4= Entre 6 y 7 actividades productivas & & & \\
\hline 5= Más de 7 actividades productivas & & & \\
\hline
\end{tabular}

\section{Distribución de ingresos anual}

La planificación permitió una mejor distribución de ingresos durante el año mejorando el flujo de caja (Cuadro 14). Eso también ha contribuido a realizar los trabajos en tiem- po y forma, al tener una menor dependencia de la situación financiera para la adquisición de insumos. En definitiva, se fue mejorando de manera paulatina el perfil financiero, lo que permitió comprar los distintos insumos en fecha, ordenando el trabajo de la empresa. 
Cuadro 14. Flujo financiero anual.

\begin{tabular}{|lll|}
\hline & \multicolumn{1}{c|}{ Años } \\
\cline { 2 - 3 } & $\mathbf{1} \mathbf{2} 3$ \\
\hline 1= Existen más de 7 meses con egresos superiores a los ingresos & & \\
\hline 2= Existen entre 6 y 7 meses con egresos superiores a ingresos. & $X$ & \\
\hline 3= Existen entre 4 y 5 meses con egresos superiores a ingresos & $X \quad X$ \\
\hline 4= Existen entre 2 y 3 meses con egresos superiores a ingresos & \\
\hline 5= No existen momentos críticos con egresos superiores a los ingresos & \\
\hline
\end{tabular}

\section{Comercialización, grado de conformidad}

La venta se realizaba mediante comisionista. Si bien la estimación era que la mitad del valor de la mercadería se lo llevaba el comisionista, existía relativa conformidad con el relacionamiento y el negocio. Se empezó a trabajar con dos agentes comerciales para canalizar de mejor manera los productos $y$, ya hacia el final del proyecto, el mismo productor comenzó a colocar su producción en otros mercados distintos a la ciudad de Salto. Eso mejoró el nivel de conformidad, pero se mantenía la incertidumbre en cuanto al uso del tiempo, al tener que atender ambos aspectos del negocio: producción y comercialización (Cuadro 15).

Cuadro 15. Conformidad con la comercialización de productos.

\begin{tabular}{|c|c|c|c|}
\hline & \multicolumn{3}{|c|}{ Años } \\
\hline & 1 & 2 & 3 \\
\hline \multicolumn{4}{|l|}{$1=$ Muy desconforme } \\
\hline \multicolumn{4}{|l|}{ 2= Desconforme } \\
\hline $3=$ Parcialmente conforme & $\mathrm{X}$ & & \\
\hline 4= Conforme & & $\mathrm{x}$ & $x$ \\
\hline $5=$ Muy conforme & & & \\
\hline
\end{tabular}

\section{Uso de registros}

El productor ya llevaba registros de rendimiento y económicos, teniendo los gastos en insumos, mano de obra y servicios contratados y las ventas de productos. Ese tipo de registros se mantuvieron, pero el productor continuó sin tener la capacidad de análisis para discriminar el margen bruto por cultivo. Tampoco se lleva registro de las distintas operaciones realizadas (fertilización, curas, etc.). Por lo tanto, este indicador se mantuvo constante durante todo el período.

Cuadro 16. Uso de registros.

\begin{tabular}{|c|c|c|c|}
\hline & \multicolumn{3}{|c|}{ Años } \\
\hline & 1 & 2 & 3 \\
\hline 1= Ningún registro & & & \\
\hline $2=$ Registro de compras/ventas & & & \\
\hline 3= Registros económicos & & & \\
\hline $\begin{aligned} 4= & \text { Registros de rendimientos } \\
& \text { y económicos }\end{aligned}$ & $x$ & $x$ & $x$ \\
\hline $\begin{aligned} 5= & \text { Registros completos } \\
& \text { (cuadernos de campo) }\end{aligned}$ & & & \\
\hline
\end{tabular}




\section{Riego}

La disponibilidad de agua era una de las principales limitantes para mejorar la situación productiva y económica. Durante el proyecto se elaboró un plan para realizar una nueva perforación, con financiación del MGAP, la que se concretó. Además, se hizo una propuesta para sistematizar el área a regar. Si bien al finalizar el proyecto todavía no estaba operativa esta nueva infraestructura, significó un salto cualitativo importante para perfilar el predio, con auspiciosas perspectivas a futuro en cuanto a mejorar la productividad y el resultado económico

Cuadro 17. Disponibilidad de riego.

\begin{tabular}{|llll|}
\hline & \multicolumn{3}{c|}{ Años } \\
\cline { 2 - 3 } & $\mathbf{1}$ & $\mathbf{2}$ & 3 \\
\hline 1= Agua disponible para regar menos del 20\% del predio & & \\
\hline 2= Agua disponible para regar $20-50 \%$ del predio & $X$ & $X$ \\
\hline 3= Agua disponible para regar $50-65 \%$ del predio & & & \\
\hline 4= Agua disponible para regar $65-80 \%$ del predio & & \\
\hline 5= Agua disponible para regar todo el predio & \\
\hline
\end{tabular}

\section{Desinfección de suelos y uso de alternativas amigables con el ambiente}

Si bien el productor ya realizaba la técnica de solarización para la desinfección del suelo, durante el proyecto se incorporó el uso de abonos verdes y una mejor rotación de cultivos. En ese sentido, desde el punto de vista del cuidado del suelo se llegó a una situación mejorada, con plena convicción para el uso de estas técnicas.
Dentro de los resultados obtenidos se destaca la receptividad del productor a los planteos propuestos por el equipo de trabajo y su aceptación al acompañamiento técnico. Se evidenció un cambio en el productor en cuanto al manejo del sistema productivo y su actitud en la gestión de la empresa. En cada visita se observaba una gradual incorporación de tecnología y un estrechamiento del vínculo con el técnico.

Cuadro 18. Estrategias para desinfección de suelos.

\begin{tabular}{|c|c|c|c|}
\hline & \multicolumn{3}{|c|}{ Años } \\
\hline & 1 & 2 & 3 \\
\hline \multicolumn{4}{|c|}{$\begin{array}{l}1=\text { Desinfección químicos con bromuro de metilo y/o bromuro de } \\
\text { metilo con solarización. }\end{array}$} \\
\hline \multicolumn{4}{|l|}{ 2= Desinfección químicos diferente al bromuro de metilo. } \\
\hline \multicolumn{4}{|c|}{$3=$ Solarización y productos químicos diferente al bromuro de metilo } \\
\hline 4= Solamente solarización & $\mathrm{X}$ & & \\
\hline 5= Solarización e incorporación de abonos orgánicos & & $\mathrm{X}$ & $\mathrm{X}$ \\
\hline
\end{tabular}


Este informe consiste en un breve reporte de métodos, resultados y análisis de las tres principales variables ambientales seleccionadas para el seguimiento de los productores hortícolas participantes del proyecto en el área cercana a la ciudad de Salto. Esto implicó el relevamiento de variables de suelo, agua y biodiversidad.

\section{Carbono en el suelo}

La materia orgánica del suelo (MOS) está altamente correlacionada con la fertilidad, dada su influencia sobre las propiedades físicas y la capacidad de retener y suministrar nutrientes. También se considera que su poder buffer reduce las imprecisiones de la fertilización de cultivos y es componente esencial de la resiliencia del sistema, ya que es un importante atributo del suelo para recuperarse luego de una crisis. La clasificación de la MOS según su asociación con el fraccionamiento físico por tamaño entre las partículas del suelo se basa en la asociación encontrada entre la MOS y la fracción mineral. Esta clasificación tiene la ventaja de poder vincular más fácilmente la fracción de la MOS referida con diferentes propiedades físicas y químicas del suelo.

La clasificación de la MOS según el fraccionamiento físico puede ser por tamizado, densitometría o sedimentación. El fraccionamiento por tamizado propuesto por Cambardella y Elliot (1992) es:

\section{Materia Orgánica Particulada (MOP):}

- $\mathrm{MOP}_{200}$ - asociada a fracción suelo de tamaño mayor a $212 \mu \mathrm{m}$.

- $\mathrm{MOP}_{50}$ - asociada a fracción de suelo de tamaño entre 53 y $212 \mu \mathrm{m}$.
Materia Orgánica asociada a la fracción mineral del suelo (MOAM):

- MOAM- asociada a fracción de suelo de tamaño menor a $53 \mu \mathrm{m}$.

Puede considerarse que cuanto mayor es el tamaño de la MOP mayor será su labilidad (Franzlubbers y Arshad, 1997) o la facilidad de ser químicamente descompuesta por los microorganismos, por lo que esta fracción juega un papel importante en el ciclo de nutrientes del suelo y en el mantenimiento de energía para la actividad microbiana. Cuanto menor es el tamaño de fraccionamiento, hasta llegar a MOAM, la asociación con las fracciones minerales del suelo es mayor y esta fracción de la materia orgánica tendrá una incidencia mayor en la estructura del suelo. No obstante, hay un gradiente entre ambas fracciones y por lo tanto la incidencia de ambas en los diferentes aspectos físicos, químicos y biológicos se solapan y no son tan claramente separables. En los últimos años se ha comenzado a utilizar esta clasificación de la materia orgánica como indicador de cambios en corto plazo debido a diferencias de manejo del suelo. Los resultados no siempre concuerdan, pero en términos generales, se puede asumir que los mayores cambios ocurren en la fracción de MOP, por lo que resulta un indicador más sensible que la medición de la materia orgánica del suelo como único valor. Su valor como indicador, además de por las variaciones que presenta, radica en su vinculación con parámetros físicos vinculados con la estructura del suelo.

El muestreo se realizó en los primeros 6 $\mathrm{cm}$ de profundidad, ya que son los más sensibles a los cambios, tanto en pérdidas como en mejoras en el contenido de carbono orgánico.

*Programa Nacional de Producción y Sustentabilidad Ambiental. 
Cuadro 1. Contenido de $C$ orgánico en suelo en cada predio.

\begin{tabular}{|llcc|}
\hline \multicolumn{4}{|c|}{ Contenido en carbono orgánico del suelo en \% según fracción y uso del suelo } \\
\hline Etiquetas de fila Promedio de $212 \mu \mathrm{m}$ & Promedio de $53 \mu \mathrm{m}$ & Promedio de $<53 \mathrm{\mu m}$ \\
\hline Productor 1 & & & \\
\hline Campo Natural & $0,41 \pm 0,22 \mathrm{a}$ & $0,13 \pm 0,13 \mathrm{a}$ & $1,41 \pm 0,59 \mathrm{a}$ \\
Invernáculo & $0,29 \pm 0,28 \mathrm{a}$ & $0,08 \pm 0,01 \mathrm{a}$ & $0,64 \pm 0,04 \mathrm{~b}$ \\
Microtúnel & $0,30 \pm 0,23 \mathrm{a}$ & $0,07 \pm 0,07 \mathrm{a}$ & $0,52 \pm 0,27 \mathrm{~b}$ \\
Rastrojo & $0,09 \pm 0,03 \mathrm{~b}$ & $0,06 \pm 0,01 \mathrm{a}$ & $0,63 \pm 0,11 \mathrm{~b}$ \\
\hline Productor 2 & & & \\
\hline Cítricos entre fila & $0,07 \pm 0,03 \mathrm{a}$ & $0,03 \pm 0,01 \mathrm{c}$ & $0,45 \pm 0,09 \mathrm{~b}$ \\
Cítricos fila & $0,07 \pm 0,03 \mathrm{a}$ & $0,05 \pm 0,01 \mathrm{~b}$ & $0,59 \pm 0,13 \mathrm{~b}$ \\
Campo Natural & $0,17 \pm 0,15 \mathrm{a}$ & $0,10 \pm 0,03 \mathrm{a}$ & $1,10 \pm 0,23 \mathrm{a}$ \\
Invernáculo & $0,09 \pm 0,00 \mathrm{a}$ & $0,08 \pm 0,03 \mathrm{ab}$ & $0,66 \pm 0,09 \mathrm{~b}$ \\
\hline Productor 3 & & & $1,65 \pm 0,20 \mathrm{a}$ \\
\hline Campo Natural & $0,17 \pm 0,11 \mathrm{a}$ & $0,07 \pm 0,01 \mathrm{a}$ & $0,43 \pm 0,01 \mathrm{~b}$ \\
Invernáculo & $0,08 \pm 0,01 \mathrm{a}$ & $0,07 \pm 0,03 \mathrm{a}$ & $0,46 \pm 0,05 \mathrm{~b}$ \\
\hline Microtúnel & $0,10 \pm 0,00 \mathrm{a}$ & $0,02 \pm 0,01 \mathrm{~b}$ & \\
\hline
\end{tabular}

Letras similares en la columna, para cada productor significa que no hay diferencias significativas $p=0,05$.

Resulta claro que el uso del suelo en horticultura intensiva, tanto en cultivos protegidos como a campo, reduce los contenidos de materia orgánica con respecto al campo natural. Esto es manifiesto en la materia orgánica más recalcitrante que es la asociada a la fracción más fina $(<53 \mu \mathrm{m})$. En el caso de la más lábil, que es la de la fracción mayor a $212 \mu \mathrm{m}$, es muy baja en todos los casos dado que son suelos muy livianos y esa fracción está normalmente compuesta por arena con muy baja capacidad de fijación de carbono.

\section{Calidad de agua}

La calidad del agua se puede ver afectada por los distintos usos del suelo que se practican debido a la actividad económica que se desarrolla en la región. Se generan efectos tanto en los aspectos abióticos cómo bióticos de los sistemas acuáticos (Dunne y Leopold, 1978; Lenat, 1984; Carpenter et al., 1998; Jarvie et al., 1998). Los programas de monitoreo de calidad de agua generalmen- te incluyen la determinación de una gran cantidad de variables físicas y químicas en diferentes sitios y, en función de los valores obtenidos, se realiza una estimación del estado del recurso hídrico (Chapman, 1992). Desde esta perspectiva, la calidad se define por comparación con valores de referencia definidos en función del uso del recurso hídrico (consumo humano, riego, recreación, conservación de la biota acuática, etc.) y establecidos en un marco legal (Teixeira de Mello, 2007).

Para evaluar los casos de estudio se seleccionaron los principales macronutrientes (nitrógeno y fósforo), que se consideran las principales causas de eutrofización de cuerpos de agua.

El fósforo es un elemento natural que puede estar en rocas y materia orgánica, pero también puede provenir del uso de fertilizantes y otros químicos, por lo que puede ser hallado en altas concentraciones en áreas con actividad humana. Esto puede generar el fenómeno de eutrofización (Vega, 2009). 
Los contenidos de nitratos son importantes, ya que las fuentes de contaminación se asocian principalmente a actividades agrícolas y ganaderas (fertilización, estiércol), así como también a actividades agroindustriales (Brainwood et al., 2004).

El muestreo se realizó estacionalmente en diferentes cuerpos de agua superficial (tajamares y cañadas) y en aguas subterráneas utilizadas para riego y consumo doméstico. Los resultados obtenidos se muestran en el Cuadro 2.

En términos generales aparecen dos elementos que llaman la atención, lo que debería implicar precauciones en los sistemas intensivos de los alrededores de Salto.

El primero es la continua aparición de nitratos en las aguas subterráneas en niveles importantes. El alto uso de fertilizantes y concentración de productores producen altos niveles de nitrógeno, lo que sumado a la gran infiltración de los suelos y la baja capacidad de retención de nutrientes hace que los acuíferos, en su mayoría de recarga local, estén recibiendo cantidades importantes de nitratos.

El otro elemento que resalta es la presencia de fósforo en cursos de agua superficiales, con una variabilidad muy alta, dada las características de este elemento que es recirculado luego de lluvias y eso pone de manifiesto su presencia. Los niveles superan los $0,05 \mu \mathrm{g} / \mathrm{L}$, que es el límite que esta- blece la legislación nacional, lo que implica un riesgo inminente de eutrofización de dichas fuentes.

\section{Biodiversidad}

La biodiversidad es responsable de gran cantidad de procesos ecosistémicos y los cambios en su composición pueden afectar drásticamente el funcionamiento del ecosistema y su capacidad de proveer servicios (Pereira y David Cooper, 2006). La evaluación de estas metas depende en gran medida de los indicadores de biodiversidad que resuman la evolución observada en los ecosistemas (CBD, 2004; Gregory et al., 2005).

Se utilizó la comunidad de aves como indicadora de la biodiversidad presente en los predios, dado que son un grupo de organismos: (i) fácil de detectar ya que muchas especies son diurnas, relativamente conspicuas y/o vocalizan frecuentemente; (ii) es un grupo del que, relativamente, se cuenta con un buen conocimiento general (ej. taxonómico, biológico, poblacional biogeográfico); (iii) presenta diversidad de especies y su biología, incluyendo muchos migrantes que son sensibles a diversos cambios ambientales; (iv) presenta especies que se ubican en todo el rango de niveles tróficos y por lo tanto pueden ser sensibles o causantes de cambios a otros niveles de la red trófica; (v) responden rápido a cambios en la estructura física del ambiente; vi) generan conexión y

Cuadro 2. Contenidos de fósforo y nitrógeno para aguas superficiales y subterráneas en los distintos establecimientos

\begin{tabular}{|c|c|c|}
\hline Productor y fuente & $P \mu g / L(m e d i a \pm D S)$ & $\mathrm{N}-\mathrm{NO}_{3} \mathrm{mg} \mathrm{N} / \mathrm{L}$ (media $\pm \mathrm{DS}$ ) \\
\hline \multicolumn{3}{|l|}{ Productor 1} \\
\hline pozo & $15,4 \pm 26,6$ & $7,2 \pm 7,5$ \\
\hline tajamar & $10,7 \pm 18,4$ & $2,9 \pm 4,9$ \\
\hline \multicolumn{3}{|l|}{ Productor 2} \\
\hline pozo & $0,1 \pm 0,1$ & $4,5 \pm 6,3$ \\
\hline tajamar & $22,5 \pm 38,9$ & $3,2 \pm 5,0$ \\
\hline \multicolumn{3}{|l|}{ Productor 3} \\
\hline cañada & $185,8 \pm 321,0$ & $2,8 \pm 4,7$ \\
\hline pozo & 0,0 & $7,0 \pm 8,8$ \\
\hline
\end{tabular}


significado para las personas y sus vidas (Gibbons y Gregory, 2006; Butler et al., 2010; Gregory y Strien, 2010).

Su aplicabilidad para monitorear la salud de los ecosistemas se demuestra por la inclusión de un indicador basado en la tendencia poblacional de aves entre los principales indicadores de desarrollo sustentable del gobierno del Reino Unido (Gregory et al., 2003, 2004c; Anon, 2013) y entre los indicadores estructurales y de sustentabilidad de la Unión Europea (Gregory et al., 2005).

Una de las limitaciones de usar las aves como indicadores de la biodiversidad es que son el grupo menos amenazado para su conservación dentro de los vertebrados (Baillie et al., 2004), lo que podría sugerir que son menos sensibles a los cambios antropogénicos que otros grupos dada su alta movilidad. Sin embargo, estudios recientes han demostrado el valor de las especies comunes como indicadores (Butler et al., 2010) y para brindar servicios ecosistémicos (Gaston y Fuller, 2008), y por lo tanto la importancia de conservar sus niveles poblacionales.

Dada la escala pequeña de dos de los casos de estudio, productores exclusivamente hortícolas, en ellos se optó por estaciones de muestreo en los que se registraban especies y número de individuos durante media hora. En cada establecimiento fueron seleccionados dos sitios que contrastaban: una situación de zona de cultivos protegidos (alta modificación del medio) y una zona de la mayor naturalidad posible. En el caso del productor 3 fue un parche remanente de campo natural con árboles y en el caso del productor 1, una zona de rastrojos y cultivos hortícolas extensivos acompañada de un pastizal en zona baja.

En el caso del productor 2, de mayor tamaño, se realizaron transectas de $900 \mathrm{~m}$ en tres tramos de $300 \mathrm{~m}$. Una transecta fue realizada en campo natural y la otra en monte nuevo de citrus. El campo natural tenía síntomas fuertes de degradación de las comunidades naturales. Los resultados se aprecian en el Cuadro 3.

Cuadro 3. Especies de aves (total y por tipo de sitio) en cada uno de los predios.

\begin{tabular}{|c|c|c|}
\hline Productor 1 & Productor 2 & Productor 3 \\
\hline Total ........................ 61 & Total ..................... 52 & Total ...... \\
\hline Rastrojos ............. 36 & $\mathrm{CN}$ & $\mathrm{CN} \ldots .$. \\
\hline Invernáculos ...... 20 & Citrus .................. 31 & Nylon ...................... 21 \\
\hline
\end{tabular}

Cuadro 4. Especies prioritarias para la conservación y su presencia en los predios.

\begin{tabular}{|llccc|}
\hline Nombre científico & Nombre común & Predio 1 & Predio 2 & Predio 3 \\
\hline Donacospiza albifrons & Monterita Cabeza Gris & $>$ & & $>$ \\
Geranoaetus melanoleucus & Aguila Mora & & $>$ & \\
Nothura maculosa & Perdiz Común & $>$ & $>$ & $>$ \\
Paroaria coronata & Cardenal Copete Rojo & $>$ & $>$ & $>$ \\
Rynchotus rufescens & Martineta & $>$ & $>$ & $>$ \\
Sporophila cinnamomea & Capuchino Corona Gris & $>$ & & \\
Sporophila ruficollis & Capuchino Garganta Café & $>$ & & \\
\hline
\end{tabular}




\section{Productor 1}

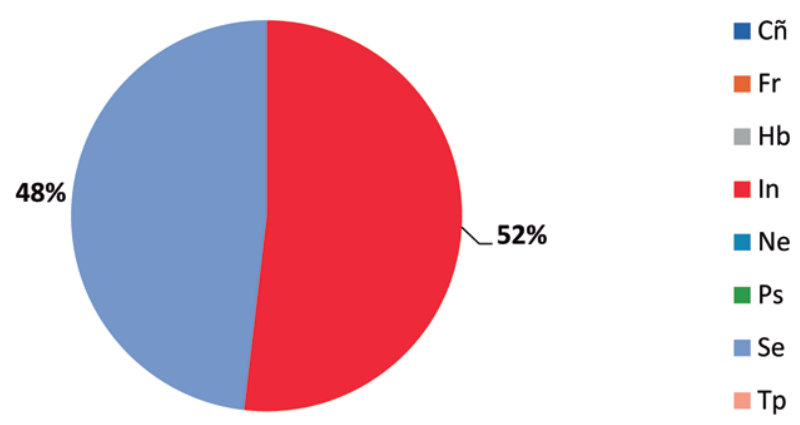

Figura 1. Porcentaje de individuos según gremio alimenticio para el establecimiento 1.

Referencias: $\mathrm{C} \tilde{\mathrm{n}}=$ carroña, $\mathrm{Fr}$ = frutos, $\mathrm{Hb}=$ herbívoros, $\mathrm{In}=$ insectos, $\mathrm{Ne}=$ néctar, $\mathrm{Ps}=$ peces y otros organismos acuáticos, $\mathrm{Se}=$ semillas y TP $=$ pequeños tetrápodos.

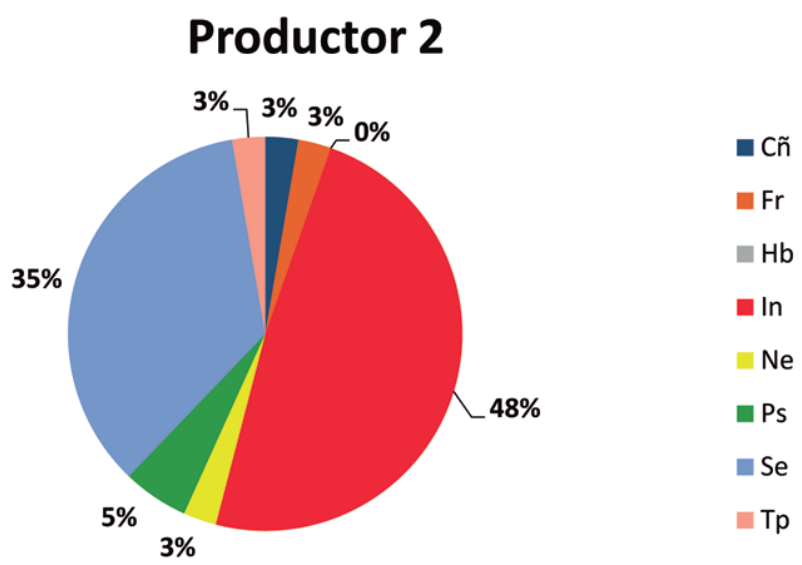

Figura 2. Porcentaje de individuos según gremio alimenticio para el establecimiento 2.

Referencias: $\mathrm{C} \tilde{n}=$ carroña, $\mathrm{Fr}$ = frutos, $\mathrm{Hb}=$ herbívoros, $\mathrm{In}=$ insectos, $\mathrm{Ne}=$ néctar, $\mathrm{Ps}=$ peces $\mathrm{y}$ otros organismos acuáticos, $\mathrm{Se}=$ semillas y TP $=$ pequeños tetrápodos.

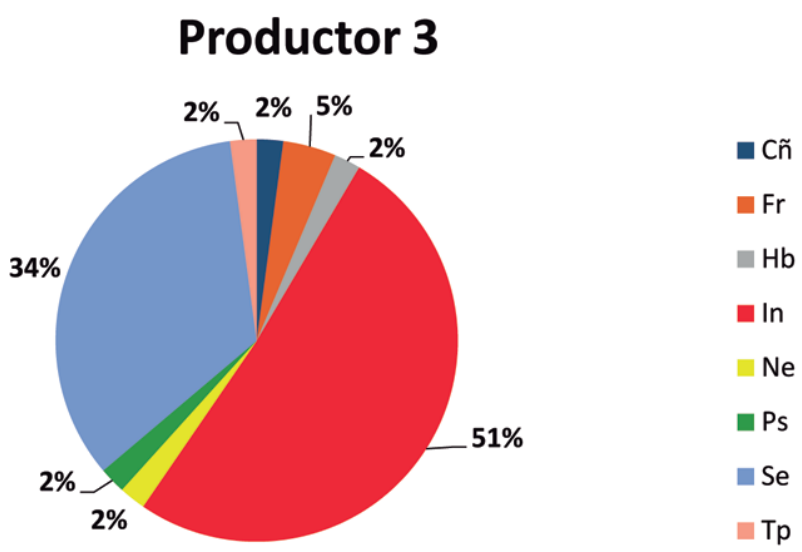

Figura 3. Porcentaje de individuos según gremio alimenticio para el establecimiento 3 Referencias: $\mathrm{C} \tilde{n}=$ carroña, $\mathrm{F} r=$ frutos, $\mathrm{Hb}=$ herbívoros, $\mathrm{In}=$ insectos, $\mathrm{Ne}=$ néctar, $\mathrm{Ps}=$ peces y otros organismos acuáticos, $\mathrm{Se}=$ semillas y TP $=$ pequeños tetrápodos. 
Para el caso de las aves, es de destacar que en aquellos casos de productores que contaban con alguna fracción importante de campo natural, estaban representados prácticamente todos los gremios, mientras que en el caso en que se evaluaron rastrojos y cultivos protegidos solo dos granívoros e insectívoros estaban presentes. Ambos gremios fueron los dominantes en todos los casos, pero eso es normal en nuestros ecosistemas.

Desde el punto de vista empírico se pudo comprobar la importancia que tiene el mantenimiento de parches de ambientes naturales o semi naturales, con presencia de árboles, arbustos y pastizales nativos para las aves. No sería muy aventurado imaginar que esto ocurre de la misma manera para otros grupos de la biota nativa. Incluso los rastrojos con vegetación espontánea aportan las variantes a la matriz dominante que son esenciales como nichos ecológicos permanentes o transitorios.

\section{Conclusiones}

Los sistemas de producción vegetal intensiva que se desarrollan en los alrededores de la capital salteña constituyen una actividad económica y socialmente importan- te para la región, pero someten los ecosistemas a presiones ambientales altas. Desde el punto de vista del suelo, es claro que el carbono orgánico ha ido decreciendo con la conversión del campo natural a cultivos y por tanto la capacidad natural del mismo para sostener algunos procesos se reduce.

Los ecosistemas acuáticos también están recibiendo esa presión, lo que se confirma por la presencia de altas concentraciones de fósforo en cursos superficiales y nitratos en aguas subterráneas. Esta última variable constituye una doble preocupación, ya que es menos visible, con efectos acumulativos y en el largo plazo afecta los ecosistemas acuáticos superficiales y en algunos casos ha alcanzado niveles de riesgo para la salud. Debe tenerse presente que esta fuente de agua es la utilizada mayoritariamente para el consumo humano y lavado de productos.

En relación con la biodiversidad, se realza la importancia de la heterogeneidad en el mosaico de uso de suelo y sobre todo el mantenimiento de parches de vegetación natural, inclusive aquellos remanentes de escasa superficie, bordes y otros, contribuye a la misma. También son importantes los rastrojos con vegetación espontánea y el no uso de herbicidas o quemas en esas zonas. 


\section{III.3. DIMENSIÓN SOCIAL}

Ing. Agr. (Mag) María Marta Albicette*

Tal como se hizo en el caso de los productores ganaderos familiares ubicados en la zona de influencia de Tacuarembó, en este capítulo se presentan los tres informes prediales de los productores hortícolas de Salto vinculados al proyecto de producción familiar del norte. En base al análisis de las entrevistas realizadas al inicio y al final del proyecto y a reuniones con otros integrantes del equipo de trabajo y el técnico de campo, se arribó a componentes del área social destacados. A su vez, se definieron los indicadores para cada productor como forma de describir los procesos sociales ocurridos durante la implementación del proyecto. Los aspectos sociales que se destacan en este trabajo y los indicadores utilizados fueron seleccionados tomando como base el aprendizaje realizado durante el desarrollo del proyecto "Co-innovando para el desarrollo sostenible de sistemas ganaderos familiares de Rocha - Uruguay", ejecutado por INIA entre 2012 y 2015 (Albicette et al., 2016; Aguerre y Albicette, 2018).

La lista de aspectos sociales que se presentan para cada productor son los siguientes:

1. Caracterización de cada productor (descriptivo)

2. Definición de sustentabilidad (descriptivo)

3. Calidad de vida estructural

4. Calidad de vida subjetiva

5. Uso de tecnologías propuestas

6. Planificación

7. Aprendizajes y cambios más relevantes

8. Relación técnico-productor
En una primera etapa se caracterizaron los predios considerando diversos aspectos de composición familiar, lugar de residencia, sistema productivo, trayectoria en el campo, tenencia de la tierra, fuerza de trabajo. Asimismo, se consensuó con cada productor y su familia la visión de futuro-sustentabilidad, que de acuerdo con Sarandón (2002) es el primer paso para orientar un proceso para evaluar la sustentabilidad. La misma da idea clara de cuál es la visión de futuro. Posteriormente se definieron indicadores sociales para evaluar el resultado de los cambios introducidos, tomando como base el MESMIS (Masera et al., 2000), relacionados con calidad de vida, sucesión, uso de tecnologías, valoración y uso de la planificación. Los mismos se complementaron con un indicador cualitativo que denominamos "aprendizajes y cambios más relevantes". Además, se destacan las principales características valoradas por los productores de la forma de trabajo y del vínculo con el técnico de campo, aspecto relevante para el logro de los resultados del proyecto.

Para los dos primeros aspectos (caracterización y definición de sustentabilidad) se hace una descripción detallada de cada caso. Para el resto de los componentes del área social se utilizaron los mismos conceptos que se definieron en el caso de los productores ganaderos familiares. Para los tres estudios de caso de Salto se presenta el indicador "uso de tecnologías propuestas" para cada productor como parte integrante de los cambios sociales relevantes para cada predio.

*Unidad de Comunicación y Transferencia de Tecnología. 


\section{III.3.1. Predio 1}

\section{Caracterización del productor}

Las principales características que describen la unidad de producción y la unidad familiar del predio 1 se presentan en el Cuadro 1.

\section{Definición de sustentabilidad}

Las principales ideas asociadas con la visión de futuro-sustentabilidad del predio y la familia se puede resumir con los siguientes conceptos.

\section{Sustentabilidad significa:}

- Que los padres y los cuatro hermanos con las familias vivan y trabajen en el predio como ha sido desde sus abuelos. Seguir con el pasaje de responsabilidad de la empresa, que se fue dando naturalmente, del padre a sus hijos, contando con la ayuda de las mujeres en algunas tareas. Son productores familiares pequeños y ninguno de los cuatro hermanos tiene pereza: "Acá no existe la pereza".

- Seguir valorando el hecho de que sea la propia familia la que trabaja en el predio. Hay además un trabajador, que es como de la familia. Se entiende que no es lo mismo depender de personal, que muchas veces no cuida.

- Tomar las decisiones entre todos, con el criterio general de la familia. Los cuatro hermanos tienen un sueldo, se cubren los gastos de producción y el resto se invierte en mejoras y arreglos. Se asume que en unos años cada hermano pueda realizar retiros.

- Pensar en que en algún momento podrán tomarse más vacaciones, pero por ahora tienen claro que es necesario estar allí con la familia, ver a los padres contentos y lograr las metas productivas.

Cuadro 1. Caracterización del predio 1.

\begin{tabular}{|c|c|}
\hline Categorías considerada & \\
\hline Composición familiar & $\begin{array}{l}\text { Cuatro hermanos que trabajan, sus esposas apoyan el trabajo } \\
\text { y los padres hacen algunas tareas. }\end{array}$ \\
\hline Lugar de residencia & $\begin{array}{l}\text { Todos los integrantes de la familia viven en el predio: los pa- } \\
\text { dres, los cuatro hermanos, tres de ellos con pareja y } 4 \text { hijos. }\end{array}$ \\
\hline Sistema productivo & Vegetal intensivo. \\
\hline Superficie manejada (ha) & 42,5 ha. \\
\hline Tenencia de la tierra & 18 ha propiedad del padre. 24,5 ha se arriendan al INC. \\
\hline $\begin{array}{l}\text { Mecanismo de acceso } \\
\text { a la tierra }\end{array}$ & Por herencia y arrendamiento al INC. \\
\hline Trayectoria en el campo & 22 años en el predio familiar. Tres años en el predio del INC. \\
\hline Historia laboral & $\begin{array}{l}\text { La familia siempre estuvo en el campo. Algunos hermanos } \\
\text { eran asalariados y volvieron a trabajar todos juntos. }\end{array}$ \\
\hline Sucesión & Tema hablado, pero no resuelto \\
\hline Trabajo extra predial & NO. \\
\hline Otras fuentes de ingreso & NO. \\
\hline Mano de obra contratada & $\begin{array}{l}\text { Una persona contratada permanente y zafrales cuando se } \\
\text { necesitan }\end{array}$ \\
\hline $\begin{array}{l}\text { Participación en } \\
\text { instancias colectivas }\end{array}$ & Dos hermanos dirigentes en la Colonia Gestido. \\
\hline
\end{tabular}


- Alcanzar la meta de $12.000 \mathrm{~m}^{2}$ de invernáculos para tomate, complementado con cultivos bajo micro túneles como frutilla, zapallito y melón y cultivos de campo: zapallito, boniato, berenjena, morrón y maíz. Analizar el uso de los macro túneles para facilitar el manejo, utilizar más abonos verdes y probar con la solarización. En un futuro tener animales si hay lugar.

- Diseñar e implementar un sistema de riego con cañería subterránea distribuida por el predio.

- Adquirir una clasificadora de tomates y lo que se necesite en el futuro, de momento se entiende que cuentan con toda la maquinaria necesaria.

- Pensar siempre en volumen productivo y no perder nunca el objetivo de calidad. Preparar el tomate de calidad con un calibre y marca y la frutilla en cajones especiales, vendiéndole al comisionista. Hoy no podrían incrementar más el área por la falta de mano de obra en la época de cosecha de frutilla.

Cuadro 2. Calidad de vida estructural.

\begin{tabular}{|l|c|c|}
\hline \multirow{2}{*}{ Variables } & \multicolumn{2}{|c|}{ Productor 1 } \\
\cline { 2 - 3 } & Año 1 & Año 3 \\
\hline Vivienda & 3 & 5 \\
\hline Energía eléctrica & 5 & 5 \\
\hline Acceso a agua potable & 5 & 4 \\
\hline Conectividad vial & 4 & 5 \\
\hline Disponibilidad de vehículo & 5 & 3 \\
\hline Distancia a centros poblados & 3 & 5 \\
\hline Conectividad digital & 5 & 5 \\
\hline Acceso a salud básica & 5 & 4 \\
\hline Nivel educativo formal & 4 & 5 \\
\hline Acceso a capacitación & 5 & 3 \\
\hline Nivel de endeudamiento & 4 & Valor absoluto $=49$ \\
\hline CALIDAD DE VIDA ESTRUCTURAL & Valor absoluto $=48$ \\
INTEGRADA & Valor del índice $=4$ & Valor del índice $=4$ \\
\hline
\end{tabular}

Calidad de vida estructural integrada: $\leq 20=1$, entre 20 y $30=2$, entre 30 y $40=3$, entre 40 y $50=4, \geq 50=5$.
- Llevar registros prolijos, parecido al "cuaderno del ingeniero" donde está especificado todo el paquete y como viene el clima y las curas. Respetar y prestar atención al asesoramiento del ingeniero agrónomo lo que los motiva y valoran.

- Seguir viendo, averiguando con técnicos y productores y con el INIA, adoptando tecnología y genética. Priorizar alguna actividad de capacitación para combinar con el trabajo. Tener reuniones abiertas ya que se aprende al ver e intercambiar.

- Agrandar el área de la explotación obteniendo otra fracción del INC, ya que nadie quiere irse del predio a trabajar afuera.

- Que alguno de los hermanos siga participando como dirigente de la S.F.R. Colonia Gestido y en la Mesa Hortícola, lo que permite en el futuro pensar en compras conjuntas de insumos que abaraten los costos.

\section{Calidad de vida estructural}

La calidad de vida estructural se presenta con 11 variables (Cuadro 2). Las medicio- 
nes se realizaron al principio (Año 1) y al final del proyecto (Año 3 ). Las variables que evidenciaron cambios se destacan con un sombreado y la valoración se destaca en rojo. Con las variables consideradas se construyó un índice denominado calidad de vida estructural integrada que es la suma de los valores de cada variable, el cual se valora con escala de 1 a 5.

En el caso de la familia 1 las mejoras en la calidad de vida estructural se relacionan con la vivienda, ya que edificaron una casa para uno de los hermanos. Por su parte, hubo un descenso en el valor del indicador de nivel de endeudamiento, ya que contrajeron deuda por la compra de la clasificadora de tomate. Estas variables dan lugar a un cambio del valor absoluto de calidad de vida estructural integrada de 48 a 49, manteniéndose el índice en 4.

\section{Calidad de vida subjetiva}

La calidad de vida subjetiva considera la valoración que los individuos hacen de su calidad de vida de acuerdo con sus criterios de satisfacción, utilizando una escala entre 5 (muy satisfecho) y 1 (insatisfecho) (Cuadro 3). Complementariamente se presentan factores asociados a la calidad de vida subjetiva en frases dichas por los productores durante la entrevista, que permiten un mejor entendimiento de la valoración numérica del indicador.
Cuadro 3. Calidad de vida subjetiva.

\begin{tabular}{|lcc|}
\hline & Año 1 & Año 3 \\
\hline Productor 1 & 5 & 5 \\
\hline
\end{tabular}

Muy satisfecho=5. Medianamente satisfecho $=4$. Satisfecho=3. Poco satisfecho=2. Insatisfecho=1

Algunos factores asociados a la calidad de vida mencionados por la familia fueron: "Cada hermano saca un sueldo y la inversión en el predio se fue haciendo". "Tomamos las decisiones entre todos los hermanos".

\section{Uso de tecnologías propuestas}

Este apartado refiere al grado de implementación de las tecnologías propuestas durante el proyecto. El uso del set de tecnologías se valora al inicio del proyecto (Año 1), a la mitad del proyecto (Año 2) y al final de este (Año 3). Para cada una de las técnicas propuestas se asignó un valor de $1 \mathrm{si}$ era utilizada y de 0 si no se utilizaba. El resultado de la aplicación de cada tecnología se observa en el Cuadro 4.

Al inicio del proyecto el productor ya venía aplicando algunas de las tecnologías (ej. manejo de tratamientos fitosanitarios, uso de semillas de calidad). Al cabo del segundo año se incorporaron en el predio las tecnologías de solarización y ferti-riego, algo que se venía evaluando y que el proyecto contribuyó a consolidar. Además, la puesta en

Cuadro 4. Uso del conjunto de tecnologías de producción propuestas para el re-diseño.

\begin{tabular}{|lccc|}
\hline Tecnologías propuestas & Año 1 & Año 2 & Año 3 \\
\hline Solarización & 0 & 1 & 1 \\
\hline Ferti-riego & 0 & 1 & 1 \\
\hline Macro túneles & 0 & 0 & 1 \\
\hline Planificación de la producción & 0 & 1 & 1 \\
\hline Manejo de tratamientos fitosanitarios & 1 & 1 & 1 \\
\hline Uso de semillas de calidad & 1 & 1 & 1 \\
\hline Abonos verdes y/o incorporación de abono orgánico & 0 & 1 & 1 \\
\hline \% de uso del set de tecnologías propuestas & $\mathbf{2 9 \%}$ & $\mathbf{8 6 \%}$ & $\mathbf{1 0 0 \%}$ \\
\hline
\end{tabular}

Valor $1=$ usa la tecnología, valor 0 = no usa la tecnología. 
marcha del proyecto permitió mejorar la gestión a través de una mayor planificación de la producción. En el último año se aumentó el área y se incorporaron macro túneles.

\section{Planificación}

La valoración y uso de la planificación a mediano (MP) y largo plazo (LP) que realiza el productor al inicio del proyecto (Año
1), a la mitad del proyecto (Año 2) y al final del proyecto (Año 3 ) se presenta en el Cuadro 5.

Los comentarios referidos a la planificación son: "Tengo un plan, pero igual es un día a día. Tengo pensado plantar tal cosa en aquel lugar y con la lluvia cambia". "Se planifica en el plazo de los cultivos e influye la comercialización y lo que piden."

Cuadro 5. Grado en que el productor valora y usa la planificación.

\begin{tabular}{|c|c|c|c|}
\hline \multicolumn{2}{|c|}{ Productor 1 } & \multicolumn{2}{c|}{ Comentarios } \\
\hline Año 1 & Año 2 & Año 3 & \\
\hline 2 & 3 & 4 & $\begin{array}{l}\text { El tema de la planificación en predios hortícolas es clave. Por } \\
\text { ejemplo, para hacer solarización hay que planificar ya que no } \\
\text { se va a poder usar el invernáculo por lo menos por 20 días. La } \\
\text { planificación además debe hacerse de manera estacional: } \\
\text { verano e invierno. } \\
\text { Tiene planificado usar las rotaciones con otras especies. }\end{array}$ \\
\hline
\end{tabular}

Valor 5=valora la planificación y tiene planes de LP; Valor 4= valora la planificación y tiene planes de MP; Valor

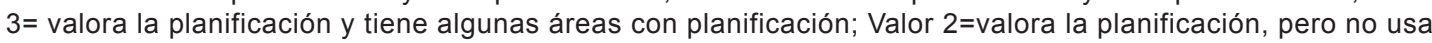
planes; Valor $1=$ ni valora ni usa planes.

\section{Aprendizajes y cambios más relevantes}

Una forma cualitativa de evaluar los cambios y aprendizajes en las personas es con el análisis de los cambios en los conocimientos, actitudes, habilidades y aspiraciones (KASA por su sigla en inglés) (Rockwell y Bennett, 2004). Los aprendizajes y cambios más relevantes se observan en el Cuadro 6. Se valoran por un lado con la descripción realizada por los productores de los cambios que ellos incorporaron en los predios y por otro con una descripción de los cambios en KASA que manifestaron los productores durante las entrevistas.

\section{Relación técnico-productor}

Durante la investigación se indagó sobre las principales características valoradas por los productores de la forma de trabajo y del vínculo con el técnico de campo. Los factores destacados por el productor fueron que el técnico ayudó a reafirmar ideas que ya tenían y que todavía no habían implementado. "Nos ayudó a organizarnos para pasar del bromuro a la solarización". 
Cuadro 6. Aprendizajes y cambios más relevantes.

\begin{tabular}{|c|c|}
\hline Cambios en el predio & $\begin{array}{c}\text { Cambios en conocimientos, habilidades, } \\
\text { actitudes y aspiraciones (KASA) del } \\
\text { productor }\end{array}$ \\
\hline $\begin{array}{l}\text { Incrementaron } 24,5 \text { hectáreas con } \\
\text { el arrendamiento del predio al INC. } \\
\text { Se mejoraron las instalaciones del } \\
\text { campo nuevo. }\end{array}$ & $\begin{array}{l}\text { Con mayor conocimiento y habilidad se pasó a hacer la } \\
\text { solarización. Antes iban a lo seguro y no se arriesga- } \\
\text { ban. }\end{array}$ \\
\hline $\begin{array}{l}\text { Hoy tienen un total de } 8000 \mathrm{~m}^{2} \text { de } \\
\text { invernáculos, } 2 \text { ha de macrotúneles } \\
\text { y } 1 \text { ha de microtúneles. De } 4 \text { ha de } \\
\text { boniatos pasaron a } 10 \text { o } 12 \text { ha. }\end{array}$ & $\begin{array}{l}\text { Antes se llevaban los números, pero solo tenían las gran- } \\
\text { des cifras de ingresos y gastos; ahora se sabe hasta } \\
\text { cuánto abono se usa en cada cultivo. }\end{array}$ \\
\hline $\begin{array}{l}\text { Se llevan mejor los registros y se } \\
\text { sacan los costos para cada cultivo. }\end{array}$ & $\begin{array}{l}\text { Se habla entre los hermanos y cada uno hace lo que le } \\
\text { corresponde y todo el día trabajan juntos. }\end{array}$ \\
\hline $\begin{array}{l}\text { Se planifica mejor. Ahora se rotan } \\
\text { los cultivos y antes era siempre bo- } \\
\text { niato. }\end{array}$ & $\begin{array}{l}\text { En este predio no se vio tanto cambio porque ya tenían } \\
\text { todo bastante organizado y encaminado y lo que se hizo } \\
\text { fue que todo se reafirmó. }\end{array}$ \\
\hline $\begin{array}{l}\text { Antes del proyecto tenían pensado } \\
\text { dejar el uso del bromuro, pero con } \\
\text { el asesoramiento se está organizan- } \\
\text { do para pasar todo a la solarización. }\end{array}$ & $\begin{array}{l}\text { Aspira a crecer en área, ampliar los invernáculos, pro- } \\
\text { ducir lo máximo y lo más sano posible. }\end{array}$ \\
\hline $\begin{array}{l}\text { Mayores ingresos por el uso de los } \\
\text { macro túneles. }\end{array}$ & $\begin{array}{l}\text { Si bien la rutina de trabajo sigue igual no se madruga } \\
\text { tanto. }\end{array}$ \\
\hline $\begin{array}{l}\text { Menos trabajo por los macro túne- } \\
\text { les, pero más trabajo en general para } \\
\text { todos los hermanos porque ahora tie- } \\
\text { nen mayor área. }\end{array}$ & $\begin{array}{l}\text { Con la clasificadora de tomate el trabajo de medio día } \\
\text { ahora se hace en dos horas. }\end{array}$ \\
\hline $\begin{array}{l}\text { Adquirieron una máquina clasifica- } \\
\text { dora de tomate financiada por el } \\
\text { vendedor. }\end{array}$ & $\begin{array}{l}\text { Uno de los hermanos es presidente de la Sociedad } \\
\text { de Fomento. }\end{array}$ \\
\hline $\begin{array}{l}\text { Se compró un tractor y se hizo in- } \\
\text { versión en agua y cañería. }\end{array}$ & Sabe usar los registros para la toma de decisiones \\
\hline
\end{tabular}




\section{III.3.2. Predio 2}

\section{Caracterización del productor}

Se presentan en el Cuadro 7 las principales características que describen la unidad de producción y la unidad familiar del predio 2. En este caso el productor integra además una sociedad con dos hermanos explotando otra fracción de la Colonia, pero la intención es dedicarse en exclusiva a la fracción de 36 hectáreas que le otorgó el INC a la familia, convirtiéndolo en una unidad productiva capaz de generar ingresos para el sustento familiar.

Cuadro 7. Caracterización del predio 2.

\begin{tabular}{|l|l|}
\hline Categorías consideradas & \\
\hline Composición familiar & $\begin{array}{l}\text { Productor, un hijo que ayuda en el predio, una hija que estudia } \\
\text { en Salto y colabora con los registros y la casa y un hijo menor. }\end{array}$ \\
\hline Lugar de residencia & Residen en otro predio a $3 \mathrm{~km}$. \\
\hline Sistema productivo & Vegetal intensivo, ganadería y citrus. \\
\hline Superficie manejada (ha) & 36 ha. \\
\hline Tenencia de la tierra & Arrendatario. \\
\hline $\begin{array}{l}\text { Mecanismo de acceso } \\
\text { a la tierra }\end{array}$ & Arrendamiento al INC. \\
\hline Trayectoria en el campo & 4 años en el predio y toda la vida en la actividad del otro predio. \\
\hline Historia laboral & Productores desde siempre. \\
\hline Sucesión & No han hablado del tema en la casa. \\
\hline Trabajo extra predial & Sí ${ }^{.}$ \\
\hline Otras fuentes de ingreso & Sí. \\
\hline Mano de obra contratada & No. \\
\hline $\begin{array}{l}\text { Participación en } \\
\text { instancias colectivas }\end{array}$ & Si, la hija integra el grupo de jóvenes de la Colonia Gestido. \\
\hline
\end{tabular}

${ }^{1}$ Corresponde al trabajo del productor en la sociedad con sus hermanos.

\section{Definición de sustentabilidad}

Las principales ideas asociadas con la visión de futuro-sustentabilidad del predio y la familia se puede resumir con los siguientes conceptos mencionados por el productor y su familia.

\section{Sustentabilidad es:}

- Crecer en el predio de 36 hectáreas arrendado al INC, realizando el esfuerzo físico y poniendo todas las ideas nuevas para lo que será de los hijos.

- Vivir en la tranquilidad del campo y construirse una casa propia donde tienen delimitado el terreno.
- Que sus tres hijos de 18, 17 y 7 años tengan una profesión. Si bien al hijo mayor, José Mario, no le gustó estudiar, se quedó en el campo y los ayuda con las tareas diarias.

- Manejarse con la menor cantidad de gente contratada ("Gana más el peón que el patrón"), trabajando junto con la familia y el casero y asesorarse. Como se mencionó, el titular también trabaja en una sociedad con sus hermanos, por lo que no está todo el tiempo para este predio. Un objetivo es planificarse para llevar registros y ver los números que se obtienen del predio. 
- En lo productivo:

* En horticultura hacer tomate, morrón, zapallitos, melón, maíz y probar con abonos verdes.

* Continuar el crecimiento del citrus incorporando 5 hectáreas y estudiando las variedades a usar, continuando con el vivero y los injertos.

* Mantener la ganadería como la forma de "hacer caja" vendiendo algo gordo del producto de las 36 vacas y las recrías que mandan al campo de recría.

* Pensar en opciones productivas para el periodo abril-julio, ya que tienen menos requerimiento de mano de obra pero que no les insuma muchas horas.
- Seguir estando orgullosos de los avances logrados y mostrar a otros lo que han avanzado.

- Quedarse en la casa en el tiempo libre, sin pensar en salir de vacaciones a otro lado.

- Integrar como ahora la Directiva de la Sociedad de Fomento Rural Colonia Gestido y pensar en proyectos como el juvenil para la edificación de un gimnasio.

\section{Calidad de vida estructural}

En el caso del productor 2, las variables de la calidad de vida estructural se mantuvieron idénticas entre los años considerados. El valor absoluto del índice de calidad de vida estructural es 48 y el valor es 4 .

Cuadro 8. Calidad de vida estructural.

\begin{tabular}{|l|c|c|}
\hline \multirow{2}{*}{ Variables consideradas } & \multicolumn{2}{|c|}{ Productor 2 } \\
\cline { 2 - 3 } & Año 1 & Año 3 \\
\hline Vivienda & 2 & 5 \\
\hline Energía eléctrica & 5 & 5 \\
\hline Agua potable & 5 & 4 \\
\hline Conectividad vial & 4 & 5 \\
\hline Disponibilidad de vehículo & 5 & 3 \\
\hline Distancia a centros poblados & 3 & 5 \\
\hline Conectividad digital & 5 & 5 \\
\hline Acceso a salud básica & 5 & 4 \\
\hline Nivel educativo formal & 4 & 5 \\
\hline Acceso a capacitación & 5 & 5 \\
\hline Nivel de endeudamiento & 5 & Valor absoluto $=\mathbf{4 8}$ \\
\hline CALIDAD DE VIDA ESTRUCTURAL & $\begin{array}{l}\text { Valor absoluto }=48 \\
\text { Valor del índice }=4\end{array}$ & Valor del índice $=\mathbf{4}$ \\
\hline INTEGRADA & & 5
\end{tabular}

Calidad de vida estructural integrada: $\leq 20=1$, entre 20 y $30=2$, entre 30 y $40=3$, entre 40 y $50=4, \geq 50=5$.

\section{Calidad de vida subjetiva}

La calidad de vida subjetiva considera la valoración que los individuos hacen de su calidad de vida de acuerdo con sus criterios de satisfacción.
Cuadro 9. Calidad de vida subjetiva.

\begin{tabular}{|lcl|}
\hline & Año 1 & Año 3 \\
\hline Productor 2 & 3 & 3 \\
\hline
\end{tabular}

Muy satisfecho $=5$. Medianamente satisfecho $=4$. Satisfecho=3. Poco satisfecho=2. Insatisfecho=1 


\section{Uso de tecnologías propuestas}

El resultado de la evolución del uso de cada tecnología para los tres años se observa en el Cuadro 10.

El set de tecnologías ha sido incorporado lentamente por el productor, quien siente cierta aversión a la innovación y a los cambios. De esa manera, se observa que al comienzo del proyecto no se usaba ninguna de las tecnologías y al final del mismo se había implementado el $43 \%$ de las tecnologías propuestas.

Cuadro 10. Uso del conjunto de tecnologías de producción propuestas para el re-diseño.

\begin{tabular}{|lccc|}
\hline Tecnologías propuestas & Año 1 & Año 2 & Año 3 \\
\hline Solarización & 0 & 1 & 1 \\
\hline Ferti-riego & 0 & 0 & 1 \\
\hline Macro túneles & 0 & 0 & 0 \\
\hline Planificación de la producción & 0 & 0 & 0 \\
\hline Manejo de tratamientos fitosanitarios & 0 & 1 & 1 \\
\hline Uso de semillas de calidad & 0 & 0 & 0 \\
\hline Abonos verdes y/o incorporación de abono orgánico & 0 & 0 & 0 \\
\hline \% de uso del set de tecnologías propuestas & $\mathbf{0 \%}$ & $\mathbf{2 9} \%$ & $\mathbf{4 3 \%}$ \\
\hline
\end{tabular}

Valor $1=$ usa la tecnología, valor $0=$ no usa la tecnología.

\section{Planificación}

La valoración y uso de la planificación a mediano (MP) y largo plazo (LP) que realiza el productor al inicio del proyecto (Año 1), a la mitad del proyecto (Año 2) y al final del proyecto (Año 3) se presenta en el Cuadro 11.

Al respecto de la planificación, el productor manifestó durante las entrevistas que piensa hacer una casita con MEVIR para el hijo.

Cuadro 11. Grado en que el productor valora y usa la planificación.

\begin{tabular}{|c|c|c|l|}
\hline \multicolumn{3}{|c|}{ Productor 2 } & \multicolumn{2}{c|}{ Comentarios } \\
\hline Año 1 & Año 2 & Año 3 & \multicolumn{1}{|c|}{} \\
\hline 1 & 1 & 2 & $\begin{array}{l}\text { Queda pendiente la planificación de la poda y la cura de los } \\
\text { citrus. } \\
\text { Tiene planificado hacer otro rancho de 1000 m y seguir con la } \\
\text { solarización y el riego. }\end{array}$ \\
\hline
\end{tabular}

$5=$ valora la planificación y tiene planes de LP. 4= valora la planificación y tiene planes de MP $3=$ valora la planificación y tiene algunas áreas con planificación. 2=valora la planificación, pero no usa planes. 1= ni valora ni usa planes.

\section{Aprendizajes y cambios más relevantes}

Una forma cualitativa de evaluar los cambios y aprendizajes en las personas es con el análisis de los cambios en los conocimientos, actitudes, habilidades y aspiraciones (KASA por su sigla en inglés) (Rockwell y
Bennett, 2004). Los aprendizajes y cambios más relevantes se valoran por un lado con la descripción realizada por los productores de los cambios que ellos incorporaron en los predios y por otro con una descripción de los cambios en KASA que manifestaron los productores durante las entrevistas (Cuadro 12) 
Cuadro 12. Aprendizajes y cambios más relevantes.

\begin{tabular}{|l|l|}
\hline Cambios en el predio & $\begin{array}{c}\text { Cambios en conocimientos, habilidades, } \\
\text { actitudes y aspiraciones (KASA) del } \\
\text { productor }\end{array}$ \\
\hline $\begin{array}{l}\text { Agrandaron dos invernáculos y pasa- } \\
\text { ron de } 400 \text { a } 1200 \mathrm{~m} .\end{array}$ & Aspira a seguir con la solarización \\
\hline Mejoraron el riego poniendo dos cintas. & $\begin{array}{l}\text { La hija tiene la inquietud de encargarse de los } \\
\text { registros y los números del predio. }\end{array}$ \\
\hline $\begin{array}{l}\text { Incorporaron la solarización en el toma- } \\
\text { te. }\end{array}$ & $\begin{array}{l}\text { Han aprendido a hacer algunas cuentas antes } \\
\text { de plantar. }\end{array}$ \\
\hline $\begin{array}{l}\text { Se incrementó el ingreso por mayor } \\
\text { área y tal vez en el futuro por la cura de } \\
\text { los tomates. }\end{array}$ & $\begin{array}{l}\text { Aprendieron de la solarización porque vino el } \\
\text { técnico que aportó la idea, lo hicieron y anduvo } \\
\text { bien. }\end{array}$ \\
\hline $\begin{array}{l}\text { La hija va juntando las boletas para sa- } \\
\text { car cuentas de lo que ingresa y lo que } \\
\text { sale. }\end{array}$ & $\begin{array}{l}\text { Las cosas que van dando resultado como la } \\
\text { solarización y el riego van quedando. }\end{array}$ \\
\hline $\begin{array}{l}\text { El área de citrus se pensaba agrandar, } \\
\text { pero no se hizo porque la naranja vale } \\
\text { poco. }\end{array}$ & \\
\hline
\end{tabular}

\section{Relación técnico-productor}

Durante la investigación se indagó sobre las principales características valoradas por los productores de la forma de trabajo y del vínculo con el técnico de campo. Los facto- res destacados por el productor fueron: "El técnico nos ayudó a aprender lo de la solarización. La relación con él está muy bien, viene seguido, recorremos y charlamos y lo llamo cuando lo preciso". 


\section{III.3.3. Predio 3}

\section{Caracterización del productor}

Se presentan en el Cuadro 13 las principales características que describen la unidad de producción y la unidad familiar del predio 3.

\section{Definición de sustentabilidad}

Las principales ideas asociadas con la visión de futuro-sustentabilidad del predio y la familia se pueden resumir con los siguientes conceptos mencionados por el productor 3 y su señora.

Cuadro 13. Caracterización del predio 3.

\begin{tabular}{|ll|}
\hline Categorías consideradas & \\
\hline Composición familiar & Productor y su señora, una hija, un hijo y otro en camino \\
\hline Lugar de residencia & Predio. \\
\hline Sistema productivo & Vegetal intensivo. \\
\hline Superficie manejada (ha) & 9 ha. \\
\hline Tenencia de la tierra & $\begin{array}{l}\text { Propietario de 4,5 ha y las otras 4,5 ha que tiene con sus tres } \\
\text { hermanas y allí vive el padre }\end{array}$ \\
\hline $\begin{array}{l}\text { Mecanismo de acceso } \\
\text { la tierra }\end{array}$ & Herencia del abuelo. \\
\hline Trayectoria en el campo & 4 años en el predio. \\
\hline Historia laboral & 15 años como empleado hortícola. \\
\hline Sucesión & Lo ha pensado, pero no lo ha hablado con las hermanas. \\
\hline Trabajo extra predial & No. \\
\hline Otras fuentes de ingreso & Llevan en camión la producción a vender en Artigas. \\
\hline Mano de obra contratada & Sí. Zafrales. \\
\hline $\begin{array}{l}\text { Participación en } \\
\text { instancias colectivas }\end{array}$ & Si, en la Colonia 18 de Julio. \\
\hline
\end{tabular}

\section{Sustentabilidad significa:}

- Mantener el campo que heredó y donde vivió de chico con los abuelos.

- Vivir y trabajar en el predio con su señora y criar allí a sus hijos.

- Planificar los cultivos, sacar las cuentas y tomar las decisiones del predio junto a la señora utilizando cultivos de ciclo corto para sacar cosecha temprana, plantándolos fuera de estación, obteniendo mejores precios y atendiéndolos con menos trabajo. Su eslogan productivo es: "Tenés que pensar en lo que sea temprano y en lo que sea seguro".
- Crecer en la producción para lograr un mayor ingreso, estar mejor económicamente, tener un mayor confort en la casa y contar con otros elementos que le faltan. A corto plazo tener otro invernáculo poniendo en práctica una transacción de reciprocidad por ladrillos con un vecino.

- En un futuro hacer un pozo de agua que les permita aumentar el riego y no tener que seleccionar los cultivos que usan poca agua. Adquirir un equipo de maquinaria básico y construir un galponcito. Considerar siempre la escasez de mano de obra. 
- Diversificar comprando animales vacunos a pastorear en el predio lindero de su padre.

- Dejarles algo armado a sus hijos, para que no tengan que salir a trabajar afuera: "Cambia del día a la noche y todo es distinto al no tener que trabajar para otro". Les gustaría que los hijos siguieran produciendo en el predio, pero deben tener libertad de elección y si toman otra decisión los van a apoyar.

- Enseñarles a los hijos el gusto por las cosas que hacen. "Hay que escuchar y aprender y largarse nomás a trabajar". "Todo se logra, sabiendo que sin esfuerzo no se hace nada. Yo empecé de cero, cero".

- Planificar tiempo libre con su familia, lo que motiva a mejorar el trabajo en el predio.
- Mantener su forma innovadora de encarar la producción y siempre estar propenso a cambiar y probar nuevas cosas sin asustarse de los vecinos que le dicen que se va a matar de tanto trabajar.

- Mantenerse socio de la S.F.R. Colonia 18 de Julio y algún día tal vez pueda tener tiempo para dedicarle a la directiva cumpliendo un rol que le gustaría desempeñar.

\section{Calidad de vida estructural}

En el caso del productor 3, las mejoras en la calidad de vida estructural se relacionan con la mejora de la vivienda y la conexión a Internet. Estas variables dan lugar a un cambio del índice de calidad de vida estructural integrada de 45 a 48 en valor absoluto y manteniendo el valor del índice en 4

Cuadro 14. Calidad de vida estructural.

\begin{tabular}{|l|c|c|}
\hline \multirow{2}{*}{ Variables consideradas } & \multicolumn{2}{|c|}{ Productor 3 } \\
\cline { 2 - 3 } & Año 1 & Año 3 \\
\hline Vivienda & 3 & 5 \\
\hline Energía eléctrica & 5 & 5 \\
\hline Agua potable & 5 & 4 \\
\hline Conectividad vial & 4 & 3 \\
\hline Disponibilidad de vehículo & 3 & 3 \\
\hline Distancia a centros poblados & 3 & 5 \\
\hline Conectividad digital & 3 & 5 \\
\hline Acceso a salud básica & 5 & 4 \\
\hline Nivel educativo formal & 4 & 5 \\
\hline Acceso a capacitación & 5 & 5 \\
\hline Nivel de endeudamiento & 5 & Valor absoluto $=48$ \\
\hline CALIDAD DE VIDA ESTRUCTURAL & Valor absoluto $=45$ \\
INTEGRADA & Valor del índice $=4$ & Valor del índice $=4$ \\
\hline
\end{tabular}

Calidad de vida estructural integrada: $\leq 20=1$, entre 20 y $30=2$, entre 30 y $40=3$, entre 40 y $50=4, \geq 50=5$. 


\section{Calidad de vida subjetiva}

La calidad de vida subjetiva considera la valoración que los individuos hacen de su calidad de vida de acuerdo con sus criterios de satisfacción, utilizando una escala que va desde: $5=$ Muy satisfecho, a 1= Insatisfecho (Cuadro 15). Complementariamente se presentan factores asociados a la calidad de vida subjetiva en frases dichas por el productor durante la entrevista.

Cuadro 15. Calidad de vida subjetiva.

\begin{tabular}{|lcc|}
\hline Valor & Año 1 & Año 3 \\
\hline Productor 3 & 3 & 4 \\
\hline
\end{tabular}

Muy satisfecho $=5$. Medianamente satisfecho $=4$. Satisfecho=3. Poco satisfecho=2. Insatisfecho=1
Se evidencia una mejora del índice a lo largo del proyecto, al sentirse más seguro en la gestión del predio. Algunos factores asociados a la calidad de vida mencionados por el productor 3 y señora fueron: "Para la familia hay más comodidades y para los hijos más oportunidades ya que pueden ir a estudiar inglés y computación y antes no lo podían hacer". "Ahora trabajamos más, pero estamos bien". "Vivimos acá y estamos tranquilos".

\section{Uso de tecnologías propuestas}

Se analiza el grado de implementación de las tecnologías propuestas durante el proyecto. El resultado de la evolución del uso de cada tecnología para los tres años se observa en el Cuadro 16.

Cuadro 16. Uso del conjunto de tecnologías de producción propuestas para el re-diseño.

\begin{tabular}{|lccc|}
\hline Tecnologías propuestas & Año 1 & Año 2 & Año 3 \\
\hline Solarización & 1 & 1 & 1 \\
\hline Ferti-riego & 0 & 1 & 1 \\
\hline Macro túneles & 0 & 1 & 1 \\
\hline Planificación de la producción & 0 & 1 & 1 \\
\hline Manejo de tratamientos fitosanitarios & 0 & 1 & 1 \\
\hline Uso de semillas de calidad & 0 & 1 & 1 \\
\hline Abonos verdes y/o incorporación de abono orgánico & 0 & 0 & 0 \\
\hline \% de uso del set de tecnologías propuestas & $\mathbf{1 4 \%}$ & $\mathbf{8 6 \%}$ & $\mathbf{8 6 \%}$ \\
\hline
\end{tabular}

Valor 1= usa la tecnología, valor 0 = no usa la tecnología.

Al inicio del proyecto el productor apenas utilizaba la solarización, lo que da un uso de un $14 \%$ de la tecnología propuesta. Al final del proyecto el productor ha incorporado la mayoría de las tecnologías que se le propusieron $(86 \%)$ y la que le faltó incorporar está pensando en hacerlo en la próxima temporada.

\section{Planificación}

La valoración y uso de la planificación a mediano (MP) y largo plazo (LP) que realiza el productor al inicio del proyecto (Año 1), a la mitad del proyecto (Año 2) y al final del proyecto (Año 3) se presenta en el Cuadro 17.

Cuadro 17. Grado en que el productor valora y usa la planificación.

\begin{tabular}{|c|c|c|c|}
\hline \multicolumn{3}{|c|}{ Productor 3 } & \multicolumn{2}{c|}{ Comentarios } \\
\hline Año 1 & Año 2 & Año 3 & \multicolumn{1}{c|}{} \\
\hline 2 & 3 & 4 & $\begin{array}{l}\text { Tiene planes para incrementar 5 macro túneles y ver con cual } \\
\text { cultivo desquita rápidamente la inversión. } \\
\text { Antes se tomaban las decisiones sobre la marcha y ahora se } \\
\text { toman dos veces por año. }\end{array}$ \\
\hline
\end{tabular}

$5=$ valora la planificación y tiene planes de LP. 4= valora la planificación y tiene planes de MP $3=$ valora la planificación y tiene algunas áreas con planificación. 2=valora la planificación, pero no usa planes. 1= ni valora ni usa planes. 
Con relación a la planificación el productor manifestó: "No planificamos con mucho tiempo de anticipación, aunque algo se ha mejorado por pensar un poco más en la rotación".

\section{Aprendizajes y cambios más relevantes}

Una forma cualitativa de evaluar los cambios y aprendizajes en las personas es con el análisis de los cambios en los conocimientos, actitudes, habilidades y aspiraciones. Los aprendizajes y cambios más relevantes se valoran por un lado con la descripción rea- lizada por los productores de los cambios que ellos incorporaron en los predios y por otro con una descripción de sus cambios en actitudes y habilidades manifestadas durante las entrevistas (Cuadro 18).

\section{Relación técnico- productor}

Durante la investigación se indagó sobre las principales características valoradas por los productores de la forma de trabajo y del vínculo con el técnico de campo. Los factores destacados por el productor y su señora fueron: "Con la fertilización que me indicó el ingeniero se gasta más, pero se ven los re-

Cuadro 18. Aprendizajes y cambios más relevantes

\section{Cambios en el predio}

\section{Cambios en conocimientos, habilidades, actitudes $y$ aspiraciones (KASA) del productor}

\section{El cambio más destacado es haber lo- grado mayores ingresos. Se gasta más y se trata de reinvertir todo para seguir creciendo}

Realizan la venta con camión por distintos lugares.

Se usa la solarización.

Incorporó 4 macro túneles en 2014 y los desquitó en la cosecha. Piensa llegar a 9 macro túneles y a tener otro invernáculo.

Hicieron el pozo nuevo y tiene agua. Falta la línea de electricidad para instalar la bomba y allí tendrá riego ya que ahora riega a mano.

Mayores rendimientos con fertilización, curas, riego y con los cambios introducidos.

Ambos trabajan más que antes y si bien contrata gente cuando necesita, cuando llegue a 9 macro túneles ya no podrán solos.

Alquiló la maquinaria y piensa comprar un tractorcito.

Llevan los registros en un cuaderno.
Hay una superación en relación con lo que estaban.

Aprendieron haciendo pruebas con la solarización de medio invernáculo, y ahora la saben hacer solos.

Muchas cosas las aprendieron haciéndolas.

Aspiran a bajar los micro túneles y subir la cantidad de macro túneles tanto por el clima, por el manejo y porque significa menos esfuerzo.

Tiene aspiraciones de hacer un curso de computación en la Colonia.

"No se habla de mostrar lo propio a otros por un tema que las cosas son de cada uno y ya está bien así".

Con la asistencia del técnico asesor se dio cuenta que le faltaba conocimiento.

Comprendió que tiene que ir entendiendo más cada cosa y eso es paso a paso.

Aspiran a trabajar con más comodidad y a avanzar. 
sultados en el mejor rendimiento". "Una parte importante ha sido la asistencia técnica del ingeniero, conversamos con él y mi señora; conversamos entre todos y resolvemos". "Su orientación es mucho mejor que antes, él sabe de cosas prácticas, tiene conocimiento y experiencia, desde que empezó a orientarnos fue todo muy diferente; compartimos ideas y nos decimos lo que queremos y compartimos". "Ese asesoramiento técnico dos veces al mes es algo que se necesita para seguir adelante".

El productor valora que el técnico se interese y proponga ideas nuevas. Por su parte, el productor ve que el técnico pone el hombro, lo que le permite ir poco a poco tomando las experiencias y aprender. Este caso reafirma lo importante que es la elección de la persona que va a asesorar directamente en los predios. 
Se seleccionaron indicadores que tratan de representar la sostenibilidad de los tres sistemas productivos, considerando las tres dimensiones. De manera gráfica permiten ver la vulnerabilidad relativa de ellos al presentarse la evolución que lograron al cabo de tres años. Este tipo de representación tuvo su origen en los llamados diagramas de araña, herramienta desarrollada por Lynam (1999), los que luego se adaptaron al gráfico de amibas, el que se ha usado para los casos de MESMIS (Astier et al., 2012).

Eso permite de manera visual tener un primer análisis sobre cuáles variables mejoraron y cuáles de ellas aún se mantienen en una situación crítica que podría estar condicionando la viabilidad futura de la explotación. En las conclusiones se analiza en mayor detalle cada uno de los tres casos, considerando la línea de base y la evolución lograda durante el proyecto.

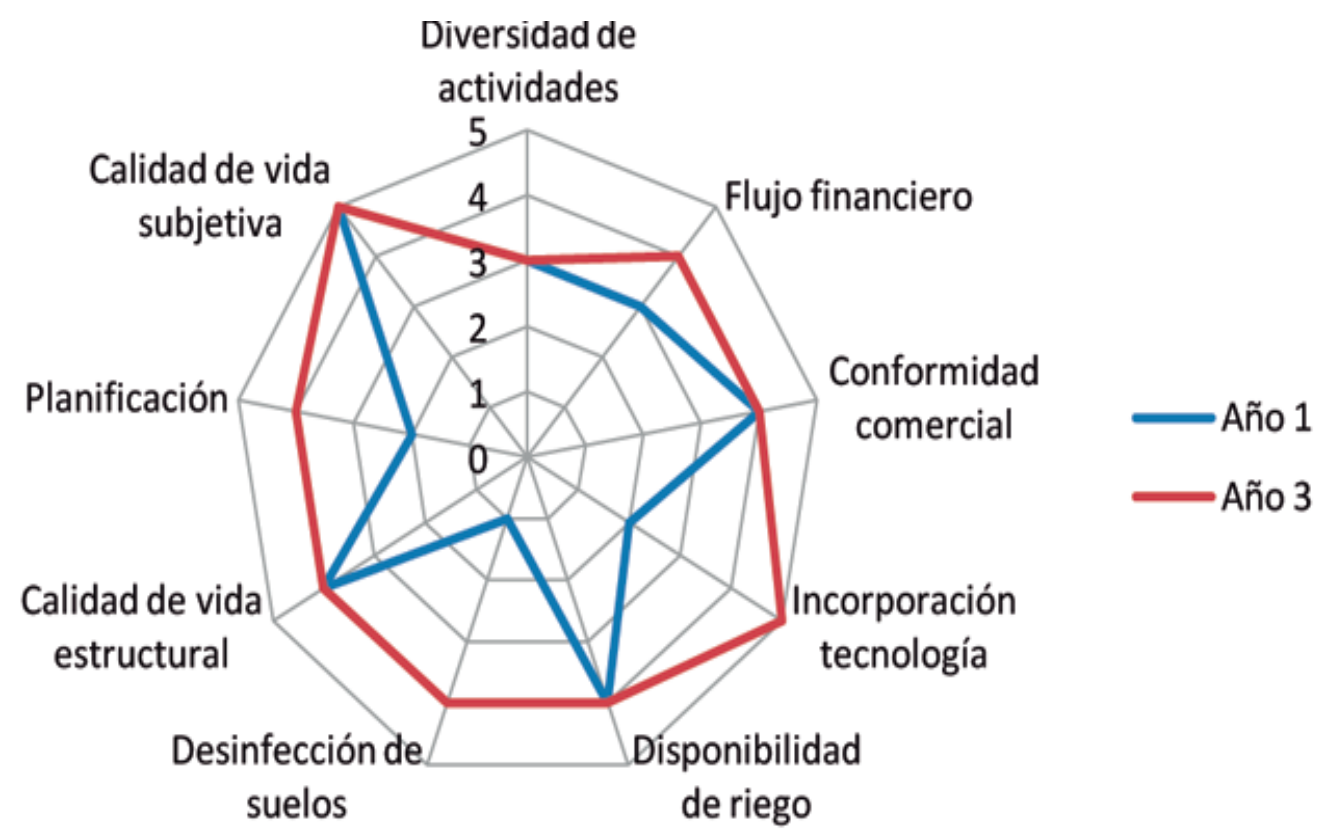

Figura 1. Evolucion de indicadores predio 1. 


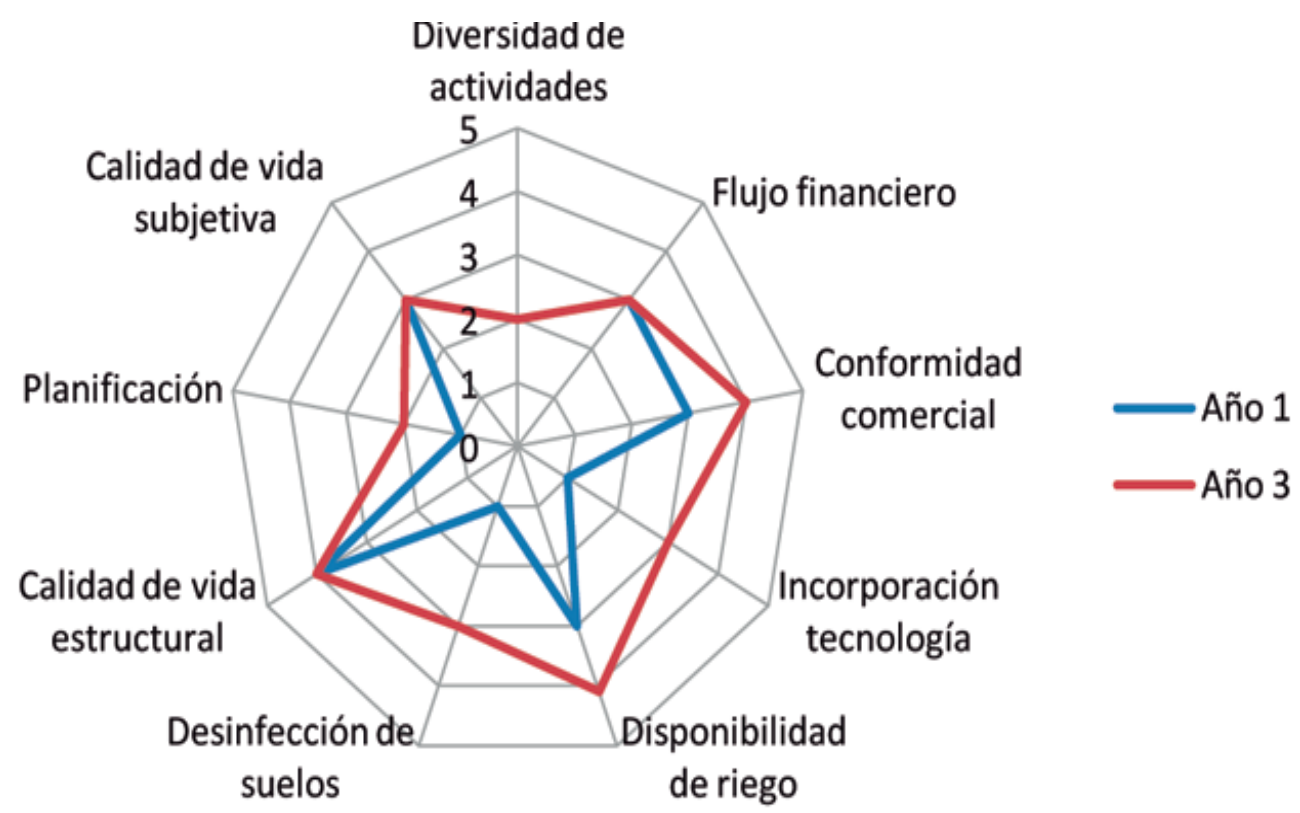

Figura 2. Evolucion de indicadores predio 2.

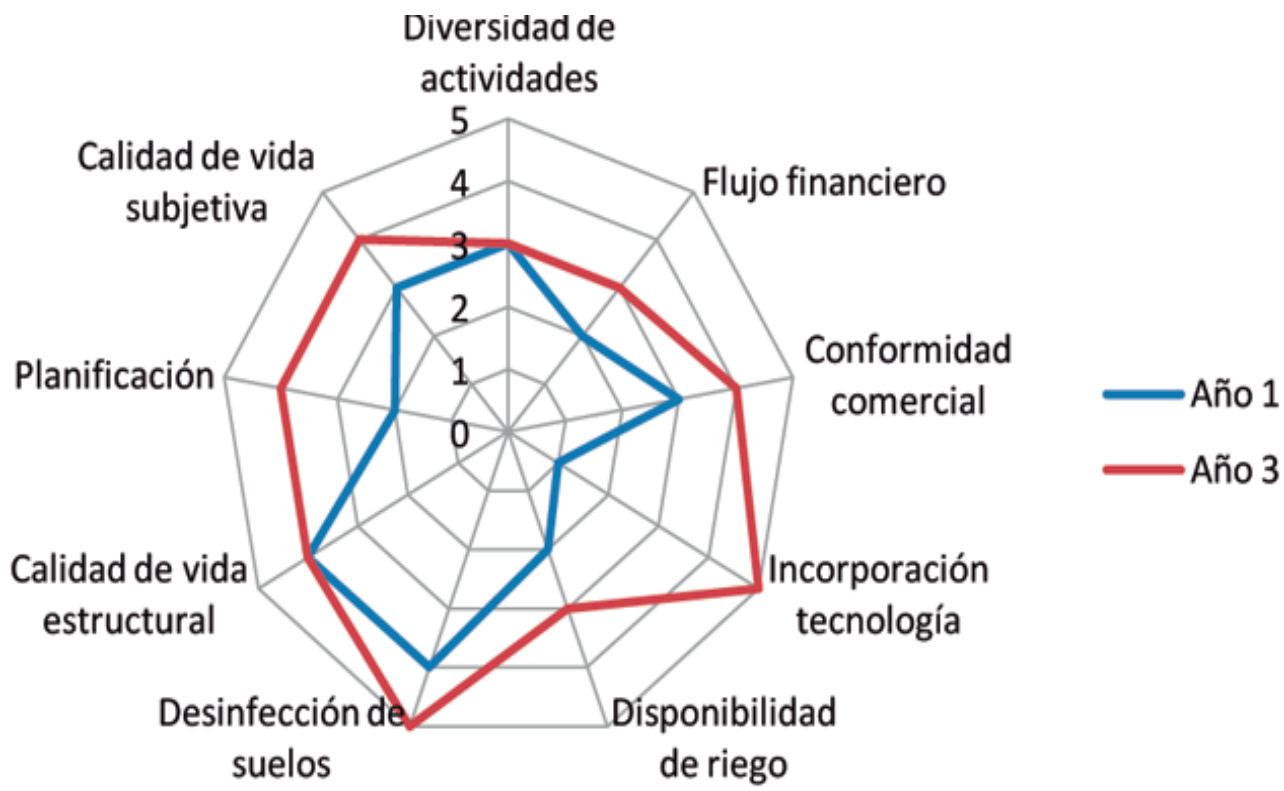

Figura 3. Evolucion de indicadores predio 3. 
Los sistemas familiares de horticultura son sistemas de producción intensivos que requieren de estrategias de gestión afinadas para asegurar su sustentabilidad. Entre otros factores, esto se debe a: i) su alta dependencia de insumos, con un elevado componente de costos por unidad de área explotada y demandas financieras constantes a lo largo del año, que pueden llevar a que se generen desequilibrios entre ingresos y gastos, con los consecuentes riesgos de endeudamiento; ii) constantes demandas de inversión: estructuras de invernaderos, infraestructura y equipamiento para riego, maquinaria, etc., para poder mantener niveles de competitividad; iii) dependencia de agentes comerciales para poder colocar la producción de manera fluida y oportuna, lo que determina que muchas veces el suceso económico dependa de terceros; iv) importante inestabilidad de precios de productos inter e intra anual, que dificulta las posibilidades de planificación y previsión; v) fuerte presión sobre recursos naturales (suelo y agua).

En este caso, la posibilidad de haber trabajado con un enfoque de co-innovación, definiendo de común acuerdo prioridades para la solución de problemas tecnológicos, permitió una instancia de aprendizaje en común, con una participación activa de los productores a través de una mirada global del sistema.

La posibilidad de elaborar un árbol de problemas, poniendo de manifiesto las principales limitantes, la definición de sustentabilidad elaborada por las propias familias y la definición de metas concretas de trabajo contribuyó a generar un estilo de trabajo interactivo. En esta dinámica, fue importante el protagonismo del técnico de campo, el que a través de frecuentes visitas monitoreaba los avances e iba acordando, de común acuerdo con los productores, los futuros pasos.
Este proceso permitió priorizar temas y definir estrategias, en cada caso, en función de las expectativas de los productores y sus familias. Se dio así una combinación de la experiencia y conocimientos de los productores y de los técnicos que participaron del proyecto, trabajando en base a consensos y discutiendo en base a información cuantitativa del predio.

Para definir criterios de sustentabilidad en los diversos indicadores se consideraron aquellos casos en los que estos alcanzaban niveles de 4 o 5 para definir la fortaleza relativa. El valor 3 es una categoría aceptable, pero que muestra cierta debilidad en su proyección a futuro y, obviamente, indicadores menores a 3 muestran la debilidad en esa variable.

En referencia a los indicadores productivo-económicos, el punto de partida fue muy variable, con un predio bastante consolidado (el caso 1) y los otros dos que mostraban muchas áreas de mejora: selección de cultivares, estrategias de manejo, rotación de cultivos, oferta consistente en volumen y calidad, canales comerciales asentados, etc.

Si bien durante el proyecto en los tres casos se vieron aspectos de mejora, estas fueron de distinta dimensión. En todos los casos se verificó una mayor incorporación de tecnología, en base a los acuerdos logrados con el equipo técnico, en aquellos aspectos que los productores entendían más funcionales a sus sistemas y posibilidades. En dos situaciones se mejoró en algo el balance financiero a lo largo del año (relación costos/ingresos mensuales) y se apreció una mejora en aspectos de comercialización.

Se realizaron inversiones productivas, entre las de mayor destaque la ampliación de estructuras de protección (productor 1) y sistema de riego en los productores 2 y 3 .

\footnotetext{
* Unidad de Comunicación y Transferencia de Tecnología.
} 
En el productor 3, la insuficiencia de riego constituía una severa limitante para la promoción del sistema productivo y se comenzó a mejorar.

En referencia a la dimensión ambiental, se comprueba el decrecimiento en el contenido de carbono orgánico que tienen los suelos, con la consecuente reducción en la posibilidad de sostener ciertos procesos. En cuanto a las fuentes de agua, se verifica una alta concentración de fósforo en cursos superficiales y nitratos en aguas subterráneas, lo que supone un riesgo pues esta última es la fuente de agua utilizada para consumo humano y lavado de productos.

En cuanto a prácticas más conservacionistas implementadas durante el proyecto, se destaca la supresión del uso de bromuro de metilo como desinfectante de suelo, en todos los casos, con paulatina incorporación de la práctica de solarización y el incipiente uso de la rotación de cultivos. El caso del productor 3 fue el que mostró una mayor evolución en ese sentido.

De futuro, se debería insistir en consolidar estas prácticas y comenzar con el uso de mecanismos de control biológico como forma de disminuir el uso de agroquímicos.

En lo social, se valoró la calidad de vida, tanto estructural como subjetiva. El único caso en el que se constató una mejora en la apreciación subjetiva fue el del productor 3 , que al ir superando alguna de las principales limitantes de su sistema mostró una mayor conformidad por la gestión lograda. En el caso del productor 2, al no poder resolver algunos de los problemas que surgieron en el diagnóstico, como por ejemplo independizarse de la sociedad con sus hermanos e ir a vivir en el predio propio, se mantuvo la valoración de calidad de vida subjetiva en puntaje 3 (aceptable).

Una variable que mostró una evolución positiva en todos los casos, aunque desigual en su evolución, fue la planificación y la incorporación de registros. Aunque aún apare- ce como insuficiente en algún caso (productor 2) se pasó de una situación en la cual los registros no eran valorados y no se contaba con datos objetivos para planificar, a contar con elementos como para poder hacer un análisis más exhaustivo de datos y poder tomar decisiones en base a ellos.

Otra variable que, si bien no se relevó a nivel de indicadores apareció en las entrevistas con los productores y sus familias como un punto de vulnerabilidad, fue la presión de trabajo. En sistemas de producción vegetal intensivo de carácter familiar, con pocas posibilidades de contratación de mano de obra, la carga horaria destinada a la gestión del predio es un aspecto que puede condicionar su sustentabilidad. Cabe esperar que, a través de una planificación más ordenada, con una definición anticipada del calendario de trabajo, en base a registros y planes operativos, se pueda contribuir a mitigar esa vulnerabilidad.

En términos generales, al igual que en el caso de los productores ganaderos, la incorporación de cambios fue variable y estuvo asociada a un componente actitudinal, en el que obviamente inciden los objetivos que se plantean, la percepción de espacios de mejora, la disposición a asumir nuevos riesgos y desafíos, el destinar tiempo a la planificación y capacitación en nuevas técnicas, etc. En el enfoque, encarado como estudio de casos, queda claramente explícita la diversidad de conductas frente a una determinada propuesta.

Un proceso de co-innovación de estas características requiere de continuidad para reafirmar los cambios iniciados y de la incorporación de nuevos casos para validar este enfoque a nivel regional, capitalizando aprendizajes y realizando ajustes, mediante apoyo técnico. Se asume la necesidad de involucrar a más productores y organizaciones de productores para dar consistencia a ese proceso y lograr una escalabilidad que permita generar un impacto efectivo. 


\section{IV - BIBLIOGRAFÍA}

Ågren, G. I.; Bosatta, E. 1998. Theoretical Ecosystem Ecology: Understanding Element Cycles, primera edición. Cambridge University Press.

Aguerre, V.; Albicette, M.M. (Eds.) 2018. Coinnovando para el desarrollo sostenible de sistemas ganaderos familiares de Rocha - Uruguay. Montevideo: INIA. 146 p. (Serie Técnica INIA; 243)

Aguirre, S.; Chiappe, M. 2009. Evaluación de la sustentabilidad en predios hortícolas salteños. Agrociencia 13 (1): 38-47.

Albicette, M.; Brasesco, R.; Chiappe, M. 2009. Propuesta de indicadores para evaluar la sustentabilidad predial en agroecosistemas agrícola-ganaderos del litoral del Uruguay. Agrociencia 13 (1): 48-68.

Albicette, M. M., Bortagaray, I., Scarlato, S., Aguerre, V . 2016. Co-innovación para promover sistemas ganaderos familiares más sostenibles en Uruguay. Análisis de tres años de cambios en la dimensión social de la sostenibilidad. Revista Latinoamericana de Estudios Rurales I (2): 105-136.

Astier, M.; Masera, O; Yankuic, M. 2008 Evaluación de sustentabilidad. Un enfoque dinámico y multidimensional.

Axelrod, R.; Cohen, M.D. 2000. Fostering complexity. Basic Books

Bennett, E. M.; Carpenter, S. R.; Peterson, G. D.; Cumming, G. S.; Zurek, M.; Pingali, P. 2003. Why global scenarios need ecology. Frontiers in Ecology and the Environment 1(6):322-329.

Berretta, E.; Bemhaja, M. 1997. Producción de pasturas naturales en el basalto: producción estacional de forraje de tres comunidades nativas sobre suelos de basalto. In:

Pasturas y producción animal en áreas de ganaderia extensiva. 2a. reimpresión. Montevideo (Uruguay): INIA, 1997. p. 1923 (INIA Serie Técnica 13)

Blumetto, O., Castagna, A., Cardozo, G., Ruggia, A., Scarlato, S., Tiscornia, G., García, F. and Aguerre, V. (2016)
Ecosystem Integrity Index: A new tool for ecosystem services evaluation in livestock production systems. Proceedings of the International Rangeland Congress, Saskatoon, Canadá

Brink B., Hinsberg A van, Hoek DCJ van der, Knegt B de, Knol OM, Ligtvoet W, Rosenboom R y Reijnen MJSM. 2002. Technical design Natural Capital Index framework and implementation for the Nature Outlook 2. National Institute for Public Health and the Environment, Ministry of Health, Welfare and Sport.

Brossier, J.; Chia, E. 1986. Family farm and relevant management tool. In: Cristensen, J., Nielsen, A. and Pedersen, D. (eds). Implementation of Farm Management Information Systems. Wissenschaftesverlag Vauk Kiel. 9th Economic European Symposium.EAAE.

Butler, S. J.; Boccaccio, L.; Gregory, R. D.; Vorisek, P.; Norris K. 2010. Quantifying the impact of land-use change to European farmland bird populations. Agriculture, Ecosystems \& Environment 137(3-4):348-357.

Cambardella, C. A.; Elliot, E. T. 1992. Particulate soil organic matter changes across a grassland cultivation sequence. Soil Sci. Soc. Am. J. 56: 777-783.

Chapman, D. (1992) Water Quality Assessment. En: Chapman D on behalf of UNESCO, WHO and UNEP, London: Chapman \& Hall. 585p.

Costa FG, Pérez-Miles F, Gudynas E, Prand, L, Capocasale RM (1991) Ecología de los arácnidos criptozoicos, excepto ácaros, de la Sierra de las Animas (Uruguay). Aracnología 13/15, 1-41.

Courdin, V. 2011. Com. pers. Prospección de demandas tecnológicas y caracterización de la producción familiar para el área de influencia de INIA Salto Grande.

Coutts, J.; Botha; N., Turner, J. 2014. Evaluating a co-innovation policy initiative in New Zealand. In Proceedings of Farming 
Systems Facing Global Challenges. IFSA. Berlin. $11 \mathrm{p}$.

Chetty S. 1996. The case study method for research in small- and medium - sized firms. International small business journal, vol. 5, octubre - diciembre.

Debels, P; Figueroa, R; Urrutia, R; Barra, R; Niell $X$. (2005) Evaluation of water quality in the Chillán River (Central Chile) using physicochemical parameters and modified water quality index. Environmental Monitoring and Assessment, 110: 301-322

DIEA-MGAP. 2008. Anuario estadístico agropecuario 2008. Montevideo: MGAP. Disponible en: http://www.mgap.gub.uy/

Dogliotti, S. et al. 2012. Desarrollo sostenible de sistemas de producción hortícolas y hortícola-ganaderos familiares: una experiencia de co-innovación. Montevideo: INIA. 112 p. (Serie FPTA-INIA; 33)

Dogliotti, S.; García, M.C.; Peluffo, S.; Dieste, J.P.; Pedemonte, A.J.; Bacigalupe, G.F.; Scarlato, M.; Alliaume, F.; Álvarez, J.; Chiappe, M.; Rossing, W.A.H. 2014. Coinnovation of family farm systems: A systems approach to sustainable agriculture. Agricultural Systems 126: 7686.

Douthwaite, B., 2002. How to enable innovation. Agricultural Engineering International Vol IV, October 2002, 1-15.

Downie, I., Wilson,W., Abernethy, V., McCracken, D., Foster, G., Ribera, I., Murphy, K., Waterhouse, A. (1999). The impact of different agricultural land-uses on epigeal spider diversity in Scotland. J. Insect Conserv. 3, 273-286.

Echeverri, R. 2003. "Lo nuevo del enfoque territorial para el desarrollo rural" en: Desarrollo rural sostenible con enfoque territorial: políticas y estrategias para Uruguay. Montevideo, IICA

Eisenhardt, K. M. 1989. Building Theories from Case Study Research, Academy of Management Review, 14 (4): 532-550.

Engel, P.G.; Salomon, M. 1997. Faciliting innovation for development. A RAAKS resource box/the social organization. Royal Trop. Inst. (KIT): Amsterdam. 239 p.
Ferris, R., Peace, AJ, Humphrey, JW, Broome, AC, (2000). Relationships between vegetation, site type and stand structure in coniferous plantations in Britain. Por. Ecol. Administrar. 136, 35-51.

Gaeta, N.; Muñoz, G. 2014. Sustentabilidad productiva, económica y social de un sistema de producción ganadero en el nordeste de Entre Ríos. Ciencias Agronómicas. Revista XXIV -Año 14. pp11-22. ISSN On-line: 2250-8872

Gardner TA, Barlow J, Araujo IS, Ávila-Pires TC, Bonaldo AB, Costa, JE, Esposito MC, Ferreira LV, Hawes J, Hernandez MIM, Hoogmoed MS, Leite RN, Lo-Man-Hung NF, Malcolm JR, Martins MB, Mestre LAM, Miranda- Santos R, Overal WL, Parry L, Peters SL, Ribeiro-Junior MA, da Silva MNF, Motta CS, Peres CA (2008) The cost-effectiveness of biodiversity surveys in tropical forests. Ecology Letters 11, $139-150$

Gaspar García, P.; Mesías Díaz, F.J.; Escribano Sánchez, M. y Pulido García, F. 2009. Evaluación de la sostenibilidad en explotaciones de dehesa en función de su tamaño y orientación ganadera Separata ITEA Información Técnica Económica Agraria, VOL. 105 N. ${ }^{\circ} 2$ (117141)

Gibbons. M.; Limoges, C.; Nowotny, H., Schwartzman, S.; Scott, P.; Trow, M. 1997. La nueva producción del conocimiento. Ediciones PomaresCorredor, S.A., Barcelona, España, 225 p.

Gibbons D. W. y Gregory R. D. 2006. Birds. En: Ecological census techniques: a handbook, 2aedición. Cambridge University Press. Gottschalk T. y Dittrich R. 2010. Modelling land-use sustainability using farmland birds as indicators. Ecological Indicators 10(1):15-23.

Gómez, R.; Ferreira, G.; Albín, A. (Eds.) 2011. Caracterización de los sistemas de producción familiar en el área de Alrededores de Tacuarembó. Montevideo : INIA. 76 p. (INIA Serie Técnica; 195)

Gravesen, E., 2000. Spiders (Araneae) and other invertebrate groups as ecological indicators in wetland areas. Ekol. Bratis. 19, 39-42. 
Gregory R. D., Strien A. van, Vorisek P., Meyling A. W. G., Noble D. G., Foppen R. P. B. y Gibbons D. W. 2005. Developing indicators for European birds. Philosophical Transactions of the Royal Society B: Biological Sciences 360(1454):269-288

Gutman, G.; Gorenstein, S. 2003. Territorio y sistemas agroalimentarios. Enfoques conceptuales y dinámicas recientes en Argentina.

Gyawali, S., Techato, K., Monprapussorn, S., Yuangyai, C. (2013). Integrating Land Use and Water Quality for Environmental based Land Use Planning for U-tapao River Basin, Thailand. Procedia - Social and Behavioral Sciences, 91, 556-563.

Klerkx, L.; Schut, M.; Leeuwis, C.; Kilelu, C. 2012. Advances in Knowledge Brokering in the Agricultural Sector: Towards Innovation System Facilitation https:// d o i . org / 10.1111/j.1759 5436.2012.00363.x

Kremen C. 1992. Assessing the Indicator Properties of Species Assemblages for Natural Areas Monitoring. Ecological Applications 2(2):203-217.

Kaurish, F. W., Younos, T. (2007). Developing a standardized water quality index for evaluating surface water quality. 43(April), 533-546.

Laborda A., Tosi-Germán R., Donate, S. y Blumetto, O. (2013) Spider fauna (Araneae: Araneomorphae) in natural grasslands of Uruguay with different livestock management. International Grassland Congress Proceedings $p$ 1703. 15-19 Setiembre, SydneyAustralia

Lawrence KL, Wise DH (2000) Spider predation on forest floor Collembola and evidence for indirect effects on decomposition. Pedobiología, 44, 33-39.

Leeuwis, C. 1999 Integral design: innovation in agriculture and resource management.

Mansholt Studies Series, no. 15, Mansholt Institute / Backhuys Publishers, 277 p.

Leeuwis, C.; Pyburn, R.; Röling, N. 2002. Wheelbarrows full of frogs: social learning in rural resource management: international research and reflections. Koninklijke Van Gorcum. 479 pp.
Lughadha E. N., Baillie J., Barthlott W., Brummitt N. A., Cheek M. R., Farjon A., Govaerts R., Hardwick K. A., Hilton-Taylor C. y Meagher T. R. 2005. Measuring the fate of plant diversity: towards a foundation for future monitoring and opportunities for urgent action.

Philosophical Transactions of the Royal Society B: Biological Sciences 360(1454):359372.

Lynam, T. 1999. Adaptive Analysis of Locally Complex Systems in a Globally Complex World. ECOLOGY AND SOCIETY 3(2). DOI: $10.5751 /$ ES-00152-030213

Masera, O.; Astier, M.; López-Ridaura, S. 2000. Sustentabilidad y manejo de recursos naturales; el marco de evaluación MESMIS. GIRA, México.

Maxwell, J. A. 1998. "Designing a Qualitative Study". En L. Bickman D. J. y Rog (Eds.), Handbook of Applied Social Research Method (p. 69-100), Thousand Oaks, CA, Sage.

Millot, J.C.; Risso, D.; Methol, R. 1987. Relevamiento de pasturas naturales y mejoramientos extensivos en áreas ganaderas del Uruguay: informe de divulgación. Montevideo (Uruguay): MGAP, $55 \mathrm{p}$.

Mohd Noor, K. B. 2008. Case Study: A Strategic Research Methodology. American Journal of Applied Sciences 5 (11): 16021604, 2008

Niemeijer D. y de Groot R. S. 2008. A conceptual framework for selecting environmental indicator sets. Ecological indicators 8(1):14-25

Pareja, M.; Bervejillo, J.; Bianco, M.; Ruíz, A. y Torres, A. 2011. Evaluación de los impactos económicos, sociales, ambientales e institucionales de 20 años de inversión en investigación e innovación agropecuaria por parte del INIA-Uruguay. Resumen Ejecutivo. Ediciones especiales.

Pereira H. M. y David Cooper H. 2006. Towards the global monitoring of biodiversity change.Trends in Ecology \& Evolution 21(3):123-129.

Pérez-Miles F, Simó M, Toscano C, Useta G (1999) Aracnofauna del Cerro de Montevideo (Uruguay), un área rodeada por urbanización. Physis - A 60, 1-15. 
Piñeiro, D. 1999 Caracterización de la producción familiar. Montevideo: Dep. de Ciencias

Sociales. Facultad de Agronomía. 17 p. Disponible en: http://www.fagro.edu.uy/

Ploeg, J.D. van der. 1990. Labour, markets and agricultural production. Westview Special Studies in Agriculture, Science and Policy. Boulder, Colorado: Westview Press

Pombo, C.; M. Scarlato; G.F. Bacigalupe; S. Dogliotti; W.A.H. Rossing; C. Abedala; V. Aguerre; A. Albín; F. Alliaume; J. Alvarez; M. Barreto; M. Chiappe; J.P. Dieste; M. García; S. Guerra; C. Leoni; I. Malán; V. Mancassola; A. Pedemonte y S. Peluffo. 2010. Co-innovando para una agricultura más sostenible. Primer Congreso en Co-Innovación de Sistemas Sostenibles de Sustento Rural. Lavalleja. Uruguay. p. 7 - 10.

Perry, C. 1998. "A structured approach to presenting theses", Australian Marketing Journal, 6 (1): 63-86.

Probst, K.; Hagmann, J. 2003. Understanding Participatory Research in the Context of Natural Resource Management: Paradigms, Approaches and Typologies. In Agren-Network Paper No. 130, Agricultural Research and Extension Network, ISBN 0850036771

Rialp i Criado A. 1998. El Método del Caso como técnica de investigación y su aplicación al estudio de la función directiva. Ponencia presentada en el IV Taller de Metodología ACEDE, celebrado en Arnedillo (La Rioja), 23-25 de abril de 1998. Universidad Autónoma de Barcelona.

Rossengurtt, B. 1943. Estudios sobre praderas naturales del Uruguay: 5 contribución. Montevideo, Uruguay: ROSGAL. 573 p.

Rossing, W.A.H.; Dogliotti, S.; Bacigalupe, G.F.; Cittadini, E.; Mundet, C.; Mariscal Aguayo, V.; Douthwaite, B.; Alvarez, S. 2010.
Project design and management based on a co-innovation framework. In: Building Sustainable Rural Futures: The added value of systems approaches in times of change and uncertainty. IFSA 2010. Viena. Austria. pp. 402-412.

Sala O. E. y Zaitsev A. S. 2005. Biodiversity across scenarios. En: Ecosystems and Human

Well-Being: Scenarios: Findings of the Scenarios Working Group.

Sarandón, S.J. 2002. El desarrollo y uso de indicadores para evaluar la sustentabilidad de los agroecosistemas. In: Agroecología. El camino hacia una agricultura sustentable (Sarandón, S.J. ed). Ediciones Científicas Americanas: 393414

Scholes R. J. y Biggs R. 2005. A biodiversity intactness index. Nature 434(7029):4549.

Tommasino, H.; Marzaroli, J. (Eds.). 2008. Manual de evaluación de sistemas lecheros familiares a través de indicadores de sustentabilidad. Montevideo: MGAP. 110 p.

Tosi, R.; Laborda, A.; Donate, S. Blumetto, O (2013). Bird and mammal fauna assemblages in well-preserved natural grasslands of Uruguay with different livestock management., International Grassland Congress, Sydney, 2013

Vega, F. (2009). Desarrollo y aplicación de un índice de calidad de agua para ríos en Puerto Rico.

Vickery J. A., Bradbury R. B., Henderson I. G., Eaton M. A. y Grice P. V. 2004. The role of agri-environment schemes and farm management practices in reversing the decline of farmland birds in England. Biological Conservation 119(1):19-39.

Yin, R. K. 1989. Case Study Research: Design and Methods, Applied social research Methods Series, Newbury Park CA, Sage 
INIA Dirección Nacional

Andes 1365, P. 12

Montevideo

Tel.: 59829020550

Fax: 59829023633

iniadn@dn.inia.org.uy

INIA La Estanzuela

Ruta 50, Km 11

Colonia

Tel.: 59845748000

Fax: 59845748012

iniale@le.inia.org.uy

INIA Las Brujas

Ruta 48, Km 10

Canelones

Tel.: 59823677641

Fax: 59823677609

inia_lb@lb.inia.org.uy

INIA Salto Grande

Camino al Terrible Salto

Tel.: 59847335156

Fax: 59847329624 inia_sg@sg.inia.org.uy

INIA Tacuarembó Ruta 5, Km 386

Tacuarembó

Tel.: 59846322407

Fax: 59846323969 iniatbo@tb.inia.org.uy

INIA Treinta y Tres Ruta 8, Km 281 Treinta y Tres Tel.: 59844522023 Fax: 59844525701 iniatt@tyt.inia.org.uy

www.inia.uy 